\title{
Clinical and experimental aspects of sacral nerve neuromodulation in lower urinary tract dysfunction
}

Citation for published version (APA):

Weil, E. H. J. (2000). Clinical and experimental aspects of sacral nerve neuromodulation in lower urinary tract dysfunction. [Doctoral Thesis, Maastricht University]. Universiteit Maastricht. https://doi.org/10.26481/dis.20001130ew

Document status and date:

Published: 01/01/2000

DOI:

10.26481/dis.20001130ew

Document Version:

Publisher's PDF, also known as Version of record

\section{Please check the document version of this publication:}

- A submitted manuscript is the version of the article upon submission and before peer-review. There can be important differences between the submitted version and the official published version of record.

People interested in the research are advised to contact the author for the final version of the publication, or visit the DOI to the publisher's website.

- The final author version and the galley proof are versions of the publication after peer review.

- The final published version features the final layout of the paper including the volume, issue and page numbers.

Link to publication

\footnotetext{
General rights rights.

- You may freely distribute the URL identifying the publication in the public portal. please follow below link for the End User Agreement:

www.umlib.nl/taverne-license

Take down policy

If you believe that this document breaches copyright please contact us at:

repository@maastrichtuniversity.nl

providing details and we will investigate your claim.
}

Copyright and moral rights for the publications made accessible in the public portal are retained by the authors and/or other copyright owners and it is a condition of accessing publications that users recognise and abide by the legal requirements associated with these

- Users may download and print one copy of any publication from the public portal for the purpose of private study or research.

- You may not further distribute the material or use it for any profit-making activity or commercial gain

If the publication is distributed under the terms of Article $25 \mathrm{fa}$ of the Dutch Copyright Act, indicated by the "Taverne" license above, 


\section{Bij de voorpagina}

De cirkel

in gouden ombelzing omvat het weten

geopend om te geven

aan het vloeiende blauw

water en adem

en in de letters

op grijs titaan

het rood van de liefde

dew Ciaclen

Opgedragen aan allen die mij met wiisheid, inzicht en liefde inspireren 


\title{
CLINICAL AND EXPERIMENTAL ASPECTS \\ OF SACRAL NERVE NEUROMODULATION \\ IN LOWER URINARY TRACT DYSFUNCTION
}

\author{
PROEFSCHRIFT \\ ter verkrijging van de graad van doctor an de Universiteit Maasfricht. \\ op gezag van de Rector Magnificus, Prof. dr. A.C. Nieuwenhuijzen Kruseman \\ volgens het besluit van het College van Decanen, \\ in het openbaar te verdedigen op donderdag 30 november 2000 om 12.00 uur door \\ ERNEST HENK IOHAN WEIL
}




\section{Promotor:}

Prof. dr. Ph.E.V. Van Kerrebroeck

\section{Beoordelingscommissie:}

Prof. dr. J. Troost, (voorzitter)

Prof. dr. C.G.M.I. Baeten

Prof. dr. A.A.B. Lycklama a Nijeholt, (Universiteit Leiden)

Prof. dr. H.A.M. Neumann

Prof. dr. H.A.J. Struijker Boudier

Prol, dr. H.J.J, Wellens 


\section{CONTENTS}

Chapter 1 General introduction and outline of the thesis. 7

Chapter 2 Anatomy and neurophysiology of the lower urinary tract. II

Chapter 3 Pathophysiology of lower urinary tract dysfunction. 2,3

Chapter 4 History of the development of neurostimulation. 37

Chapter 5 Neuromodulation of sacral nerves for incontinence and voiding dysfunctions. A feavibility study. 51

Chapter 6 Improving neuromodulation technique for refractory voiding dysfunctions: Two-stage implant. Alecbuical study. $6 !$

Chapter 7 Clinical results of sacral neuromodulation for chronic voiding dysfunction using unilateral sacral foramen electrodes. A lang-lerm follow-up itudy. 73

Chapter 8 Sacral root neuromodulation in the treatment of refractory urinary urge incontinence. A prospective randomized clinical triat. 89

Chapter 9 Novel test lead designs for sacral nerve stimulation.

Improved passive fixation. An animat oludy. III

Chapter 10 Buttock placement of the implantable pulse generator:

a new technique for sacral nerve stimulation: 125

Chapter 11 Summary and conclusions. 137

Chapter 12 Samenvatting and conclusies. 143 



\section{Chapter 1 General introduction and outline of the thesis}

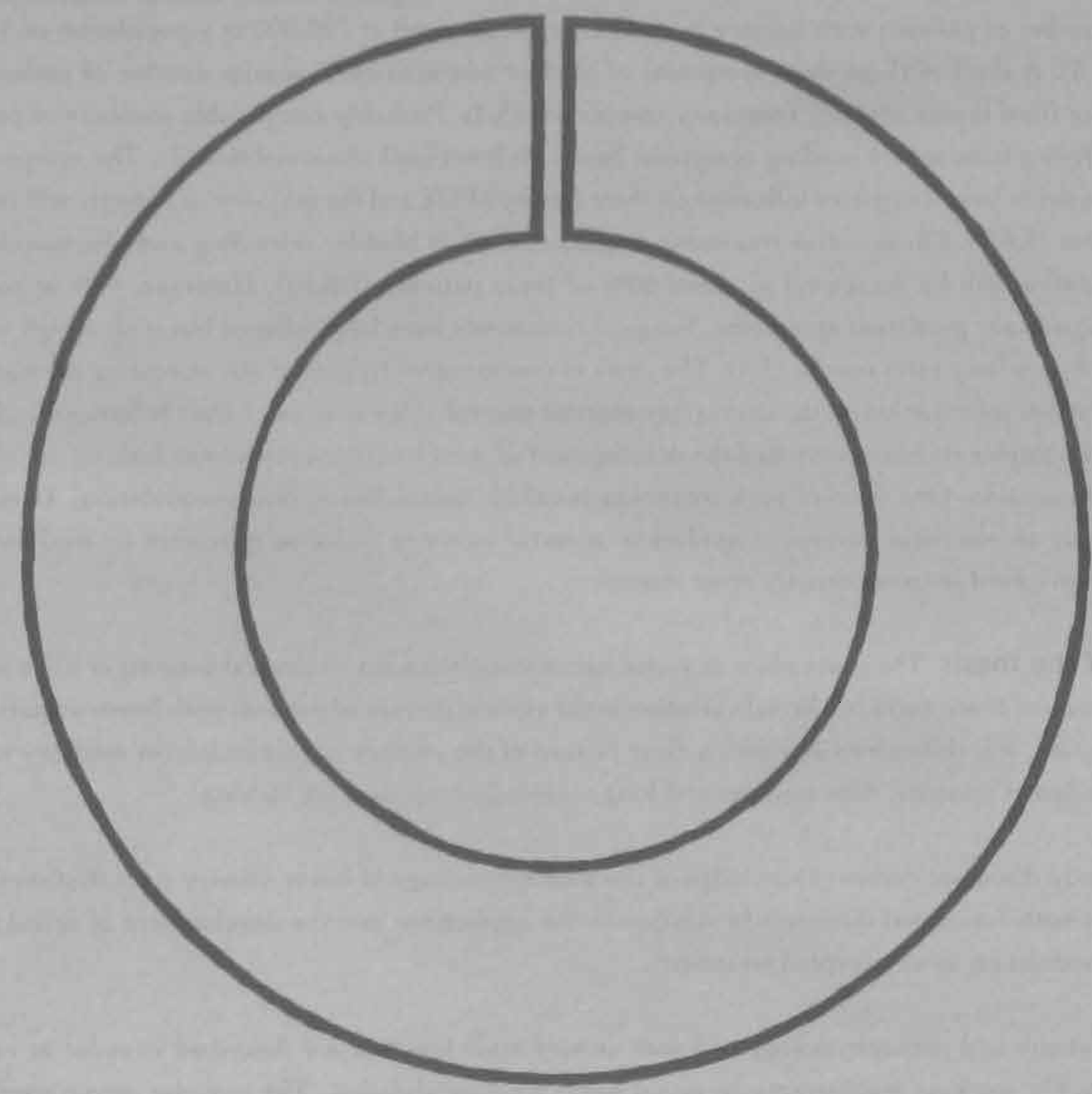




\section{GENERAL INTRODUCTION AND OUTLINE OF THE THESIS}

General introduction Functional problems of the lower urinary tract are a significant problem. The total number of patients with urinary incontinence is estimated at 700,000 in a population of $16 \mathrm{mil}$. lion (1 -3). A third of them show symptoms of bladder overactivity. A similar number of patients are suffering from severe urgency frequency complaints $(3,4)$. Probably comparable numbers of patients are suffering from severe voiding symptoms based on functional abnormalities (3). The symptoms in these patients have a negative influence on their quality of life and the majority of patients will request. treatment $(5,6,9)$. Conservative treatment modalities such as bladder retraining and pharmacological manipulation will be auccessful in about $60 \%$ of these patients $(7,8,10)$. However, $40 \%$ of patients show significant persistent symptoms. Surgical treatments have been offered but with a high morbidity and poor long-term results $(3,4)$. The costs of conservative treatment are increasing dramatically (11). Further information on the neurophysiological control of lower urinary tract behaviour and electronic developments have permitted the development of new treatment modalities making use of electrical stimulation. One form of such treatmen is called 'Sacral Nerve Neuromodulation'. Using this technique, an electrical current is applied to a sacral nerve in order to rebalance or modulate the reflexes involved in lower urinary tract control.

Aim of the thesis The exact place of sacral nerve stimulation for urological patients is still a matter of discussion. Since there is a broad variation in the clinical picture of patients with lower urinary tract dystunction, it is difficult to establish a clear picture of the efficacy of this treatment modality in specific groups of patients. Also medium and long-term follow-up data are lacking.

This study discusses current knowledge of the pathophysiology of lower urinary tract dysfunction in patients with functional disorders in relation to the application and the development of sacral nerve neuromodulation as an accepted treatment.

The anatomy and pathophysiology of lower urinary tract function are described in order to explain the possible working mechanisms of sxicral nerve neuromodulation. The complex nerve control of lower urinary tract function is discussed in detail. The etiology of lower urinary tract dysfunction is 
Chapter 1

discussed with reference to reflex control. In several clinical studies the role of sacral nerve neuro. modulation in specific groups of patients has been studied. Technical improvements are described in order to make the technique of implantation and selection of patients based on percutaneous nerve evaluation more reliable and successful. 


\section{REFERENCES}

I. Kok ALM, Voorhorst Fl, Halff-Butter CMC, e.a. De prevaleatie van urine-incontinentie bij oudere vrouwen. Ned Tivdicler Gink 1991: 135:98-101.

2. Lagro-Janssen ALM, van Weel C. Long-term effect of treatment of female incontinence in general practice. Bir I Girl Prat 1998; 48:1735-38,

i. Resnick NM. Urinary inconsinence. Lancel 1995; 346:94-9,

4. Abrams P. Assessment and treatment of urinary incontinence. Lancet 2000; 355:2153-8.

5. Van der Vaart CH, de Leeuw, JRJ, Roovers JPWR, Heintz APM. De invloed van urine-incontinentie op de kwaliteit van leven bij thuiswonende Nederlandae vrouwen van 45-70 jaar, Ned Tindicbr Gnk 2000;144(19):894-7.

6. Fonda D, Woodward M, D'Astoli M, Wai Fong Chin. Susrained improvement of subjective quality of life in older community-dwelling people after treament of urinary incontinence, Age Ageiny 1995; 24:283-6

7. Berghmans LCM, Frederiks CMA, De Brie RA e.a. Efficacy of biofecdback, when included with pelvic muscle exercise treatment, for genuine stress incontinence, Nearal //rodyn 1996: 15:37-52.

8. Branch LG, Walker LA, Wetle TT, DuBeau CE, Resnick NM. Urinary incontinence knowledge among communirydwelling people 65 years of age and older. I Am Geriar Sin 1994; -12:1257-63.

9. Cools HJM, De Bock GH. De sumenhang tussen ongewenst urineverlies met andere beperkingen in het functioneren, Ned Tijobler Cink 1993; 137:1828-30.

10. Fant IA, Bumf RC, Robinson D, McClish DK, Wyman IF and the Continence Program for Women Research Group. Eiflicacy of oestrogen supplementation in the rreatment of urinary incontinence. Ofwed Gyrect 1996: 88:745749.

11. Stichting Farmaceutische Kengetallen. Farmacie in cijfers. Incontinenticmateriaal. Pbarm Week-bl 1999; 134(13): 439 . 
CHAPTER 2 ANATOMY AND NEUROPHYSIOLOGY OF THE LOWER URINARY TRACT

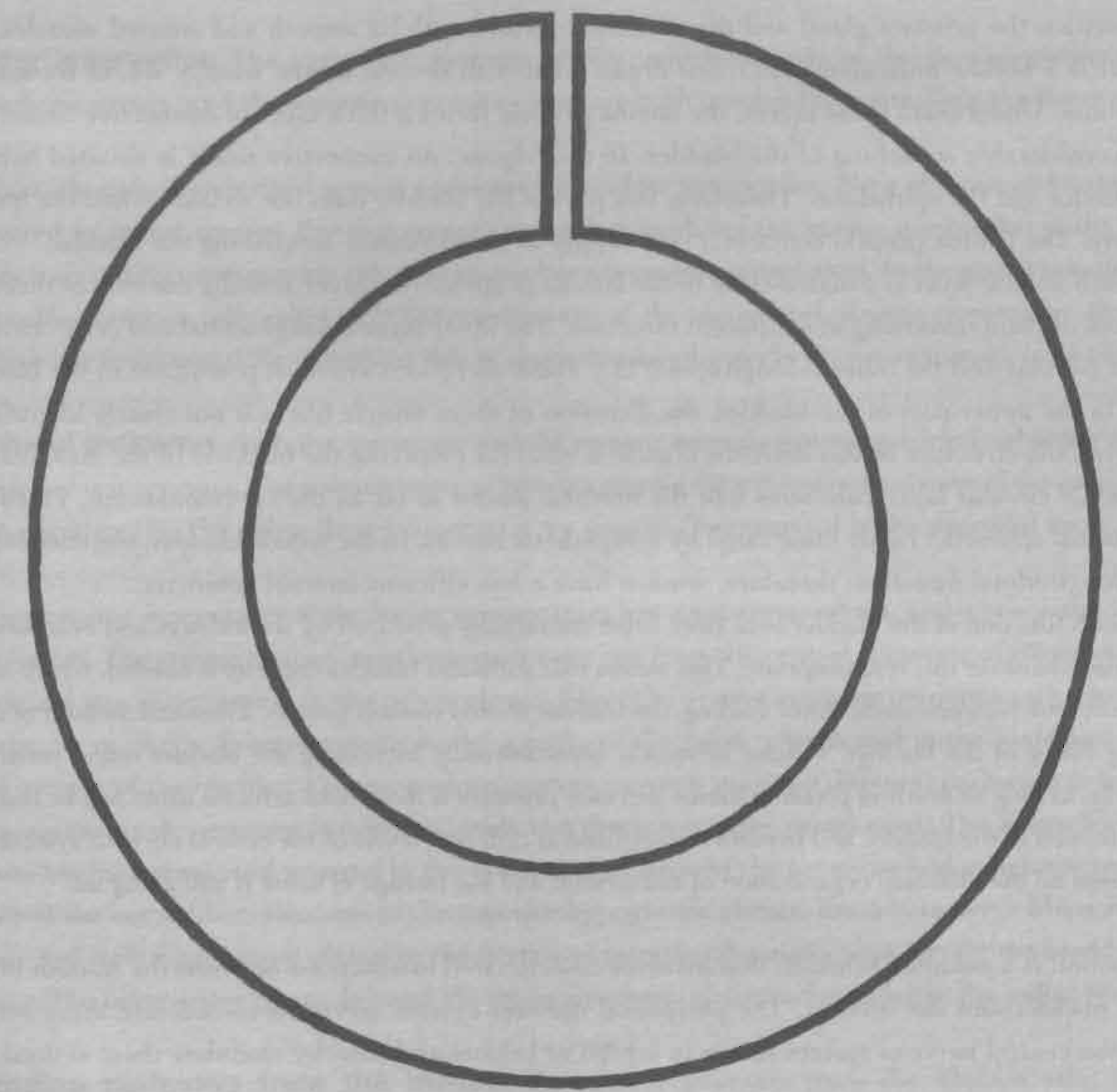




\section{ANATOMY AND NEUROPHYSIOLOGY OF THE LOWER URINARY TRACT}

The lower urinary tract consists of the bladder, the lower one third of the ureter and the ureterovesical junction, the prostate gland and the urethra, together with its smooth and striated muscles. The bladder is a hollow musculomembranous organ lined with several layers, usually six, of transitional epithelium. Underneath these layers, the lamina propria forms a thick layer of connective tissue, allowing considerable stretching of the bladder. In the trigone, no connective tissue is situated between the muscles and the epithelium. Therefore, this part of the bladder does not wrinkle when the bladder is empty. The lamina propria contains a rich supply of blood vessels, nourishing the bladder. A smooth muscle layer is situated close to the lamina propria. This layer actually consists of three layers, each of them traversing in a different direction. The inner layer is longitudinal and criss-cross, the

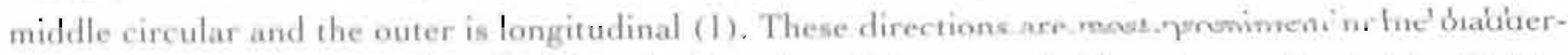
neck. In the upper part of the bladder, the direction of these muscle libers is not clearly identifiable. However, the structure of this detrusor muscle is ideal for emptying the bladder. In the male bladder, the middle circular layer continues into the urethra, almost as far as the verumontanum. This forms the internal sphincter. richly innervated by sympathetic nerves. In the female bladder, the muscle layer has a longitudinal direction; therefore, women have a less efficient internal sphincter.

The main function of the bladder is to store urine continually produced by the kidneys and evacuation of the urine whenever this is appropriate. This means that sufficient bladder capacity is needed, which allows sufficient time between voids. After voiding, the bladder should contain none or a minimal amount of urine. During filling of the bladder, volume increases, simultaneously increasing the bladder outlet resistance. Basically, as long as urethral pressure minus detrusor pressure is more than zero, no urine will be lost. The dual function of the bladder and urethra is organized at different levels of the central nervous system. The discussion on the neuronal organization of micturition and the storage of urine is still going on.

Micturition is a complex function that involves co-ordinated interactions between the smooth muscle of the bladder and the urethra. The peripheral nervous system serves to co-ordinate these actions, while the central nerwous system serves to inhibit or initiate and thereby modulate these actions.

In the mature animal, the ultimate control of micturition resides in the central nervous system and is under 
control of the cortex. With maturity, cortical input is mandatory to determine the optimal social setting for micturition. The cortical input then serves to remove any inhibition of the micturition centre, which in turn removes any descending inhibiting signals. It is the supraspinal structures that allow the micturition to proceed. Upon completion of micturition, the spinal pathways return to the inhibiting mode,

Bladder innervation The autonomic nervous system, which consists of the parasympathetic and sympathetic nerves, and the somatic nervous system are both involved in controlling the lower urinary tract.

Several authors have described several pathways for bladder innervation. Most of these pathways were discovered in animal studies. For that reason, a complete model of the human innervation of the lower urinary tract is difficult to provide (2). Consensus has not yet been established. In the past, it was thought that bladder function fully relies on rellex mechanisms at the sacral level. Recent research by Holstege and Blok has emphasized the important role of supraspinal pathways in the lower urinary tract (3).

Peripheral pathways Both the autonomic and the somatic nervous systems are involved in the control of the lower urinary tract. The somatic nervous system controls the striated musculature of the pelvic floor and the urethra (4). The pelvic floor is innervated by somatic fibers carried in the pudendal nerve.

The autonomic innervation of the lower urinary tract has a parasympathetic and a sympathetic nervous system. The afferent parasymparhetic pathways run from the ventral segments of S2 to S4 in the spinal cord to a relay station in the pelvic plexus. The pelvic nerve contains predominantly parasympathetic nerve fibers. Synapses occur in the ganglia of the pelvic plexus and in the juxta and intramural ganglia of the bladder. The sympathetic nervous system uses two different pathways to link the target organs to the vesicomotoneurons inside the thoraco-lumbar spinal cord. The fibers leave the thoraco-lumbar spinal cord synapse in the sympathetic chain on the paravertebral gangtia or traverse it. Part of the nerve fibers then run to the superior hypogastric plexus. From here nerve fibers run via the left and right hypogastric plexus to the juxta and intramural ganglia to innervate the bladder and urethra. The other nerve fibers descend via the sympathetic chain and synapse in the pelvic plexus.

Ascending pathways from the bladder Autonomic afferents from the bladder star: in the mechanoreceptors in the bladder wall. Afferent parasympathetic pathways travel from these receptors 
in the bladder to the sacral spinal cord via the pelvic nerve. Afferent sympathetic pathways also travel from these receptors in the bladder wall, which are conveyed by the pelvic nerve. These neurons enter the spinal cord. Somatic afferents are conveyed by the pelvic nerve and project to the Onuf's nucleus in the spinal cord (2,5-12). The pelvic floor muscles and the striated musculature of the urethral sphincter are conveyed by the pudendal nerve. These neurons synapse in the dorsal horn of the spinal cord. It is also suggested that these neurons project to Onuf's nucleus, indicating a myotonic reflex arc (2).

Afferents travelling via the pelvic nerve to the sacral spinal cord consist of small myelinated (A $\delta$ ) and unmyelinated (C) fibers (13). The myelinated A $\delta$ afferents are connected to the mechanoreceptors (volume and tension receptors) (14,15) and respond to stretching distension of the bladder. The C-fiber afferents do not respond to distension but they are activated by noxious stimuli, like irritation or inflammation. Therefore, they cause a painful sensation. In animal testing. reflex micturition is initiated by bladder filling. The $A \delta$-fiber afferents detect bladder distension. C-fiber afferents are not involved in normal voiding mechanisms but can modulate voiding reflexes and induce hyperactivity in response to bladder pain (6). Mechanoreceptor afferents from the bladder and urethra have also been identified in sympathetic nerves passing to the lumbar cord. These afferent neurons consist of myelinated and unmyelinated axons, which respond to stimulus modalities similar to those triggering afferents in the pelvic nerve (16). The function of the sympathetic nerve afferents is still obscure. Clinical observations suggest that they forward nociceptive information. Afferents from the urethra, travelling in the pudendal nerve, induce the sensations of pain, temperature and passage of urine. These afferents and the pudendal nerve afferents from the striated sphincter muscle have a modulatory influence on micturition.

Spinal Center This functions as a relay center for afferent and efferent parhways: It does not contain. grey matter nuclei (17). The sympathetic neurons are located in the tractus intermediolateralis of the spinal cord T1 1-L2 (1.18). The parasympathetic preganglionic neurons are located in the S2-S4 segments of the spinal cond (19). Somatic efferents are located in the anterior horn of S2-S4 in an area called Onuf's nucleus (also known as the pudendal nucleus or sphincter motor nucleus) (20).

The cerebellum The cerebellum serves to modulate motoractivity that is initiated in other parts of the central nervous system. It receives sensory afferents from the bladder and pelvic floor muscles. Its 
efferent role is to maintain tone and co-ordination in the striated muscles of the pelvic floor and periwrethral striated muscle, and it has an influence on co-ordinating relaxation of the pelvic floor with detrusor contraction. It is also suggested that it is responsible for suppression of spontaneous detrusor contractions (9,21-23). In addition, cerebellar ataxia can cause hyperreflexia of the bladder (24).

Basal ganglia The basal ganglia are nuclei located below the cortex and adjacent to the thatamus. There is evidence that these structures have an inhibitory influence on the pontine micturition center in that spontaneous detrusor reflex contractions are suppressed $(25,26)$. The clinical correlate is seen in patients with Parkinson's disease who have lost their dopaminergic neurons within the substantiat nigra, and. who have hyperactive detrusors. Stimulation of certain zones in the striate nuclei appears to suppress the micturition reflex. Destruction of these zones leads to hyperreflexia (27).

The thalamus and hypothalamus The thalamus is a collection of nuclei that together relay sensory information upward to the cerebral cortex (28). It relays sensory afferents from the sphincter to the cortex (29). The hyporhalamus consists of major groups of nuclei whose known effects include maintaining body temperature and fluid balance through neuro-endocrine mechanisms. It seems that the thatamus and hypothalamus are involved in the control of micturition and defecation through the autonomic nervous system $(30.31)$.

The limbic system The limbic system comprises areas located primarily in the temporal lobe. Depending on the stimulated zones, bladder activity may be facilitated or inhibited. As mentioned before, the bladder and its sphincter have two main functions: storage of urine and voiding or micturition. In the storage phase, the external urethral sphincter is conically contracted, while the detrusor. the muscle of the bladder, is relaxed. During the micturition phase, the opposite takes place. The de* trusor contracts and the external urethral sphincter relaxes (32). The synergy between detrusor and external urethral sphincter is under brain stem control (11) (33). The brain stem neurons are located in a medial and a lateral cell group in the dorsolateral pons (34). The medial cell group specifically projects via long-descending parhways to the sacral intermedial cell group and to the intermediolateral cell column containing autonomic motor neurons to the detrusor muscle of the bladder. The medial cell group in the dorsolateral pons is called the M-region (33), or Barrington's nucleus (1925), or pon. tine micturition center. The lateral cell group is called the L-region (33) and sends fibers throughout 
the length of the spinal cord to the nucleus of Onuf in the SI-SIV spinal segments. Onuf's nucleus contains motor neurons innervating the pelvic floor including the external urethral sphincter as mentioned in the sacral spine anatomy. Electrical stimulation in the M-region produces an immediate and sharp decrease in the urethral pressure and pelvic floor EMG, followed after 2 seconds by a steep rise in intra-vesical pressure as a result of contraction of the bladder (33).

Bilateral lesions of the M-region result in long-term retention of urine (35). Electrical stimulation in the L-region results in strong excitation of the pelvic floor musculature and an increase in the urethral pressure, because of strong contraction of the external urethral sphincter (33). Bilateral lesions of the Lregion produce urine incontinence (35). The M-region may be regarded as the micturition control center and the L-region as the control centre for storage of urine. The M-region is stimulated by the PAG (Peri Aqueductal Gray). Information concerning the degree of bladder filling enters the lumbo-sacral cord via afferents in the pelvic nerves. These afferents terminate on sensory neurons in the dorsolateral part of the caudal lumbar and sacral spinal cord. These sensory neurons receiving bladder filling information project to the lateral and dorsal parts of the periaquaductal grey. If the bladder is sufficiently filled, the PAG turns on the 'switch' to start micturition via its projection to the M-region. Finally, the M-region starts micturition by inhibiting the urethral sphincter and activating the bladder via descending pathways to the sacral parasympathetic neurons (36). It is not yet known in which brain structure voluntary micturition is initiated. Holstege presents the existence of 3 motor systems $(37,38)$. The first system is formed by the pre-motor interneuronal projections of the motor neurons. These neurons receive direet or indirect afferent information from the periphery via peripheral afferent nerves and from the second and/or third motor systems. They are of paramount importance for determining the final output of the motor neurons. It is not atways true that these interneurons are located close to the target motor neurons. Holstege classifies the micturition-related inter-neurons in the dorsolateral pons as part of this system. They are of importance for micturition, because they determine whether bladder and bladder-sphincter function synergistically, via their long-descending pathways.

The question arises why these neurons are located so far from their target motorneurons. In that respect, it is important to realize that micturition is correlated with the emotional state of the individual. Therefore, the micturition interneurons need to receive afferent information from the limbic sys. tem. which is available in the dorsolateral pons, but not in the sacral cord. The interneurons involved 
in blood pressure control and projecting to the sympathetic motor neurons in the intermediolateral cell column of the thoraco-lumbar cord are located in the ventrolateral medulla. Their afferent information enters the central nervous system via the brainstem (vagal nerve), while afferent information from the limbic system that plays an extremely important role in determining the level of the blood pressure is also available. The second motor system consists of thick fibers that can be detected using the lesion degeneration technique. The fibers of this system terminate only to a limited extent directly on motor neurons, but for the most part on the inter neurons of the first motor system. The second system is the so-called somatic component of the motor system. It consists of a medial and a lateral component. The medial motor column controls eye and neck movements and axial and proximal body movements. The lateral motor column innervates the distal body musculature for independent movements of the extremities. The thind motor system was discovered only recently using modern tracing techniques. It consists of thin fibers and therefore could nor be demonstrated using earlier lesion-degeneration techniques. The third system seems to be the limbic component of the motor system. This also consists of a lateral and medial part. The medial component originates in the medial portions of the hypothalamus and in the mesencephalon and terminates in the ventral part of the caudal pontine and medial segmental field.

The lateral component originates laterally in the limbic system and in the lateral hypothalamus. These structures project to the lateral segmental field of the caudal pons and medulla, but not to the somatic motor neurons in this area. Within in the PAG (Peri-Aqueductal Grey), the center that can trigger the M-region and the lateral adjacent tegmentum, some specific groups of neurons are found. These neurons are probably related to specific functions, such as vocalisation, head movements involved in emotional behaviour or blood pressure control. The emotional brain has a great impact on the sensory as well as on the motor system. In both systems, it sets the gain or level of functioning of the neurons. The emotional state of the individual determines this level. For example, it is well known that many forms of stress such as aggression, fear and sexual arousal induce analgesia, while at the same time the motor neuron is set at a high' level and motor neurons can easily be excited by the second motor sys. tem. In this concept, the brainstem structures, which project diffusely to all parts of the spinal cord, can be considered as tools for the limbic system controlling spinal cord activity. The lateral component of the third motor system projects to the caudal brainstem lateral segmental field (not far from the dorsolateral area where the M-region is located), which contains first motor system interneurons invol- 
ved in specific functions such as respiration, vomiting, swallowing, chewing and licking. These activities are displayed at the beginning of fight or defense response and can be easily elicited by stimulation of lateral parts of the limbic system. Therefore, it seems that the lateral component of the third motor system is involved in more specific activities, related to emotional behaviour. Although the existence of an 'emotional motor center' never has been demonstrated in human beings, it could be quite possible that emotional behaviour in humans can have an acute and long-term influence on the control of urine storage and micturition. There is clinical evidence that in circumstances of stress, like moments of fighe and flight, micturition or detrusor contraction can be provoked. From clinical experience, it is well known that psychological and psychiatric problems in human beings such as for example stress, depression and sexual abuse have a direct effect on micturition behaviour and pelvic floor. This can lead to symptoms like urgency, frequency, urge incontinence and even retention.

Voiding mechanisms Voiding starts when tension receptors in the bladder wall reach a threshold tension, due to bladder filling (39). Afferents start firing bursts via the pelvic nerve, entering the spinal cord at L,4-S2 and ascend in the lateral spinothalamic tract (36). These afferents activate a spinalbulbospinal reflex that passes through the pons $(5,40)$. These sensory neurons in turn project to the lateral and dorsal parts of the peri-aquaductal grey (PAG). The PAG then switches from urine storage to urine release, starting micturition via the M-region. The $M$-region also receives information from the angulate gyrus, medial preoptic region of the hypothalamus, bed nucleus of stria terminalis and amygdala; these structures are concerned with emotional and homeostatic activities $(3,36)$. If the $\mathrm{PAG}$ has turned the 'switch' to start voiding, the M-region will increasingly excite the sacral parasympathetic motor neurons, causing bladder contraction. Simultaneously, the L-region is inhibited by the Mregion. causing relaxation of the intrinsic external urinary sphincter and pelvic floor via Onufs nucleus and the pelvic nerve (3).

In addition. the inhibitory effect of the vesicosympathetic reflex is eliminated by the M-region's activity. Because the M-region has connections to the intermediomedial cell group, this is a part of this vesicosympathetic reflex arc. The inhibition will end detrusor inhibition and cause bladderneck opening (2). 
Storage mechanisms To achieve continence, the urethra should be closed at the level of the sphincter. This means that the urethral sphincter parhways should be stimulated, especially during a rise in abdominal pressure as for example coughing. In addition, the micturition reflex (spinobulbospinal) should be inhibited. During bladder filling, the vesicosympathetic reflex is activated via afferents in the pelvic nerve (41). The sympathetic activity of these nerves induces a negative feedback mechanism. which inhibits the bladder and allows further bladder stretching. The efferent sympathetic action: closure of the vesical neck and proximal urethra due to direct stimulation of 8 -adrenoreceptors, and stimulation of $\delta$-adrenoreceptors inside the bladder wall, inhibiting the bladder $(11,12.42$ 44). The inhibitory input of the hypogastric nerve is stopped prior to voiding (41). Due to an acrive L-region. Onuf's nucleus is stimulated; urethral closure is supported by contraction of the pelvic floor and intrinsic external urethral sphincter $(5,42)$. Presumably, the M-region is inhibited by the activity of the L-region. A rise in intravesical pressure of a full bladder causes an increased activity of the striated musculature in the pelvic floor. This reflex is called the guarding reflex (45). 


\section{REFERENCES}

1. Juskiewenski, S., et al., Innervation of the bladder and urethra. Ahatamia Clinica, 1981. 2: p. 243-263.

2. Kinder, M., et al., Neuronal circuitry of the lower urinary tract: central and peripheral neuronal control of the micturition cycle. Anat Embryat, 1995, 192: p. 195-209.

3. Blok, B.F., The organization of central control of micrurition in cats and in humans. Anatomical and physiological inventigations, in Mediscle uelestickappen. 1998. Rijksuniversiteit Groningen: Groningen, p. 127.

4. Elbadawi, A. and F. Schenk. A new theory of the innervation of bladder musculature. 2. Innervation of the vesicourethral junction and external urethral sphincter. Jl'rol, 1974. 111 (5)(May): p. 613-615.

5. De Groat, W, and W. Steers, Autonomic regulation of the urinary bladder and sexual organs, in Central regulation of autonomic functions. A. Loewy and K. Spyer, Editori. 1990, I'niversity Press: Oxford. p. 310-32.3.

6. De Groat, W.. Anatomy and physiology of the lower urinary tract. Lrol Clin Norlb Am. 1993. 20(Aug): p. 383401.

7. De Groat, W., Central nervous system control of micturition, in Cirinary Incontunence, P. O'Donnell, Editor. 1997. Mosby: St 1,ouis. p. 33-47.

8. Bradley, W., Innervation of the male urinary bladder. J Urol, 1978. Irol Clin Nortb Am (5): p. 279-293.

9. Bradley, W., G. Timm, and F. Scott, Innervation of the detrusor muscle and urethra. Unol Clin Nortb Am, 1974. I: p. $3-27$.

10. Bradley, W. and C. Teague, Spinal cord organization of the micturition reflex afferents. Exp Ncurol, 1968b. 22: P. $504-516$.

11. Blaivas, 1.G., The neurophysiology of micturitions a clinical study of 550 parients. I Lint, 1982. 127(5): p. 958 . 963.

12. Blaivas, J.G., Pathophysiology of lower urinary tract dysfunction. Clintes in Obstetriat and Gynacolegy, 1985. $12(2)$ (June): p. 295-309

13. Hulsebosch, C. and R. Coggeshall, An analysis of the axon populations in the nerves to the pelvic viscera in the rat. J if Cimparatere Neuroliogy, 1982. $211(1)$ : p. 1-10.

14. Winter, D., Receptor characteristics and conduction velocites in bladder afferents. If of Pacbatrie Reacancb. $1971.8(3):$ p. $226-235$.

15. Uemura, E., T. Fletcher, and W. Bradley, Distribution of lumbar and sacral afferent axons in submucosa of caturinary bladder Anatomical Rowed, 1975. 185(-4): p. 579-587.

16. Torrens, M. and I. Morrison. The physiology of the lower urinary tract, in Human plyswology. M. Torrens and J. Marrison. Editors. 1987. Springer: Heidelberg-London. p. 333-350.

17. Kokotas, N., R. Schmidt, and E. Tanagho, Axonal transport of horseradish peroxidase: a new method for tracing 
nervous control of the bladder. C'nologia Internationalis, 1978, 35(6): p. 427-434.

18. Larellel, L and M. Reumont, Histologie de quelques aspects physiologiques de la poliomyelite humaine, Acta Nound Bele, 1958. 58: p. 297-302.

19. Schnitzlein, H., et al. A study of the parasympathetic nucleus, I Cump Ncund, 1965, 120: p. $477-481$.

20. Holstege. G., Some anatomical observations on the projections from the hypothalamus to brainstem and inpinal cond: an HRP and autoradiographic tracing study in the cat. I Comp Newnd, 1987. 260 (.Jun 1): p. 98. 126.

21 Bradley, W., Regulation of the micturition reflex by negative fecdback. / /hw, 19696. $101:$ p. $400-402$.

22. Bradley, W. and C. Teague, Hypogasmic and pelvic nerve activity during the micturition reflex. $J / / n d, 19696$. 102: p. $438-440$.

23. Martner, J., Inlluences on the defecation and micturition reflexes by the cerebellar fastigial nucleus. Awh Pbytiol Siand, 1975. $94(1):$ p. 95-104.

24. Leach, G., et al.. Urodynamic manifestations of cerebellar ataxia. / Urol, 1982, 128(2): p. 348.360.

25. Lewin, R. and R. Porter, Inhibition of spontaneous bladder activity by stimulation of the globus pallidus. Neumd 1965. 15(11): p. 1049-1052.

26. Lewin, R., G. Dillard, and R. Porter, Extrapyramidal inhibition of the urinary bladder. Rrain Rewark, 1967. $4(4):$ p. $301-307$.

27. Bors, E. and A.E. Commarr, Classificarion, in Neuroligical/holory, E. Born and A. Commart. Editora, 1971. Karger: New York. p. 129.

28. Bradiey, W. and T. Sundin. The physiology and pharmacology of urinary tract dysunction. Clin Neuropbarm, 1982.5(2): p. 13T- 158.

29. Mcleod, J., The representation of the splanchnic afferent pathways in the thalamul of the cat . I Pbysul. 1958. $140 ;$ p. 462 .

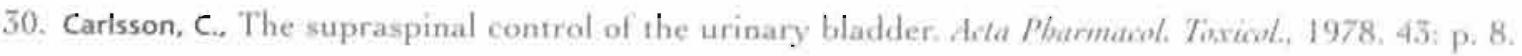

31. Koldewijn, Progress in neuro-urology, in Geneakunde. 1994. Katholieke Universiteit Nijmegen: Nịmegen.

32. Tanagho, E. and E. Miller, Initiation of voiding. Br. I ( $/ \mathrm{m} /, 1970,42(2): \mathrm{p}, 175-183$.

33. Holstege, G., et al. Anatomical and physiological obscrvations on supraspinal control of bladder and ure. thral sphincter muscles in the cat. I of Comparalive Neuml, 1986, 250(4): P. 449-461.

34. Holstege, G., H. Kuypers, and R. Boer, Anatomical evidence for direct brain stem projections to the somatic moroneuronal cell groups and autonomic preganglionic cell groups in cat spinal cord. Brain Rexamb, I979. $171(2):$ p. $329-333$.

35. Griffiths, D., et at., Control and coordination of bladder and urethral function in the brain stem of the cat. Neurourd Lrodyn, 1990. 9: p. 63-82

36. Blok, B.F. and G. Holstege, Direct projections from the periaqueductal gray to the pontine micturition center 
(M-region). An anterograde and retrograde tracing study in the cat. Neunwcience Letter, 1994. 166(1): p. 9396.

37. Holstege, G., R. Bandler, and C.B. Saper, The emotional motor system. Prognaw in brait ruearch, 1996. 107: p. 3-6.

38. Holstege, G., The emotional motor system in relation to the supraspinal control of micturition and mating behavior. Befariaural Grain necarb, 1998. 92(2): p. 103-9.

39. Iggo, A., Tension receptors in the stomach and urinary bladder. J Pbywiology, 1955. 128: p. 593.

40. Blok, B.F., H. De Weerd, and G. Holstege, Ultrastructural evidence for a paucity of projections from the lumbosacral card to the pontine micturition center or M-region in the cat: a new concept for the organization of the micturition reflex wish the periaqueductal gray as central relay. I Compantive Neurvl, 1995, 359(2): p. $300-309$.

41. De Groat, W. and P. Lalley, Reflex firing in the lumbar sympathetic outflow to activation of vesical afferent fibera. I Pbuscel. 1972. 226: p. 289.309.

42. Blaivas, J.G., Mechanisms of voiding, in Sctentific foundations of urology, G.D. Chisolm and W.R. Fair, Editors. 1990, Oxford. p. 273-286.

43. De Groat, W., A. Booth, and J. Krier, Interaction between sacral parasympathetic and lumbar sympathetic inputs to pelvic ganglia, in Integrative functions of the autonomic nervous system, C. Brooks, $\mathrm{K}$. Koizumi, and A. Sato, Editors. 1979a, Chiversity prose: Tokye, p. 50-67.

44. De Groat, W., et al., Neural control of the urinary bladder and sexual organs, in Integrative functions of the autonomic nervous system, C. Brooks, K. Koizumi, and A. Sato, Editors, 1979b. Universily praws Tokyes, p. 50-67.

45. Blaivas, J.G., et al., A new approach to electromyography of the external urethral sphincter. $J$ U/mo, 1977. $117(6): p, 773-777$. 
CHAPTER 3 PATHOPHYSIOLOGY OF LOWER URINARY TRACT DYSFUNCTION

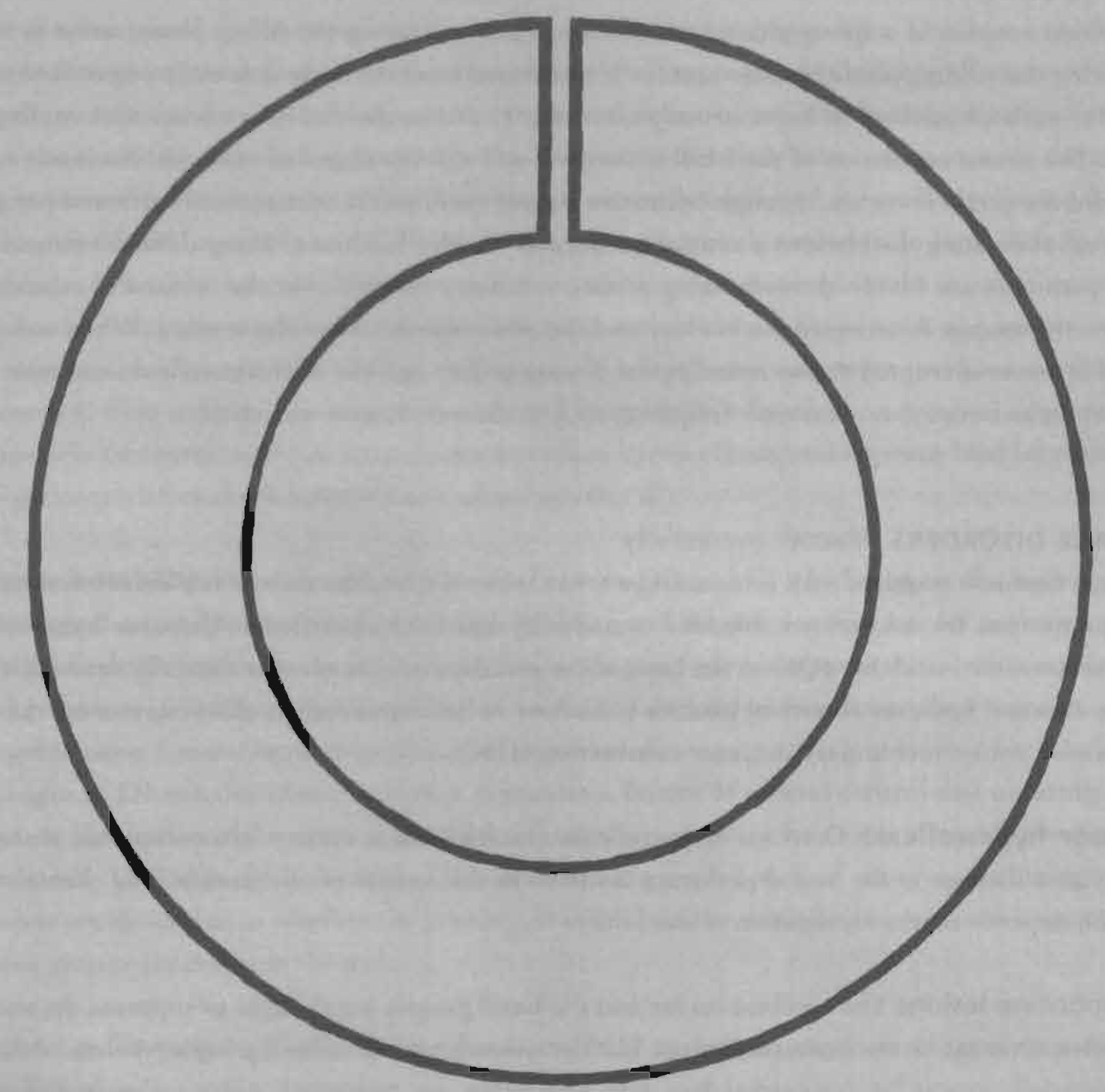




\section{PATHOPHYSIOLOGY OF LOWER URINARY TRACT DYSFUNCTION}

\section{INTRODUCTION}

Micturition consists of a filling phase and a voiding phase. During the filling phase, urine is stored and during the voiding phase bladder content is eliminated from the body at socially convenient times. Thus, the pathophysiology of lower urinary tract (LUT) can be divided into storage and voiding disorders. The neural regulation of the LUT is complex and still the object of research. An intact neural axis from the cerebral cortex, through brainstem, spinal cord, sacral micturition center and peripheral nerves innervating the bladder is crucial for normal bladder functions, Many different neurotransmitter pathways are involved, modulating proper voluntary control over the reciprocal relationship between the storage function of the bladder and the outlet sphincters of the urethra. When voluntary control is lost or disrupted due to neurological disease or damage, the aberrant reflexes can take over. resulting in incontinence, abnormal frequency of urination or urinary retention.

\section{STORAGE DISORDERS. Bladder overactivity}

The most common problem with urine storage arises when the bladder fails to remain relaxed until an appropriate time for micturition. Bladder overactivity has been classified as detrusor hyperreflexia (DH) or detrusor instability (DI) on the basis of the presence or absence of a clinically detectable neurologic disorder, however abnormal bladder behaviour in both situations is characterized by the same urodynamic entity: involuntary detrusor contraction (IDC).

Detrusor hyperreflexia Detrusor hyperrellexia results from a variety of neuropathic disorders, which cause damage to the neural pathways involved in the control of micrurition. The clinical manifestation depends on the localization of the injury.

Suprapontine lesions The cerebral cortex and the basal ganglia are thought to suppress the micturition rellex. 1)amage to the brain can induce bladder overactivity by reducing suprapontine inhibition.

Spinal cord lesions 1)amage to axonal parhways in the spinal cord leads to the emergence of primi- 
tive spinal bladder reflexes. A spinal cord lesion above the lumbosacral level eliminates voluntary and supraspinal control of micturition, leading to bladder overactivity mediated by spinal reflex pathways. There is an impairment of voluntary command of micturition and detrusor contraction on external mechanical stimulation. Due to the disruption of the pontine reflex pathways, micturition contractions are often unsustained and uncoordinated with detrusor-sphincter dyssynergia. Detrusor hyperreflexia has been thought to result from a combination of decreased supraspinal inhibitory effects on the sacral micturition reflex and re-entorcement of the segmental reflex by neuronal re-organization following loss of the excitatory descending pathways. An alternative theory is based on changes in the afferent input to the cord. The sensation of bladder filling is normally conveyed by small myelinated $\delta$-fibers. On the other hand, unmyelinated C-fibers convey noxious stimuli and seem to have little functional significance in healthy humans. However, in the cat, chronic spinal iniury results in automatic voiding via a sacral reflex arc mediated by C-fiber afferents rather than 8 -fibers as in the healthy animal. However, it is not known how C-fiber endings could adapt to become more mechano-sensitive (1). Enhanced C-fiber activity may also play a role in hyperreflexia in man, as intravesical administration of Capsaicin (a neurotoxin) has been shown to reduce hyperrellexia and improve bladder capacity in some patients with multiple sclerosis and spinal injuries (2).

Detrusor Instability There are some similarities between DH and DI which suggest that both may have a neurological cause. Detailed neurophysiological testing and imaging has failed so far to show any such deficit in idiopathic instability. In this context, non-neurogenic refers simply to the fact that a neurogenic disorder is not evident. Given the complexity of neuromuscular control of vesicourethral function, a subtle neurogenic cause (central or peripheral) cannot be excluded.

The origin of DI remains obscure. It may represent a failure of central control due to occult neural processes, facilitation of the micturition reflex of unknown cause, or be due to a local factor in the detrusor itself. Undoubtedly, idiopathic DI represents a complex web of many contributing causes. Opinions are divided as to whether the primary problem is in the detrusor (myogenic theory) or in the nervous system (neurogenic theory).

Congenital (immature bladder) The development of normal urinary control involves a complex physiological relationship dependent on maturation and also behavioral influences. Persistence of spontaneous instable detrusor contraction (IDC) and the child's response to them play a key role in 
the origin of many pediatric urologic conditions. Enuresis, recurrent cystitis, vesicourethral reflux and Hinman's syndrome may all be manifestations of dysfunctional voiding patterns that are associated with persistent DI. The degree of structural damage to the urinary tract depends on the frequency, magnitude and duration of elevated intravesical pressures and the degree of obstruction that is produced by uncoordinated sphincteric contraction. Always taking into account that the main expression of the immature bladder is DI persistence.

Various theories have been proposed to explain the cause of this dysfunctional voiding. The one that best explains this condition in adults is that of McGuire and Savastano (3). They believe that the primary abnormality is DI and that the detrusor sphincter dyssynergia that occurs develops as a result of sudden unanticipated detrusor contractility. Contraction of the pelvic floor-external sphincter complex is a normal response to control urgent urination and results in a reflex inhibition of the detrusor. When this becomes habitual over a period of time the abnormal incoordination carries over to voluntary voiding, resulting in an intermittent urinary stream and residual urine.

Outlet obstruction The DI associated with outflow obstruction has long been recognized (4). Approximately, it is present in $60 \%$ of patients with benign prostatic obstruction. After prostatic transurethral resection, the outlet obstruction disappears in two-thirds of patients. The best theory to explain this has been based on an animal model. Urethral obstruction in the pig produces a similar situation as seen in obstructed men by benign prostatic hypertrophy. Prolonged obstruction results in detrusor muscle hypertrophy and connective tissue infiltration of the bladder wall. The combination of these changes and raised voiding pressures leads to a reduction in blood flow and oxygen tension in the detrusor: Consequently, the derrusor is denervated through ischaemic nerve injury in the intramural ganglia. Motor denervation of the detrusor causes a generalized increase in sensitivity of smooth muscle cells through partial depolarization of the cell membrane (postjunctional supersensitivity), which is said then to cause IDC (5).

Aging In the elderly, $\mathrm{DI}$ is more common and the prevalence of urge incontinence increases with age; independent of outlow obstruction or neurologic disorder. Older men have the same symptoms as women, suggesting that LUT symptoms are a manifestation of aging in eicher gender. However, the boundaries berween DI and DH are uncertain in this group of patients, since age-associated neurologic diseases such as subclinical cerebrovascular disorders, autonomic neuropathy and chronic brain failure com- 
monly occur. Functional brain scanning using single-photon emission computed tomography has shown that there is underperfusion of the cortex as a whole, and of the frontal lobes in particular, in geriatric patients with D1. The underperfusion is particularly noticeable in the right superior lobe (6). Thus, DI has been linked with both cognitive impairment and decreased perfusion of the fron. tal lobes (7).

On the other side, abnormal cell to cell communications have been reported in aging people with DI. Electron microscopy of detrusor biopsies carried out by Elbadawi et al. revealed a characteristic structural pattern. (8) The main features of this dysfunctional pattern are abundant protrusions, junctions and abutments which mediare in electrical coupling between muscle cells generating myogenic contractions $(9,10)$.

Psychosomatic factors There is little current support for a psychological cause for DI in women. This has been based on the response to behavioral treatment and on the fact that certain psychological factors may trigger urge incontinence, such as the sound of running water, a stressful event or an event such as turning the key in the door. Although these events certainly do act as triggers, there is no evidence that the mechanism is primarily psychogenic. By triggering the emotional motor system in the brain, it is possible to influence micturition behavior (I I, I2).

Anatomical incontinence Approximately $30 \%$ of women with stress incontinence have concomitan! DI (26). After surgical correction of stress incontinence. D! disappears in approximately two-thirds of these patients $(27,28)$. A decreased inhibition of the pelvic floor or the urethra (due to pelvic floor or urethra deficiency) can lead to increased efferent activity and subsequent detrusor overactivity. The best support for this hypothesis is given by the clinical results of pelvic floor electrical stimulation and rehabilitation. However, this pathogenesis remains to be proven.

There is also evidence that abnormal urethral relaxation may be the primary event which precipitates IDC (13). The sequence of events in the normal initiation of voiding is still debated. Classically, detrusor contraction is preceded by an appreciable fall in urethral pressure. Wise et al. recently showed that urethral instability is strongly associated with the sequence of urethral relaxation prior to detrusor contraction, whereas primary detrusor activity is almost exclusively associated with a stable urethra. They described rwo different types of DI patients. Those with a pure detrusor (myogenic) problem, with IDC not preceded by urethral relaxation and those without urethral relaxation prior to IDC, 
where the problem could be in the urethra or due to a premature micturition reflex. Urine in the posterior urethra may result in the urgency to void and an involuntary bladder contraction. This may occur by eliciting a urethral reflex (13). However, studies of bladder pressure while injecting saline into the proximal urethra have not provoked bladder contraction (14).

Hypersensitivity disorders Evidence has been presented indicating that neuropeptides containing sensory nerves innervate the human bladder $(15,16)$. These sensory afferents are Capsaicin-sensitive unmyelinated C-fibers and usually transmit sensations of bladder fullness, urgency and pain. Local release of tachykinin and other peptides from sensory nerves in the bladder wall has been shown to produce diverse biological effects such as bladder smoorh muscle contractions, facilitation of neural transmission and increased vascular permeability (16). These properties of bladder sensory nerves. may suggest the hypothesis that increased afferent activity can induce bladder overactivity in patients with hypersensitivity disorders. Since Capsaicin can suppress C-fiber sensory neuron activity, Maggi et al. instilled Capsaicin intravesically in patients with hypersensitive disorders of the LUT, showing: disappearance or marked attenuation of their symptoms. This result may support the hyporhesis above, but knowledge about the sensory function of the bladder is still limited $(15,16)$.

Current theories of bladder overactivity Current thinking explains all forms of bladder overac. tivity by two principal hypotheses: the myogenic and neurogenic theories. Separation into these two groups is useful when attempting to explain the etiology of the disorder. However, the division is artificial, as muscle and nerve function are so intimately linked. A disorder in one will produce seconda. ry changes in the other. Mechanisms of bladder overactivity vary with different etiologies (neurogenic bladder, outlow obstruction, aging hypersensitivity etc). Therefore, it is not easy to find a common feature that underlies detrusor overactivity. In this respect. Brading and Turner (17.18) have emphasized the myogenic changes (regardless of etiology). On the basis of observations that denervation is consistently found in detrusor biopsy specimen from patients with various forms of DI, they proposed that partial denervation of the detrusor may alter the properties of smooth muscle, leading to increased excitability and increased coupling cells. Thus, local contraction that occurs somewhere in the detrusor will spread throughout the bladder wall, resulting in coordinated myogenic contraction of the whole detrusor. However, what actually triggers this local contraction is not resolved. Thus, as Brading stated, the changes in smooth muscle properties seem to be a necessary prerequisite for the 
production of IDC (18).

Bladder overactivity may be caused by decreased inhibitory control in the central nervous system, reorganization of spinal reflex pathways, increased afferent activity, increased sensitivity to efferent stimulation in the detrusor or a combination of these factors. Whichever factors are involved, it is important to note that IDC is actually induced by post-ganglionic neurons in the detrusor. From a clinical point of view, it is clear that in any form of detrusor overactivity, antimuscarinic drug can improve symptoms, reduce urgency and increase bladder capacity. This may suggest that postganglionic cholinergic neurons are activated, leading to IDC. Even in the myogenic theory of DI, the neurogenic factors are required for triggering IDC. Thus in the case of DI, some activation of postganglionic neurons (cholinergic or purinergic) may occur during bladder filling. whereas this activation can be directly caused by an uninhibited micturition reflex (supraspinal or spinal) in the case of DH. Both neurogenic and myogenic mechanisms may be involved in the pathogenesis of bladder overactivity. Although the cause of overactivity bladder is different in neurogenic bladder, etiology-related DI and idiopathic DI, an activation of postganglionic neurons may finally produce the same effect on bladder behavior, IDC.

\section{URGENCY-FREQUENCY SYNDROME}

The urgency-frequency syndrome is another form of overactive bladder. It is characterized by an uncontrollable urge to void, resulting in frequent, small amounts of urine voided as often an every 15 minutes. Patients report that they do not leel empty after voiding. Often but not always, pain or dis. comfort accompanies this condition. Incontinent episodes may occur but are not the primary complaint. Urologic diseases related with this syndrome are: urethral syndrome, pelvic pain such as prostatodinia, orchalgia, interstitial cystitis. Also, several non-urologic diseases are related: irritable bowel, proctalgia and anal sphincter instability.

From a urodynamic point of view, these patients do not show IDC on provocative cystometry. Thus they have been diagnosed as having sensory as opposed to motor urgency.

The etiology of irritative voiding symptoms such as urgency frequency remains unknown. Thus, knowledge about pathophysiology is still fairly limited. Current theories have recognized this syndrome as a significant indication of increased fragility or excitability in sacral reflex neural regulation of voiding. It is considered as the result from an imbalance between facilitatory and excitatory control systems causing a hyperexcitable micturition reflex. Pelvic floor spasticity seems to be a main consequen- 
ce provoked by augmentation of sensory input into the central nervous system (e.g., peripheral inflammation) or a loss of intrinsic central nervous system inhibitory circuits due to neural parhology (19).

\section{EMPTYING DISORDERS}

Patients with bladder emptying problems can experience voiding symptoms (e.g. hesitancy, loss of force of the urinary stream, decrease of the caliber of the stream), incomplete void (significant volumes of residual urine greater than 50 ce remaining in the bladder post voiding) or complete retention (inability to initiate a void). Functionally, micturition is a result of two factors, viz detrusor contraction and urethral resistance. Therefore, bladder emptying problems can be caused by impaired detrusor contraction (weak or no bladder contraction) or bladder outlet obstruction (high urehtral resistance).

Both can have organic or functional causes. Impaired detrusor contractions secondary to benign prostatic hyperplasia or high urethral resistance due to strictures are examples of organic causes and can be surgically treated. Functional causes means that organic defects cannot be demonstrated, so that the treatment of these disorders very often does not address the cause. Detrusor hypocontractilty or acontractility and/or spastic pelvic floor syndrome might be responsible for failure to empty the bladder. The underlying pathophysiology of these functional causes has not been clearly elucidated and is supposed to be multifactorial.

\section{BLADDER HYPO-ACONTRACTILITY}

The acontractile detrusor is one that does not demonstrably contract during urodynamic studies. Detrusor areflexia is defined as acontractility due to an abnormality of nervous control and denotes the complete absence of centrally coordinated contraction. In cases where no neurogenic disease is evident, the hypocontractility is considered as idiopathic.

Neurogenic hypo-acontractility (areflexia) Detrusor areflexia is the absence of spontaneous detrusor contractions in a patient with neurologic lesion. Bladder and urethral function become altered in response to neurologic disease in a limited number of ways. Neurologic lesions produce a loss of function, through a decrease in facilatory nervous transmission. Such loss of function is characterized by 
paralysis of the detrusor in those patients with lower motor neuron lesions. Patients with lumbosacral lesions, such as cauda equina injury or myelodisplasia are more likely to develop a flaccid bladder. In such cases, facilatory impulses are inadequate to generate a detrusor contraction. Therefore intravesical pressure does not develop and voiding does not occur.

Non-neurogenic bladder hypo-acontractility Idiopathic non-obstructive bladder hypo- to acontractility is a perplexing entity in modern urological practice. Some functional disorders during the maturation phase, like poor voiding habits or forced toilet training, can become manifest over time. The desire to void is a sensation which, in the developed child, is incorporated into daily life so that voiding takes place at an appropriate time and place. Problems with training or psychological diffi= culties can have a great impact on the results of training. Misuse of the pelvic floor may cause a change in dynamics of the lower urinary tract function. If the neural reflexes are not conditioned appropriately due to constant misuse (e.g. voiding by using abdominal muscle instead of relaxing pelvic floor muscles), a permanent change in these neural reflexes may result. Since inhibitory reflexes are learned behavior during maturation of the nervous system, proper use of the pelvic floor is critical to proper development of these behavioral reflexes (20). Some parents send their child to the toilet many times, although the bladder may be empty. Voiding in these circumstances can only be achieved by abdominal straining. As the child will be rewarded to produce even the smallest amount of urine, the result may be an abnormal voiding pattern. The same is true when children receive negative feedback related to voiding. Children with a lazy bladder void infrequently. They usually resuls in urinary trace infection and overflow incontinence. Long-standing overactivity of the pelvic floor is thought to be responsible for decompensation of the detrusor, leading to a noncontractile bladder. However, no data are available to support this theory.

A mild degree of bladder weakness occurs quite commonly in older individuals. There is a clear and significant reduction in detrusor contractility with age, both in women and in men. In the absence of previous obstruction, the detrusor is characterized at the cellular level by widenpread degenerative changes of both muscle cells and axons, without accompanying regenerative changes. These degenerative changes can easily explain the limited capacity of muscle cells to generate contraction, as well as being an impediment of the neural mechanism that triggers it at the muscle cell level. 


\section{PELVIC FLOOR MUSCLE-URETHRAL EXTERNAL SPHINCTER OVERACTIVITY.}

The sacral micturition reflex is a posirive feedback system that is poised to empty the bladder unless acted on by inhibitory reflexes. Any deficiency in the inhibitory reflexes acting on the detrusor are likely to result in bladder overactivity, including urge incontinence and urgency frequency. One of the best known inhibitory reflexes of the detrusor results from external sphincter contraction. Weaknesses in the pelvic floor that prevent sufficient contraction of the sphincter may, therefore, result in an uninhibited detrusor. The contrary is also true in patients with voiding dysfunction. If the pelvic floor muscles and sphincter are tetanically contracted, the detrusor is inhibited to the point of overfilling and distending the bladder.

Some casen of voiding dysfunction are associated with some degree of hyperactivity of the pelvic floor and external urethral sphincter muscles. These patients have a lack of pelvic control based on the observation of their inability to localize the pelvic floor. Vapnek and Schmidt theorized that in these patients there is an over-inhibition of the voiding reflex through a pathological reflex (21). Schmidt believed that neuromodulation may function through directing the patient to relocalize the pelvic floor and, hence, regain the capability of relaxing it and initiating voiding (22).

\section{FOWLER SYNDROME}

In 1988, Fowler et al. described a syndrome in young women in whom urinary retention was the predominant clinical teature and electromyography (EMG) of the striated muscle of the urethral sphincter revealed abnormal activity (23). The EMG activity is localized exclusively to the urethral sphincter and consists of a type of activity that would be expected to cause inappropriate contraction of the muscle in which it is found. The EMG activity has many features of myotonia, a condition in which a striated muscle remains in a state of sustained activity following contraction. However, detailed EMG analysis shows there are significant differences and that sphincter acrivity consists of two components; viz complex repetitive discharges and a decelerating burst. Why this type of EMG activity should develop in the urethral sphincter is unknown. The observation by Fowler that women with urinary retention also often have policystic ovaries raises the possibility that the activity is linked in some way to an abnormal hormonal imbalance. Perhaps impaired muscle membrane stability results. allowing a direct spread of electrical impulses throughout the muscle. Whatever the cause or nature of the abnormal EMG, urinary retention scems to be produced by an impaired sphincter relaxation. Although the 
Chapler 3

hypothesis that urinary retention in these young women is the result of a primary failure of relaxation of the sphincter remains to be demonstrated, some indirect findings support this idea.

Evidence has been provided showing the existence of a group of women with an abnormally high urethral pressure profile and obstructed voiding in whom ultrasound studies focusing on sphineter volume showed local muscle hypertrophy (24-26). 


\section{References}

1. De Groat wC. Central neural control of the lower urinary tract. Neurobiol of Lncon Ed. Bock G and Whelan J. Ciba Foundation Sympowium, Vol 151.p 27.

2. Fowler SL, Jewkes D, MCDonald. Intravesical capsaicin for neurogenic bladder dysfunction. Lancet 1992 , $339: 1239$

3. McGuire EJ, Savastano JA. Urodynamic studies in enuresis and the nonneurogenic neturogenic bladder. I Unol. $198-1,132: 299$.

4. Abrams P. Detrusor instability and bladder outlet obstruction. Nearourol Cinodyn. 1985, 4:317.

5. Brading Af, Turner WH. The unstable bladder: towards a common mechanism. Br. J U/mL, 1994, 74:3.

6. Blok FMB, Willemsen ATM, Holstege G. A PET study on brain control of micturition in humans. Brair. 1997, 120. 111.

7. Griffiths DI, McCraken PN, Harrison GM, Gormley EA, Moore K, Hooper R, McEwan AJ, Triscott J. Cerebral etiology of urinary urge incontinence in elderly people. Alge and Aaing. 1994, 23:246.

8. Elbadawi A, Yalla SV, Resnick NM. Structural basis of geriatric voiding dysfunction. Aging detrusor: normal vs impaired contractility. I / frof, 1993, 150:1657.

9. Elbadawi A, Yalla SV, Resnick NM. Structural hasis of geriatric voiding dysfunction. Detrusor overactivity. Illow 1993. 150:1668.

10. Elbadawi A, Yalla SV, Resnick NM. Structural basis of geriatric voiding dysfunction. Bladder outlet obstruction. Illowl 1993, 150:1681.

11. Holstege, G, R.Bandler, C.B.Saper, The emotional motor system. Pngrew in brain rocanc6, 1996. 107:3-6.

12 Holstege, $G$, The emotional motor system in relation to the supraspinal control of micturition and mating behavion: Bebartonal bentin rescarcb, 1998, 92(2):103-9.

13. Wise BG, Cardozo LD, Cutner A, Benness CJ, Burton G. Prevalence and significance of urethral instability in women wirh detrusor instability. Br. J L hol, 1993, 72:26.

1-1. Suthhurst IR, Brown M. The effect on the bladder pressure of sudden entry of fluid into posterior urethra. Br.t livel. 1978, 50:400).

16. Maggi CA. Tachykinins and calcitonin generelated peptide (CGRP) as cotransmitters released from peripheral endings of sensory nerves. Progr licurobial. 1995, 45: 1.

16. Maggi CA, Barbanti G, Santiciolo P, Beneforti P, Misuri D, Meli A, Turini D. Cystometric evidence that capsaicin-sensitive nerves modulate the afferent branch of micturition reflex in humans. J ITol. 1989, 142:150.

17. Brading AF, Turner WH. The unstable bladder towards a common mechanism. Br J I/noL 1994. 73:3.

18. Brading AF, A myogenic basis for the overactive bladder. ('nology, 1997, 50 (suppl): 57. 
19. Schmidt RA, Doggweiler $R$. Neurostimulation and neuromodulation: a guide to selecting the right urologic patient. Eair Ulool. 1998, 34 (suppl):23.

20. Nijman RJM. Classificarion and treatment of functional incontinence in children. BJ/L International, 200085 (suppl 3):37.

21 Elabbady AA, Hassouna MM Elhilali MM. Neural stimulation for chronic voiding dysfunctions, / Uho/, 1994, $152: 2076$

22. Schmidt RA. Advances in genitourinary neurostimualtion. Newmitince. 1986, 19:1041.

23. Fowler C, Christmas TI. Chapple CR, Fitzmaurice PH, Kirby RS, lacobs HS. Abnormal electromyography activity of the urethral sphineter, voiding dysfunction and polycystic ovaries: a new syndrome? B,IJI. 1988, $297: 1436$.

24. Raz S, Smith R. External sphincter spasticity syndrome in female patients, J I rol 1976, $116: 446$.

25. Noble J, Dixon P, Rickards D, Fowler C. Urethral sphincter volumes in women with obstructed voiding and abnormal sphincter EMG activity. Br J Urol, 1995, 76:741.

26. McGuire E J. Idiopathic bladder instability. Female Chol . 1994,95 .

27. Blaivas JG, Saulinas J. Type III stress urinary incontinence. The importance of proper diagnosis and treatment. Sary Forum. 1974, 35:472.

28. Awad SA, Flood HD, Acker KL, The significance of prior anti-incontinence surgery in women who present with urinary incontinence, fllm/, 1988, 140:514. 



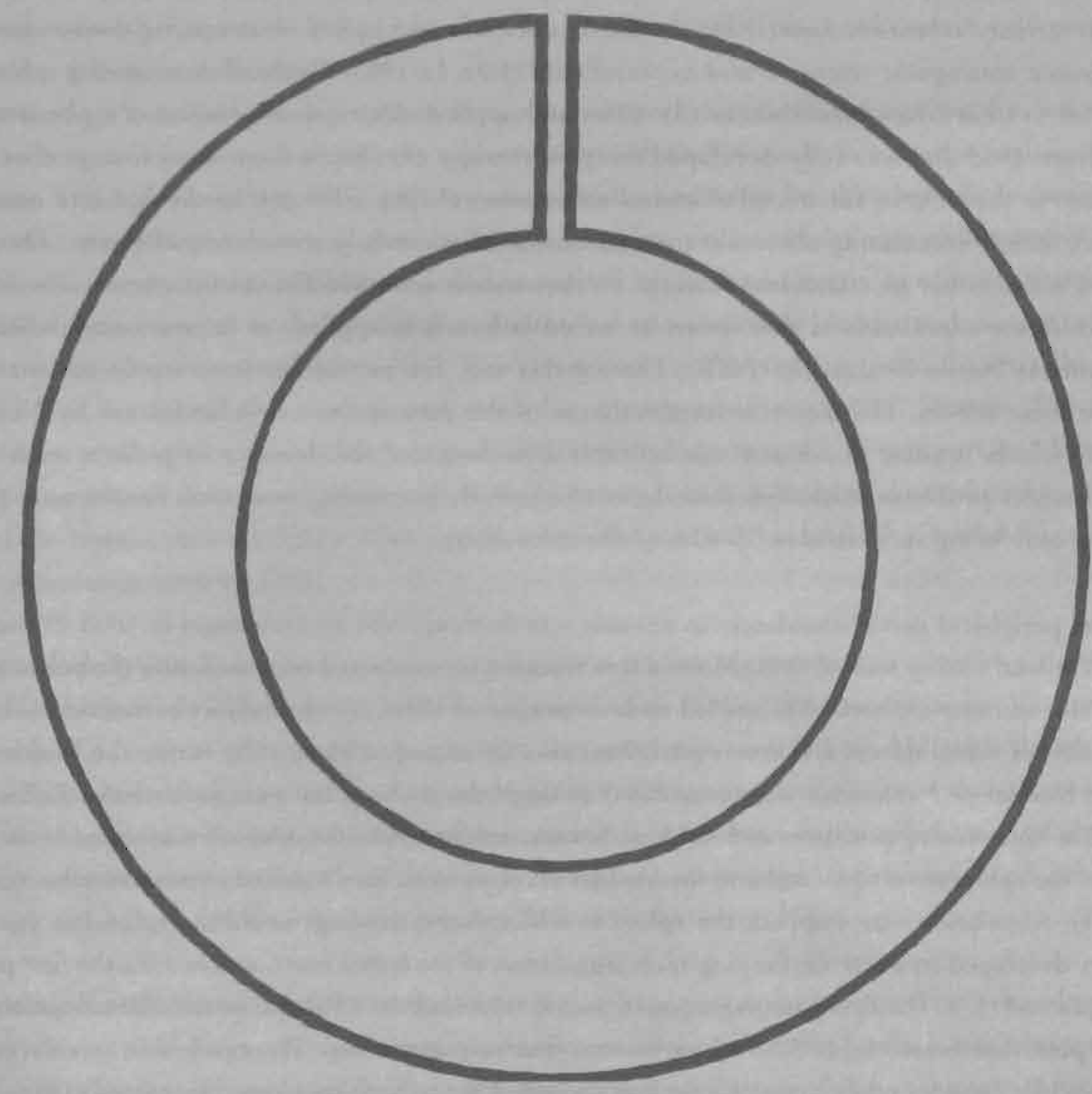




\section{Chapter 4}

\section{HISTORY OF THE DEVELOPMENT OF NEUROSTIMULATION}

In 1878, Saxtorph reported intravesical electrostimulation in patients with an acontractile bladder and complete urinary retention. Later Katona, Ascoli and Federici applied electrostimulation in patients with chronic neurogenic retention and hyperreflexia $(1,2)$. In 1963, Caldwell developed a sphincterstimulator to treat stress incontinence (3). Clinically applied electrical stimulation is a phenomenon dating from 1965 and was fully developed for pain therapy (4). Since then, numerous studies have been done in the field of functional electrical stimulation (FES). FES can be divided into neurostimulation, mainly stimulating efferents, and neuromodulation, mainly stimulating afferents. The bladder muscle can either be stimulated directly, on the muscle, or indirectly, via the nerves. The advantage of indirect stimulation is that it can be tested before it is applied, as in neuromodulation and Percutaneous Nerve Evaluation (PNE). During this test, the nerves are temporarily stimulated to evaluate these neryes. The direct neurostimulation of the detrusor was first performed by McGuire (5). Afterwards Bradley developed transmittable stimulation of the detrusor in patients with neurogenic bladder problems. Although short-term results were promising. long-term results were disappointing, only being successful in 30-40\% of the cases (6-8).

After the peripheral nerve stimulation in animals was first reported by Giannuzzi in 1863 (9), several series of animal testing started (10). Most of this research concentrated on stimulating the pelvic nerve. Due to this stimulation, nerve librosis led to deterioration of these nerves and loss of function (11,12). Stimulation of sacral nerves and conus medullaris was developed to electrically empty the bladder (1315). The bladder and sphincter were stimulated through the roots of the parasympathetic S2-S4. This resulted in high voiding pressures and residues, because sphincter and bladder are stimulated at the same time, i.e. the sphincter is tightened and the bladder is contracted. This resulted in post-stimulus voiding: when the stimulation was stopped, the sphincter relaxed and voiding would start (14-16). In 1969, Brindley developed an electrode for long-term stimulation of the spinal roots, and in 1972 the first patient was implanted (17). The first paraplegic patients were implanted in 1978 and since 1986 a de-afferentiation, or posterior rhizotomy, of S2-S4-5 nerves was routinely pertormed. This resulted in an enlargement of the bladder capacity while hyperreflexia was abolished, thus continence could be gained (18).

During the sixties, intra-anal and intra-vaginal probes were developed to achieve non-invasive elec- 


\section{Chapter 4}

trical stimulation of the pelvic floor (3). In experiments with this kind of stimulation, it was found that stimulation of the pudendal nerve could inhibit instable detrusor contractions (19,20). Studies have indicated that stimulation of the afferent system activates the sympathetic inhibitory system of the bladder and preganglionic motor neurons through a spinal inhibitory system (21). Ascending spinal neurons, which project to the pons and cortex, are also inhibited. This could explain a decreased urge sensation during stimulation.

These findings form the basis of the application of sacral nerve stimulation through the third sacral canal. This technique is performed in parients wirhour neuronal disabilities, or in partial spinal cord injured patients, although nowadays these patients are possible candidates for this therapy. In patients with symptoms of urge incontinence or chronic urinary retention, neuromodulation is a therapeutic option. In this treatment, electrical field stimulation is applied to the sacral nerve, mostly S.3. Starting from the fifties, interest went to the application of electrical stimulation to bladder and urethral sphincter to obtain continence or bladder control. The development of a transistor, shortly after the Second World War, facilitated the development of cardiac muscle stimulation (22). Shortly after this, the development of urinary pacemakers began, at first with litule success. However, Giles Brindley in London and Emil Tanago together with Richard Schmidt in San Francisco developed useful functional electrostimulation $(17,23)$. 'They are therefore the pioneers in the field of useful functional urinary stimulation systems (24).

Neuromodulation This procedure was introduced in the late eighties and involves two steps. First a stimulation electrode is introduced in the sacral canal, close to the S.3 nerve. Secondly, if a good result is obtained during the test period, a permanent implantarion is undertaken. Although already a lot of research has been done on neuroanatomy and neurophysiology, in particular in animals, the exact working mechanism is still obscure and therefore neuromodulation is an empirically based therapy. Tanago and Schmidt treated 20 patients with therapy resistant urge incontinence, and achieved an average reduction of $90 \%$ of the symptoms in $70 \%$ of the patients (25).

Working mechanism of neuromodulation A first hypothesis was proposed by Schmidt, who stated that neuromodulation changed the spastic behavior of the pelvic floor, which was presumed to be the cause of most functional bladder disorders (26). The electrical stimulus was thought to activate the pudendal nerve, contracting the pelvic floor musculature and external urinary sphincter. This con- 


\section{Chapter 4}

traction should result in an inhibition of the detrusor muscle and therefore produce a detrusor relaxation. This means that, when increasing stimulation is applied on the nerve, improved contraction of the muscles is obtained (=neurostimulation), resulting in more efficient detrusor inhibition (25). The nerves projecting to the pelvic floor musculature are large diameter nerves. Because of their large diametern, depolarisation occurs at a lower amount of energy applied to the nerve, compared with smaller diameter autonomic nerves, especially unmyelinated nerves. This implies that the large somatosensory nerves in the pudendal nerve are first excited $(25,27)$. After implantation, it is important that the electrode is fairly close to the nerve. If the distance is too far, a higher amount of energy is applied to a larger field. Then the nerves in the proximity of the electrode, e.g. unmyelinated nerve fibers and small 8 -fibers, will be stimulated, causing pain (27).

Nowadays it in clear that neuronal bladder inhibition, through sacral neuromodulation, is not caused by pelvic floor contraction, but through afferent stimulation. Animal experiments show that pharmacological paralysis of the pelvic floor does not reduce bladder inhibition during electrostimulation (28).

Hence, bladder inhibition is not the result of activaring somatosensory efferents of the pudendal nerve (10). In addition, stimulating the afferents of the pelvic floor through the pudendal nerve results in neither bladder stimulation nor inhibition (28). Bladder excitation was found during stimulation of pelvic nerve afferents from the bladder and urethra as well as pudendal nerve afferents from the urinary sphincter. The bladder was inhibited by pudendal nerve afferents from the clitoris and the glans as well as pelvic nerve afferents from the anorectal region $(10,28)$. Furthermore, after chemical deefferentiation of the sacral nerves that innervate the pelvic floor. the effects of electrical stimulation on the bladder were inhibited. This also indicates that sacral neuromodulation has a direct effect on the sacral afferent nerves and that it is not a reflex mediated by the pelvic floor (28).

Schulz-Lampel holds the $\beta$-fibers of the sacral nerve afferents responsible for the electrically induced inhibition of bladder contraction (10). Pudendal afferent $\beta$-fibers from the urinary sphincter and/or pelvic floor induce electrical inhibition of bladder contractions (10). As these fibers are large in diameter, these nerve cells can be depolarised with minimal amounts of energy. Therefore, neurostimulation should not be applied through muscle contraction, nor should excess energy be applied to produce depolarisation of the smaller nerve fibers, like $\beta, B$ and unmyelinated $C$ fibers, which results in a painful sensation. These fibers are also responsible for bladder contracrions, induced by bladder dis- 


\section{Chapter 4}

tension or chemical excitarion. These are conveyed by the pelvic nerve. Therefore, stimulating the pudendal afferents can inhibit detrusor contractions (29). Stimulating the large-diameter afferent fibers can inhibit the parasympathetic motor neurons (21).

Sacral neuromodulation inhibits reflex afferent input from the bladder. The stimulation of afferent nerves might result in inhibitory or stimularory reflex activity (10).

In patients with chronic retention, voiding is believed to take place through a rebound response of the bladder. During neuromodulation the bladder is inhibited. If this inhibition is stopped, by turning of the electrical stimulation, a rebound contractile effect on the bladder can be measured $(30,31)$. Surprisingly, most of the patients do not need to turn off the stimulation to be able to void (32). It was found that patients with urinary retention had a significantly stronger bladder contraction and lower urethral resistance after six months of neuromodulation. Furthermore, the neuropathology of chronic retention, even when it is seen after pelvic surgery. remains obscure. Detrusor hypocontractility or acontractility and/or a spastic pelvic floor syndrome might be the cause of bladder-emptying problems (26,33-35). In 1988, Fowler et al. described a syndrome in young women in whom urinary retention was the predominant feature and in whom the electromyography (EMG) of the striated urethral sphincter revealed a striking abnormality. Due to this abnormality, the women could not relax the sphincter and retention would therefore result $(36,37)$.

Although the pathophysiology and aetiology of voiding dysfunction has not been clarilied totally, it can be influenced successfully by sacral neuromodulation.

Percutaneous Nerve Evaluation (PNE) Before a patient can be provided with an implantable sacral nerve stimulator, first a trial period is applied. Not every patient will benefit from this therapy. A provisional test can establish whether patients are likely candidates for successful implanturion. During a 3-5 day trial period, the sacral nerve is stimulated with a temporary electrode (38).

If a patient is a candidate for sacral nerve stimulation, it is suggested that a voiding diary is kept. This has to be done to identify the voiding complaints and to compare the voiding pattern before and during stimulation. If there is a decrease of voiding complaints of $50 \%$ or more, the percutaneous nerve evaluation test is considered to be successful. Then the patient is a candidate for implantation. If the test fails, another test can be performed. If this fails again, the physician should find another alternative or try a 'two-stage implant' (see this thesis, chapter 6). If a patient is very nervous about taking this test, diazepam can be administered orally, one hour before testing. 


\section{Chapter 4}

PNE test (see pages 134 and 135)

1. Localization and identification of the sacral foramina S2-S4.

2. Probing the sacral foramen.

3. Stimulation of the sacral nerve.

4. Instruction of the patient.

\section{How to Perform a PNE LeA}

To perform a PNE, the patient should be in a prone position on an examination table with the lumbar spine and sacral bone in one horizontal plane. Bolsters can be used to obtain a correct position, the hips should be in a slight anteflexion $\left(30^{\circ}\right)$. A pillow should be under the feet to allow free movement of the feet. There should be a good exposure of the anus and perineum. To obtain this, the buttocks are spread with tape. Also the leet and the calves should be exposed.

Then the sacral foramina can be localized. Several techniques can be used to localize the sacral foramina through surface markers $(39.40)$. We prefer the following method:

After the anal region has been exposed, palpate the iliac crest and the spinous process of LA and L.5. Palpate the $\operatorname{coccyx}$, the sacrococcygeal joint and the sacrolumbar joint. Mark these bony landmarks. $A$ line is drawn between the spinous process of L.5 and the sacrococcygeal joint, exactly in the midline to the natal cleft. Then a line is placed at the sacrolumbar joint. In the middle of the cranio-caudal line between the sacrolumbar joint and the sacrococcygeal, a transverse line is drawn. One finger to the right $(+1-1.5 \mathrm{~cm})$ or one finger to the left of the midline is the puncture location for the S3 foramen. The puncture location to reach the foramen of S2 is located one finger or approximately 1.5-2 $\mathrm{cm}$ cranial of the location of S3. The same goes for S4 in the caudal direction.

If these puncture sites are marked, a large region is to be desinfected, approximately 30 cm surrounding the S3. The patient is draped on the superior side and both lateral sides. The caudal side should not be covered, because this would prevent observation of the motor response at the perineum.

\section{Probing tbe sacwal faramen}

After this, the patient can be tested. First, the puncrure site must be anaesthetized. This is done with lidocaine. First the skin is infiltrated, then the periost is infiltrated, neat the foramen. Avoid intiluration of the foramen, as this would paralyze the sacral nerve, resulting in no response.

Then the needle can be positioned. The needle is inserted perpendicular to the bony surface of the 


\section{Chapter 4}

sacrum, in a $60^{\circ}$ angle to the skin (lumen of the needle facing caudal). Then the S3 foramen can be probed. Try to find the cranial and medial rim of the foramen. The sacral nerve lies $1-4 \mathrm{~cm}$ below the foramen opening in a small mediocaudal area of the lower medial quadrant of the foramen. The needle must be in a correct plane, not facing medially nor laterally, as it is inserted into the sacral canal (45).

\section{Stimulating the nerve}

After the needle is inserted into the S3, resting can take place. A sterile mini test-hook is connected to the superior part of the test needle, and the amplitude of the test stimulator is gradually increased. Now the patient must be observed to see if there is bellow-like contraction of the levator-ani muscle and a plantair-flexion of the first digit of the ipsilateral foot. This bellow-like contraction results in an elevation of the anus, due to a contraction of the pelvic musculature. In addition, the patient must be asked what he feels and at which location. A pulling like sensation should be felt in the anal, perineal, scrotal, and/or vaginal region. The place of the needle can be slightly adjusted in depth or angle to obtain the best response. If good responses are obtained, the lead can be inserted through the needle and the nerve is tested again. Afterwards, the lead is fixed to the patient with a transparent dressing. A small opening is made for drainage of blood. Cover this hole with a gauze and cover the gauze with another dressing. Extra dressing is used to minimize lead migration. Then the electrode and ground pad are connected to the test stimulator for a trial period of 3-7 days.

\section{Instruction to the patient}

The patient is instructed how to use the test stimulator. It is advisable to avoid bending of the back or strenuous household chores, to minimize chances of lead migration. Also cycling should be discouraged. In addition, the patient is instructed to complete the voiding diaries. After $3-7$ days, the patient is seen again and the test period is evaluated.

\section{A definition of a good ratult is:}

A. In urge incontinence, a reduction of at least $50 \%$ of the following parameters.

1. incontinent episodes

2. pads usage.

3. urge sensation

B. In urinary retention: micturition with a maximum of 50 ce retention. 


\section{Chapter 4}

C. In urgency frequency syndrome patients, a decrease of frequency to fewer than 8 times daily has to be obtained.

Implantation of the sacral nerve stimulation system During implantation, no muscle relaxants must be given, because this will abolish muscle response to the stimulation. The patient is then placed in a prone position, with 30 degrees anteflexion of the hips and knees. When the patient is draped, use transparent drapes, so as to be able to see the muscle reactions to the stimulation. Then, the procedure for the PNE as referred to above is followed. If good responses are obtained, a midline incision from $\mathrm{S} 4-\mathrm{SI}$ is made. The fascia is freed of subcutaneous tissue on the site of implantation. Then a paramedian incision is made through the paraspinal muscle. Next, the S3 foramen is located and probed with the test needle. Stimulation is applied by the mini l-hook and the nerve is tested for response. If good pelvic floor responses are obtained with or without toe response, the lead is inserted in the third sacral foramen perpendicularly. Puncture in the medial superior quadrant of the foramen is done, followed by insertion of the lead in this quadrant. The nerve lies in the inferior-medial part of the foramen(43). The lead is slightly curved to follow the curvature of the nerve laterally. Some authors have proposed inserting the sacral lead as far medially as possible in the foramen and rurning the bend in the lead medially, so as to prevent post-operative leg pain (41). If the lead is in place, it is anchored to the periosteum of the sacral bone. The four electrodes on the lead are tested for proper response. After that, all lour electrodes are tested for their response. Then the lead is connected to the implantable pulse generator (IPG). An extension cable is tunneled subcutaneously to the IPG. The IPG can either be implanted in a subcutaneous pocket of the anterior abdominal wall or in a subcutaneous poc. ket of the superiolateral buttock.

In our clinic, we recently started to implant the IPG in the gluteal region, in the top lateral buttock quadrant, the same location where intramuscular injections are given. We prefer buttock placement of the IPG, because the operating time is reduced by I hour, because repositioning of the patient may be required and, moreove, because a short subcutaneous tunnel is needed and only two instead of three incisions are required (chapter 10).

Post-operative IPG management The day after surgery, if the patient feels well, the IPG can be turned on. Normally, we start with unipolar stimulation. This means that the case of the IPG is pasi. tively charged and one of the 4 electrodes of the lead in the sacral foramen is negatively charged. It is 


\section{Chapter 4}

also possible to apply bipolar stimulation. This means that the case of the IPG has no charge and one of the electrodes is positively and one is negatively charged. In unipolar stimulation, a larger electrical field is active, stimulating a larger part of the sacral nerve. So in unipolar stimulation it is possible that side effects like pain or sensations in other places than the anus, labia, perineum, vagina, testes or penis are felt. In that case patients mostly complain about pain or sensations in the leg or buttock. If this is the case, one should switch to bipolar stimulation, which results in a smaller electrical lield, thus reducing side effects.

As it is possible that in the first weeks after surgery the lead slightly moves, at first unipolar stimula. tion should be applied. Because the nerve is in a larger electrical field, slight movements of the lead will not cause different sensations and the correct nerves will still be depolarised.

When stimulation is started, it should be felt close to or in the midline of the anus, vagina, labia, perineum, testes or penis. The amplitude should be set just so that the patient can feel the stimulation in one ore more of the above-mentioned regions. The patient should feel a tingling or throbbing sensation. This sensation should never be painful. If the sensation is not felt in the correct position, other electrodes (0-3) should be switched to negative to obtain the correct position of the stimulation, also in the unipolar setting. If there are more possibilities, the setting with the lowest amplitude should be chosen.

If unipolar stimulation causes uncomfortable side effects switch to bipolar stimulation. The electric charge of the case should be turned off and one of the electrodes of the lead should be switched to positive, another one should be negatively charged. If only one electrode is negatively charged, there are twelve possibilities to establish a bipolar senting. It is not advisable to set more electrodes negative, as this uses more battery power, reducing battery life.

Stimulation of the nerve is pulsed. The amplitude of the pulse is in volts, which we have just discussed. The width is called the pulse width and expressed in microseconds. The amount of space below this curve is the amount of energy applied to the nerve. This energy is needed to depolarize the nerve, causing the desired effect. From the point of view of battery life, a pulse width of $210 \mu$ s is advisable, though slight variations are allowed. By changing pulse-width, it is also possible to diminish side effects, or pain. The pulse-width should be between 60 and $270 \mu$ s. but slight variations of pulse width cause large changes in battery life. Because a change in pulse-width causes a different amount of energy to be applied to the nerve, the amplitude may have to be adjusted to keep the energy at the same level (27). 
The frequency of pulses, viz the rate, can be adjusted. Initially, a pulse frequency of $10-15 \mathrm{~Hz}$ is advised, although we normally use $10 \mathrm{~Hz}$. Animal studies have shown that stimulation at $5 \mathrm{~Hz}$ induces an increase in bladder pressure due to stimulation of large myelinated efferent fibers. At $10 \mathrm{~Hz}$, bladder inhibition is induced by stimulation of $A \beta$ afferent fibers (10). If the frequency is set too high (more than $19 \mathrm{~Hz}$ ), pain may be induced by stimulation of the thinner $\mathrm{A} \delta$, B and $C$ fibers. Higher frequencies may cause nerve damage (42).

The parameter continuous or cyclic stimulation can either be used if a patient gets used to the stimulation very easily or to save battery life. If we apply the cyclic mode, we usually put it 10 seconds on and 2 seconds off with a soft-start time of 1 second. The latter means that the voltage is increased to normal amplifude in one second and not all at once. Of course, other configurations are possible in on/ofl time.

It is advisable to apply the continuous mode in the first months after surgery, before switching to cyelic mode. 


\section{REFERENCES}

1. Ascoli R. Le traitement des vessies neurogènes. Avta Ulind Belg 1965: 33:76-8.3.

2. Katona $F$. Stages of vegetative afferentiation in reorganization of bladder control during intravesical electrotherapy. Unol litt 1975: 30:192.

3. Caldwell K. The electrical control of sphincter incontinence. Lancet 1963: 11:174-175.

4. Melzack R, Wall P. Pain mechanisms: a new theory. Scieno 1965; 150:971-979.

5. McGuire WF. Response of the neurogenic bladder to various electrical stimuli (thesis): Deph. of Sury Bewman Giny Sibool of Med; 1955.

6. Bradley W. Wittmers L, Chou S, French L. Use of a radio transmitter receiver unit for the treatment of neuroge nic bladder: a preliminary report. J of Neurowurgery 1962: 19:782-786.

7. Bradley W. Wittmers L, Chou S, French L. Further experience with the radio Iransmitter receiver unit for the neurogenic bladder. I of Neurwuryery [963: 20:953-960.

8. Hald T, Meier W, Khalili A, Agrawal G, Benton J, Kantrowitz A. Clinical experience with a radio-linked bladder stimulator: I of l/rol 1967: $97(1): 73-78$.

9. Giannuzzi M. Nerfs moteur de la vessie. Jeurnal de la Pboviolagie de Brown-Séquard 1863; 6:22-29.

10. Schultz-Lampel D. Neurophysiologische Grundlagen und klinische Anwendungen der salcraten Neuromodulation zur Therapie von Blasenfunktionsstörungen (I Tabilitationsschrifo), Wuppertal: Fakultătsklinik Witten/Herdecke: 1997.

11. Hald T, Argawal G, Kantrowitz A. Studies in stimulation of the bladder and its motor nerves. Suryery 1966: 60: 848-856.

12. Bradley W, Timm G, Chou S. A Decade of experience with electronic stimulation of the micturition reflex. I/rol Int 197!: 26: 83 .

13. Eidelberg E, Bors E, Woodbury C, Brigham A. Effect of electrical stimulation of dorsal and ventral npinal cond roots on the cat's urinary bladder. Unologia Internationale 1974; 29(5):375-381.

14. Jonas U, Heine H, Tanago E. Studies on the feasibility of urinary bladder evacuarion by direct spinal cord stimulation. 1. Parameters of most effective stimulation. Inves Crol 1975: 13(2):142-150.

15. Jonas U, Tanagho E. Studies on the feasibility of urinary bladder evacuarion by direct spinal cord stimulation. II. Poststimulus vaidings a way to overcome outflow resistance. Invert / Trol 1975: 13(2):151-153.

16. Brindley G. An implant to empty the bladder or close the urethra. If Neurol. Neunburigery and Pivebiatry 1977 ; $40(4): 358-369$

17. Brindley G. Experiments directed towards a prosthesis which controls the bladder and the external sphincter from a single sise of stimulation. In: Procecdinge of tbe Bublogical Lingincering Soctety, 46th Meeting; 1972 . 
Liverpool, England; 1972.

18. Brindley G. History of the sacral anterior root stimulator, 1969-1982. Neurourol and Crodyn 1993; 12(5):485. 486.

19. Fall M, Erlandson B, Sundin T, Waagstein F. Intravaginal electrical stimulation. Clinical experiments on bladder inhibition. Jof ('rol and Neplorel 1978 b; Suppl 44(part 4):4 [-48.

20. Fall $\mathrm{M}$, Lindstrom 5 . Electrical stimulation: A physiologic approach to the treatment of urinary incontinence. Itrot Clin Nerlb Am 1991; 18:393-407.

21. Lindstrom S, Fall M, Carlsson C.A, Erlandson B-E. The neurophysiological basis of bladder inhibition in response to intravaginal electrical stimulation. I Lind 1983; 129:405-410.

22. Hald T, Bradley W. The urinary bladder. Battimore/London: Williams and Wilkins; 1982.

23. Schmidt RA, Bruschini H, Tanagho EA. Feasibility of inducing micturition through chronic stimulation of sacral roots. Lineleyy 1978: 12(4):471-7.

24, Kerrebroeck van P. Nog maar net... Maar toch. In: 1997.

25. Schmidt R. Advancen in genitourinary neurostimulation. Neunumyery 1986; 19(6):104 1-1044.

26. Schmide R. Applications of neurostimulation in urology. Neurourd Utrodyn 1988; 7:585-592.

27. Gleason C. Electrophysical fundamentals of neurostimulation. Wiofd . of (Tro/ 1991; 9;110 113.

28. Lindstrom S, Sudsuang $\mathrm{A}$. Functionally specific bladder reflexes from pelvic and pudendal nerve branches; an experimental study in the cat. Neursumtogy and Unotynamice 1989;8:392-393.

29. Winter D. Receptor characteristics and conduction velocities in bladder afferents. A. of Psycbialrí- Rocarxb $1971 ; 8(5): 225-235$.

30. Thon, Gruenwald. Neurostimulation. L'rology 1993:295-302.

31. Schultz Lampel D, liang C, Lindstrom S, Thuroff JW. Experimental results on mechanisms of action of electrical neuromodulation in chronic urinary retention, World J of L irol 1998; 16(5):301.4.

32. Bosch, Groen, Essink-Bot, Krabbe, Seerden, Hout V. Sacral segmental (S.3) nerve stimulation as a treatment for urge inconfinence due to detrusor instability: Quality of life analysis and cost-effectiveness. I Crol 1996; 594 A (5 suppl): 155

33. Everaert K, Plancke $\mathrm{H}$, Lefevre $\mathrm{E}$, Oosterlinck W. The urodynamic evaluation of neuromodulation in patienrs with voiding dysfunction. Br , / lim/ 1997: 79:702-709.

34. Gruenewald V, Hoefner K, Becker A, Krah H, Gonnermann O, Jonas U. Clinical results and complicarions of chro nic sacral neuromodulation afier four years of application. In: Annual meeting of stov international contincme wricty: $199627-30$ August; Athens: 1996.

35. Schmidt, Kaula. Sacral nerve root stimulation: Sereening eflicacy in management of pelvic pain. Amerioan Unologioal hemeciatrim 1996; 594 A. 
36. Fowler C, Christmas TJ, Chapple CR, Parkhouse HF, Kirby RS, Jacobs HS. Abnormal electromyographic activity of the urethral sphincter, voiding dysfunction, and polycystic ovariest a new syndrome? $\mathrm{Br} / \mathrm{Me}) . J 1988 ; \mathrm{Dec} 3$; $297(6661): 14306-8$.

37. Goodwin R, Swinn M, Fowler C. The neurophysiology of urinary retention in young women and its treatment by neuromodulation. Wirld J Unol 1998; 16:305-307.

38. Hassouna, Elhilali. Role of sacral root stimulator in voiding dysfunction. Firfe J Uno/ 1991:145-148.

39. Siegel SW. Management of voiding dysfunction with an implantable neuroprosthesis. The Unologic Clinis of Nortb America 1992; 19(1):163-70.

40. Hasan S, Shanahan D, Pridie A, Neal D. Surface localization of sacral foramina for neuromodulation of bladder function. An anatomical study. Eur Unol 1996: 29:90-98.

41. Swinn M, Schott G, Oliver S, Kitchen N, CI F. Leg pain affer sacral neuromodulation: anatomical considerations. Brd Unol International 1999; 84(9):1113-1115.

42. Agnew WF, McCreery DB, Bullara LA, Yuen TGH. Effects of prolonged electrical stimulation ol peripheral nerve. In: Agnew WF, McCreery DB. editors. Neamal prowbews fundamental, tudter, Prentice Hall, Englewood Cliffs, New Jersey: 1990. p. 148-167.

43. Mersdorf A, Schmidt RA, Tanagho EA. Topographical-anatomical basis of sacral neurostimulation: neuroanatomical variations. The . Iournat of Unology 1993; 149:345-349 
CHAPTER 5 NEUROMODULATION OF SACRAL NERVES FOR INCONTINENCE AND VOIDING DYSFUNCTIONS Clinical Results and Complications

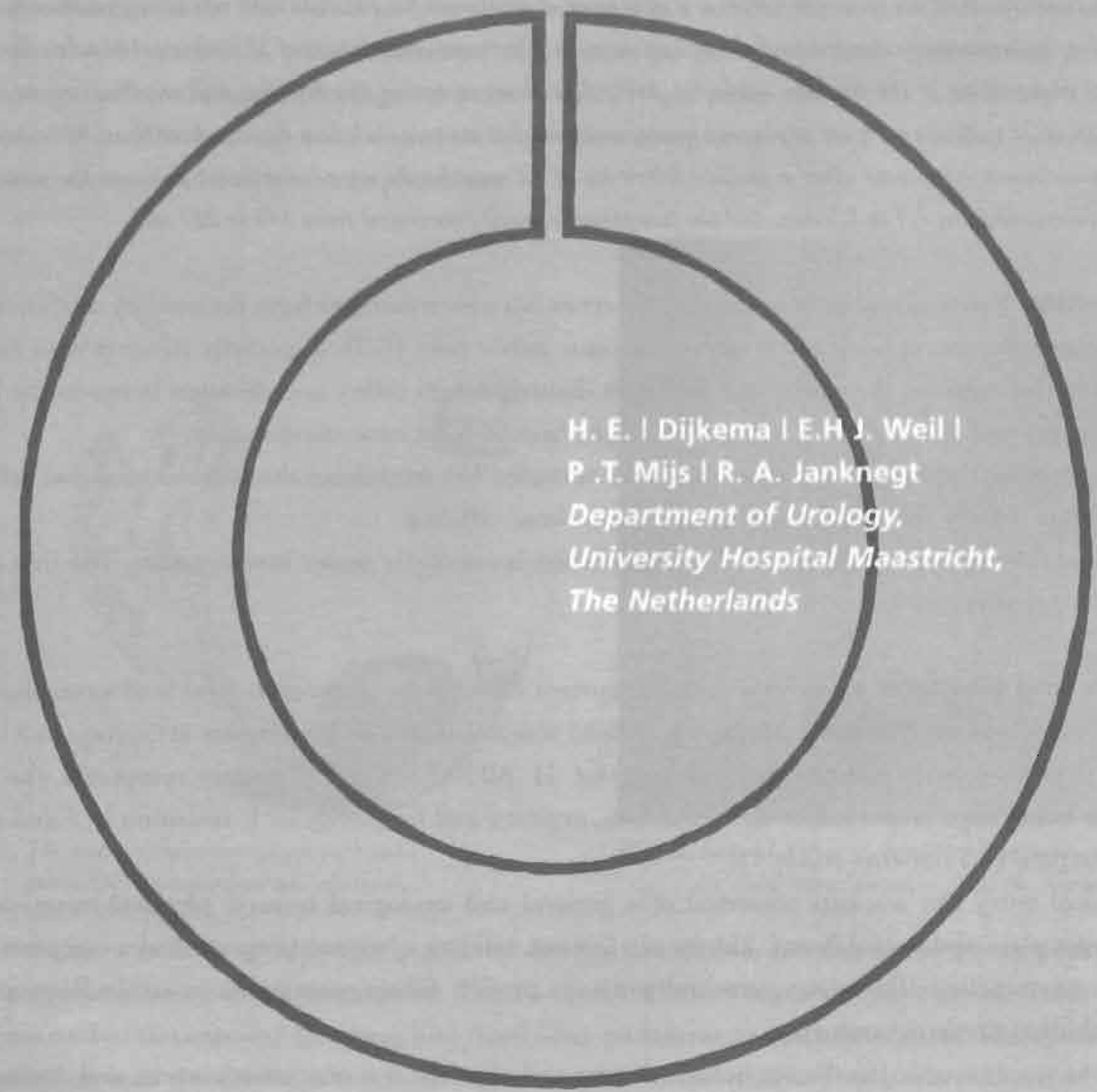

Eur Urol 24:972-76, 1993 


\title{
NEUROMODULATION OF SACRAL NERVES FOR INCONTINENCE AND VOIDING DYSFUNCTIONS
}

\begin{abstract}
Neuromodulation of sucvel nerves is a new form of treatment for patiente witb refractory woding dysfunc-

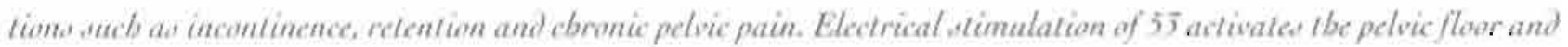

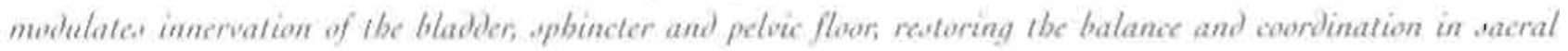

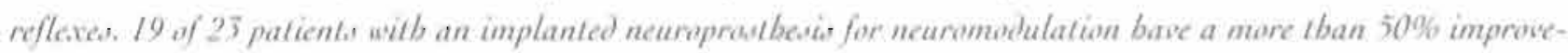
ment in their main symptoms after a median follow-up of 12 montbs. In urge-incontinent patienter the number of leakings decreaied from 7,4 to $1.5 /$ day. and the functional capacily increased from 155 to $227 \mathrm{ml}$.
\end{abstract}

Introduction Neuromodulation of the sacral nerves is a new treatment form for voiding dysfunctions. such as incontinence; urinary retention and chronic pelvic pain (1-3). Especially patients who did not respond to the common therapies, and in whom disturbance in reflex coordination between the bladder, sphincter and pelvic floor is suspected, might benefit from neuromodulation.

Chronic electrical stimulation of a sacral nerve (usually S3) modulates the pattern of sacral reflexes and can thus restore the normal balance between these reflexes.

An implantable neuroprosthesis for neuromodulation is currently under investigation. The first clinical results are presented.

Patients and Methods A neuromodulation system (lirel pulse generator, Itrel lead extension and Pisces Quad foramen electrode, Medronic. USA) was implanted in 23 patients after they had had a successful pereutaneous fest neuromodulation (fig. 1). All had refractory urinary symptoms, the main symptom being urge incontinence in 16 patients, urgency and frequency in 1, retention in 3 and chronic pelvic pain in 3 patients (table 1 ).

At protocol entry the workup consisted of a general and urological history. physical examination. cystoscopy, plain abdominal X-ray, kidney ultrasound, vaiding cystourerhrogram and a complete urodynamic examination (flowmetry, urethral pressure profile, filling cystometry, pressure flow, and 7 hour ambulant urethrocystometry).

Symptoms were recorded in diaries before, during and after the test neuromodulation, and during follow-up after implantation. Urodynamic evaluation was repeated. 6 months after implantation. 


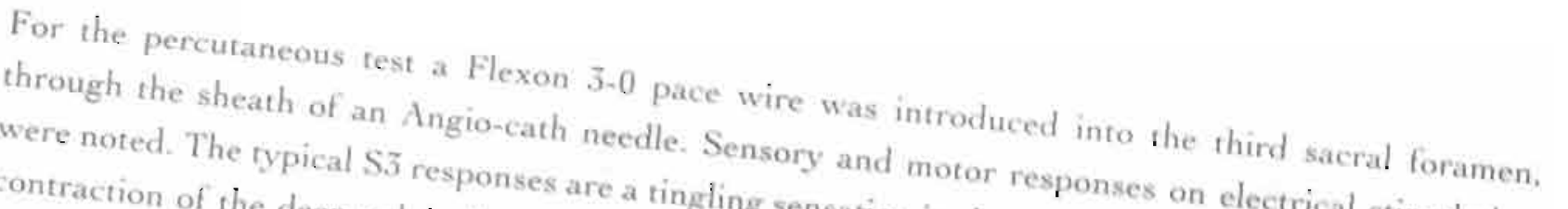
contraction of the deep pelvic foor mare a tingling sensation in the genitals an electrical stimulation neuromodulation in the individuat puscles and flexion of the great toes and around the anus, with were: unipolar monophasic, reetangubar, punnect to an external pulse generaic test (4-7 days), for which the If a more than $50 \%$ improvement walar, pulse width $210 \mu s$, pulse rate 10 . Stimulation parameters the patients were candidates for inpleen in the main symptoms, the test was amplitude 0.5-20 mA.

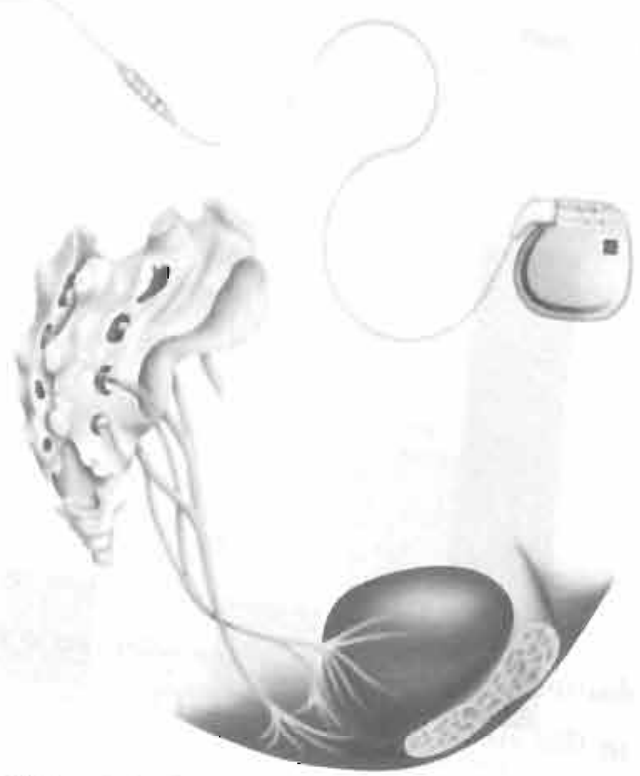

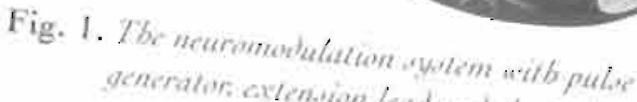
generater avemwion lead and clectrote. Implantation was done with the patient under general anesthesin. starting in the prone position with
a paramedian incision to the sacral bone. The Pisces Quad electrode with four pos sible
was inserted in the exposed foramen, and fixed

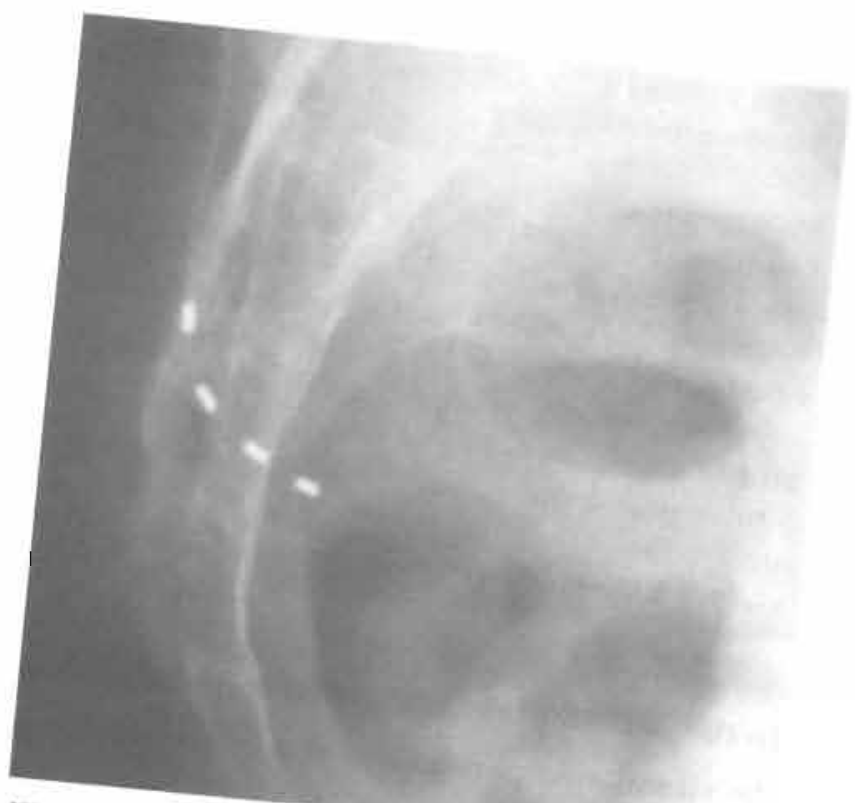

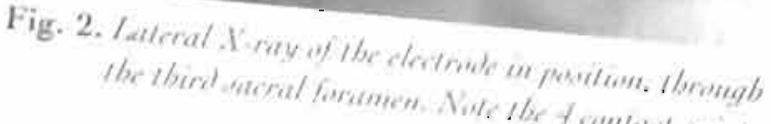
was inserted in the exposed foramen, and fixed after peroperatrede with four possible contact points an extension lead were then subcutaneously tunneled to the aberative test stimulation. The electrode and tor was implanted in a pocket, after placing the patient in the labdominal wall, where the Itrel stimula- 
Table I. Patient characteristio

\begin{tabular}{|c|c|}
\hline \multicolumn{2}{|l|}{ Age, years } \\
\hline Mean & 46 \\
\hline Range & 25.67 \\
\hline \multicolumn{2}{|l|}{ Sex } \\
\hline Femate & 16 \\
\hline Male & 3 \\
\hline \multicolumn{2}{|l|}{ Etiology } \\
\hline Neurogenic & 5 \\
\hline Pelvic surgery & 5 \\
\hline Bladder/prostate surgery & 11 \\
\hline \multicolumn{2}{|l|}{ Main symptom } \\
\hline Incontinence & 16 \\
\hline Urgeifrequency & 1 \\
\hline Retention & 3 \\
\hline Pelvic pain & 3 \\
\hline \multicolumn{2}{|l|}{ Median follow-up } \\
\hline $2-20$ months & 12 \\
\hline Itrel 1,9.20 months & 16 \\
\hline Itrel II, 2-7 months & 5 \\
\hline
\end{tabular}

In the first 15 patients the Itrel I stimulator was implanted, which only enables telemetric resetting of the stimulation parameters at a fixed contact point on the electrode. In the next 8 patients the improved ltrel II version was used, which enables telemetric switching between the 4 contact points (fig. 2). Stimulation parameters were: unipolat, nomophasic, rectangular. pulse width $60-210 \mu$, pulse rate $5-10$ Hz, amplitude 0.5-4. V. Stimulation was eirher continuous or cyclic, for example $10 \mathrm{~s}$ on and $2 \mathrm{~s}$ off.

Results Fourteen patients had a good result, a more than $90 \%$ improvement in their main symptom: 9 incontinent patients are dry: I urge parient has a normal voiding partern; 2 retention patients void without residual urine, and 2 patients are free of pain (fig. 3).

Five patients had a partial, but still more than $50 \%$ improvement. Two urge-incontinent patients still 


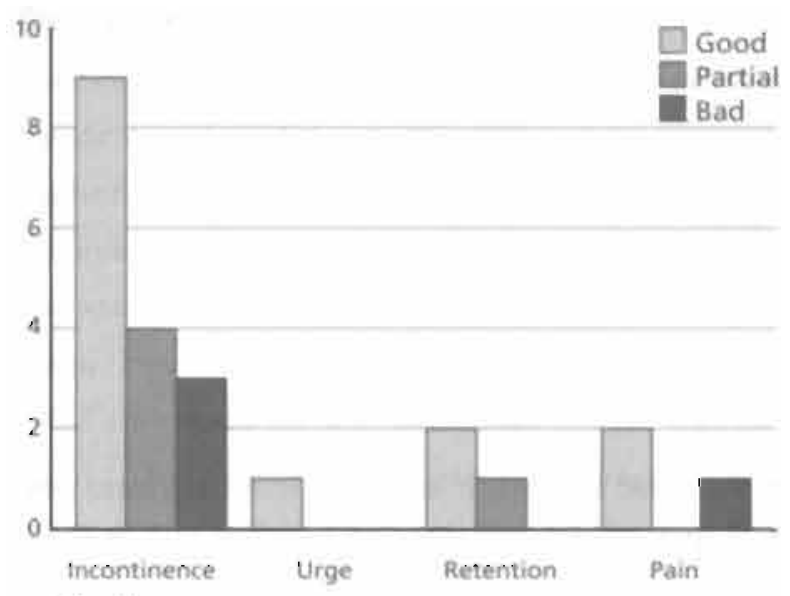

Fig. 3

Fig. 4.

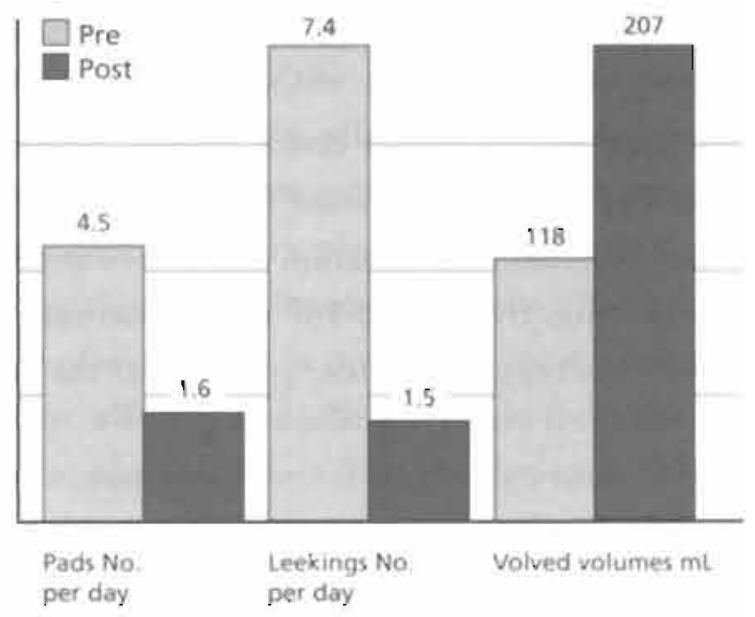

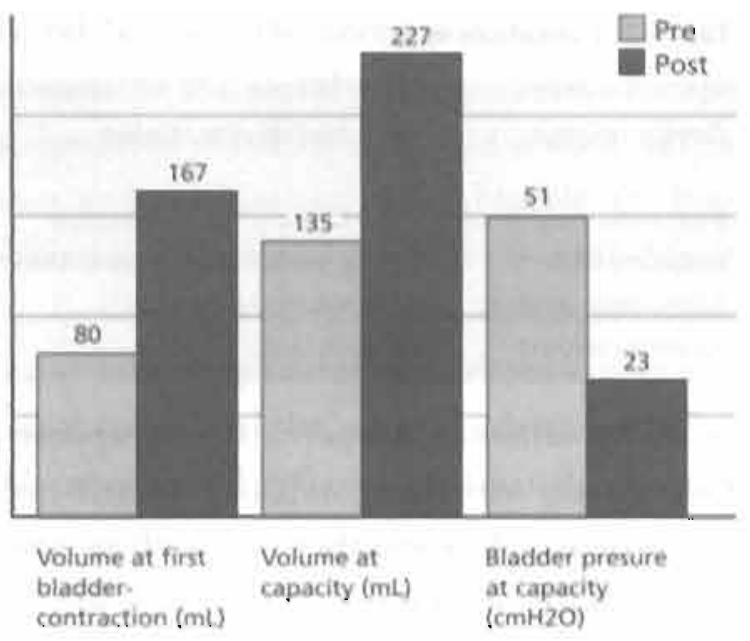

Fig. 5.

Fig. 3. Rerult, of recusomodulation in 25 patients afler implantation. Goond $=$ s9096 improsecment; pars liat' $=>50$ and $<90 \%$ impreventent; bad $<50 \%$ imporvement. The ! 'Trad' patient in Ibe paingnup aceme to bave impowed after exclanging tbe defect aystem for a new dyetem.

Fig. 4. Reactex from tbe diaries of incortinener patientis.

Fig. 5. Results, from axodynamies in insontincture paticats.

experience some urgency, 1 incontinent parient has been cured of her frequency but still looses drops of urine, and 1 patient is still stress-incontinent, being cured of the urge incontinence. Finally I patient with urinary retention can void now, but with residual urine varying from 100 to $200 \mathrm{ml}$.

Three patients had a bad result. One urge-incontinent patient never had a good response after the implant. She had an excellent result at the percutaneous test, but with the implant the stimulation response could not be reproduced. Two urge-incontinent patients had secondary loss of the therapeu- 
Table 2. Complicatione

$\begin{array}{llll}\text { Device related } & n \text { Not device related } & n \\ \text { Electrode migration } & 2 & \text { Urinary tract infection } & 3 \\ \text { Isolation defect } & 1 & \text { Cerebrovascular accident } & 1 \\ \text { Stimulator defect } & 1 & \text { Wound infection } & - \\ \text { Paindiscomfort } & 5 & & \end{array}$

tic effect, although the pelvic floor response remained.

One patient with ileocystoplasty, on self-catheterization for total retention suffered from chronic pelvie pain, which responded very well to neuromadulation. When the ileum patch was removed from the bladder, neuro-modulation was effective again, now against pain, urgency and frequency. Unfortunately the good result was lost soon after, due to a defect in the isolation of the electrode. Recently the defective system was totally replaced because a percutaneous test showed that neuromodulation was still successful. At a first follow-up visit the patient reported less frequency and pain. However, in figure 3 this patient is still in the 'bad' group.

For the incontinent patients the average number of pads used per day went down from 4.5 before implantation to 1.8 afterwards. The number of leakings per day was reduced from 7.4 to 1.5 , and the mean voided volume increased from 1 i 8 to $207 \mathrm{ml}$ (fig. 4). Urodynamic evaluation in the incontinent patients showed an increase in bladder volume at first contraction from 80 to $167 \mathrm{ml}$, an increase in bladder volume at the end of filling from 135 to $227 \mathrm{ml}$, and a decrease in bladder pressure at the end of filling from 51 to $23 \mathrm{ml}$ (fig. 5).

\section{Cimplications}

Complications are listed in table 2. Several re-operations were done. A stimulator had to be replaced because of a malfunctioning on-off switch (magnet-controlled). After several corrections a complete system was replaced because of an isolation defect. Repositioning of the electrode was done 3 times. because of migration $(\mathrm{n}=1)$ and faulty positioning at implant $(\mathrm{n}=2)$.

In the Itrel I group, the stimulated contact point on the electrode was changed 8 times, a minor reoperation under local anesthesia. For the Itrel II pulse generator this procedure can easily be done with an external programmer, without the need of re-operation. 


\section{Chapter 5}

Discussion Urine storage and voiding are regulated at several levels of the nervous system. The micturition reflex. descending from the ponfine micturition center to the sacral efferent centers for the pelvic nerve and the pudendal nerve, is thought to have a threshold (4). This threshold is set lower or higher by many afferent nerves, coming from the conscious and unconscious cortical levels, the limbic system, the peripheral organs in the pelvis like the bladder, sphincter and pelvic floor. Probably at the sacral level the same thresholds exist, again with many facilitating and inhibiting influences upon them. Several sacral reflexes are known, either stimulating or inhibiting sacral micturition center and Oluf's nucleus for the pudendal nerve, e.g. the pudendo-anal reflex and the pudendo-detrusor reflex $(5,6)$. The pelvic floor plays an important role in this system of sacral reflexes. At least the activity state of the pelvic floor influences the sacral level of the neural network controlling bladder functioning, but most probably afferents from the pelvic floor ascend to the pontine level too. An activated pelvic floor inhibits the detrusor, explaining the efficacy of pelvic floor excercises, biofeedback and external stimulation in treating urge incontinence. Also activated afferent fibers in the pudendal nerve inhibit the detrusor, again explaining the efficacy of external stimulation $(7,8)$. With neuromodulation efferent fibers to the pelvic floor as well as afferent fibers in the sacral nerve are stimulated. Myelinated somatic afferents will be stimulated more than the thinner parasympathic afferents (9). There is still debare on the question of whether it is the activation of the pelvic floor, with subsequent amplified and more physiologic afferent impulses, that is essential for neuromodulation to be effective, or the direct stimulation of the afferents.

Stimulation of S3 is optimal in most patients. S3 contains sensory fibers from the genitals and perineum, afferent and efferent fibers from the anterior part of the levator ani and the urethral sphincter, and autonomic fibers from the detrusor. Stimulation of S2 causes too much exorotation of the leg, with mainly a contraction of the superficialpelvic floor. S4 projects more on the posterior part of the levator ani with sensations around the anus.

With neuromodularion a weakened pelvic floor gets stronger. Patients become aware of their pelvic floor and learn how to use it. For example, by correcting a hypoactive pelvic floor, detrusor instability can be treated. On the other hand, by correcting a hyperactive, spastic pelvic floor, voiding problems, urinary retention and pelvic pain may be treated.

Neuromedulation developed out of the neurostimulation program for spinal cord injuries at the University of California. San Francisco (10). A multicenter phase-2 trial has been going on in the USA and Europe since 1990. 
The first clinical results of the largest European group of patients from one institution are presented here, 63 patients with urge incontinence $(n=39)$, urgency $(n=4)$, retention $(n=9)$ or pain $(n=11)$ had percutaneous test neuromodulation. In 28 patients, a more than $50 \%$ improvement in their main symptoms was seen. This is in accordance with earlier results by Schmidt and Tanagho (10). Depending on patient selection, in 20-50\% of the patients neuromodularion will be successful. Percutaneous testing is absolutely necessary before implanting a neuroprosthesis, as there is no other way of predicting success.

With an implanted neuromodulation system 19 of 23 patients, refractory to all other treatments, were improved by at least $50 \%$. One primary failure was seen and 2 recurrences. Of course the follow-up is relatively short so some more recurrences may be expected in this very difficult to treat patient group. The recurrences could not be explained, as the stimulation response at the pelvic floor was still present. Perhaps the pathologic impulses, at first overruled by the neuromodulating impulse, were becoming even stronger than before. One patienr suffered from technical problems, necessitating several re-operations, but neuromodulation still seems to be effective.

The materials used in this first group of patients were not especially designed for sacral neuromodulation. With the development of new equipment, even better results with less complications may be expected.

Conclusion Neuromodulation of the sacral nerves, by means of an implantable pulse generator and foramen electrode, is a promising new treatment for patients with otherwise untreatable voiding dysfunctions. A percutaneous test should be done on patients selected for implantation. Before turning to irreversible, organ-damaging surgery like ileocystoplasty or urinary diversion. neuromodulation should be considered. 


\section{REFERENCES}

1. Siegel SW Management of voiding dysfunc-tion with an implantable neuroprosthesis. U/wo/ C/in Nerth A Im 1992;19:163-170.

2. Thon WF, Schmidt RA, Jonas U, Tanagho EA Neurostimulation der sakralen Spinalnerven bei Blasenfunktionsstorungen. Akt $\operatorname{thol} 1991 ; 22: 41-44$.

3. Dijkema HE, Weil EHJ, Janknegt RA First experience with neuromodulation as a treatment of incontinence and disorders of micturition in the Netherlands. Ned Tijow be Gencolv 1992:136:88-90.

4. Vodusek DB Perineal neurostimulation: Neurophysiological basis. Urwdinamica 1992: 1:39-45.

5. Mahony DT, Laferte RO, Blaiș DJ Incontinence of urine due to isntability of micturition reflexes. 1. Detrusor reflex instability. Unvlogy 1980;15:229-239.

6. Mahony DT, Laferte RO, Blais DJ Incontinence of urine due to instability of micturition reflexes. II. Pudendal nucleus instability. Urology 1980; 15:379-388.

7. Fall M Does electrostimulation cure urinary incontinence? J U/ro/ 1984:131:664-667.

8. Vodusek DB, Light JK, Libby JM Detrusor inhibition induced by stimulation of pudendal nerve afferents. Neundarol Umolyn 1986:5:381-389.

9. Gleason CA: Electrophysiological fundamentals of neurostimulation. Whold J Und 1991; 9:110-113.

10. Schmidt RA, Tanagho EA Klinische Anwendung der Elektrostimulation. l'rologe A 1990; 29:191-195. 

CHAPTER 6 IMPROVING NEUROMODULATION TECHNIQUE FOR REFRACTORY VOIDING DYSFUNCTIONS: TWO-STAGE IMPLANT

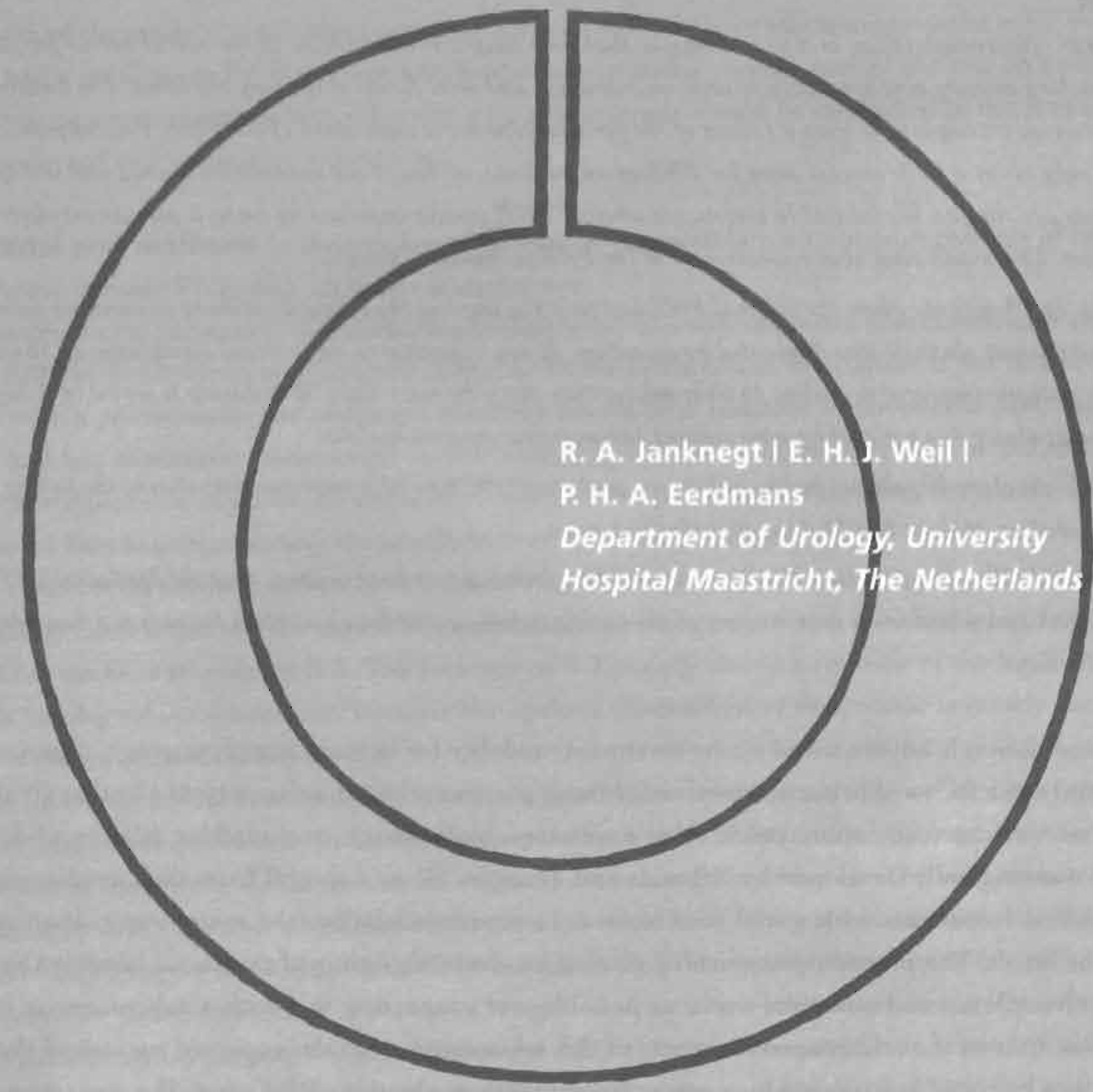

Urology 49:358-362, 1997 


\title{
IMPROVING NEUROMODULATION TECHNIQUE FOR REFRACTORY VOIDING DYSFUNC- TIONS: TWO-STAGE IMPLANT
}

\begin{abstract}

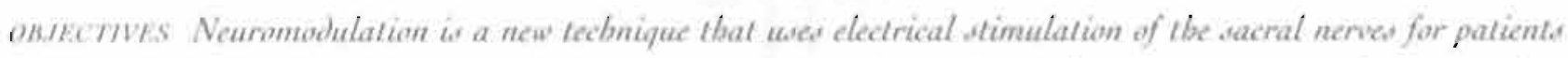
with refractory urinary urgelfrequency or urge-incontinence, and some forme of urinary retention. The limiting fac-

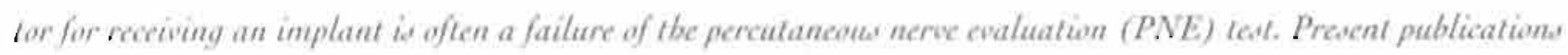

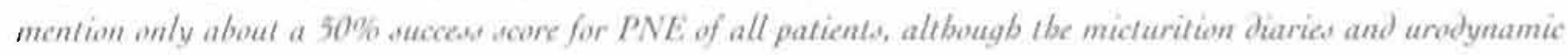
parametere are similar: We wanted bo invatigate wbetber PNE rewults improved by using a permanent electrode as a PNE ceat. Thie would abou tbat improvenent of tbe PNE tectonique is feasible.
\end{abstract}

Irsthons In 10 patientw wbers the ortiginal PNE bad failed to improve tbe micturition diary parametere more tban

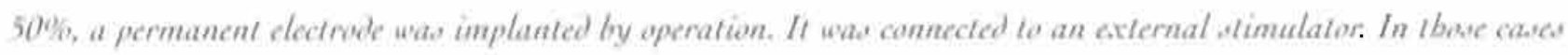
where the paliene improwed accorting to their micturition diary by more than 50 os during a period of 4 days, the external stimulator was replaced by a permanent subculaneats netrostimulator:

REsthezs Eigbt of ibe 10 patiente bad a good to wery good rault ( $60 \%$ to $90 \%$ improvement) during tbe teating period and received beir implant 5 to It day. after lbe first atage.

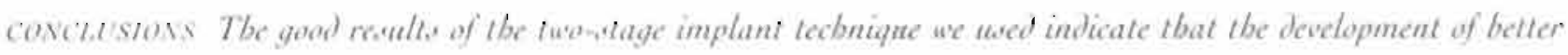

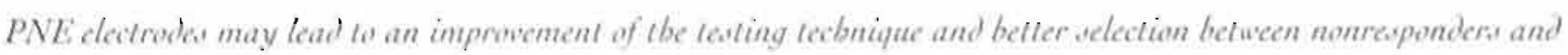
terbuical failures.

Neuromodulation is advocated as a new treatment modality for urinary urge/frequency, urge-incontinence, and some forms of urinary retention for those patients who are refractory to all other treatment modalities, such as medication. pelvic floor excercises, biofeedback, and bladder dilation (1-5). The method was originally developed by Schmidt and Tanagho (1) as a spinoff from their studies on neurostimulation in parients with spinal cord lesions. In neuromodulation, the entire innervation system should be intact. The procedure consists of placing an electrode in one of the sacral foramina as close to the pelvic plexus and pudendal nerve as possible and connecting this with a subcutaneous neurostimulator. One of the advantageous aspects of this treatment is that the expected success of the final implant can be tested beforehand by a percutaneous nerve evaluation (PNE) test. However, one of the disadvantages is that the reported success rates on the PNE testing average from $240 \%$ to $75 \%$. 
Although these patients are called nonresponders, the real reason for their nonresponse often might be a technical failure, meaning that there is dislodgment of the testing wire from the original position close to the sacral branches of the pelvic plexus or pudendal nerve. Quite often it is seen on an $x$-ray that the wire is lying our of the foramen after I or 2 days.

The aim of the study was to investigate whether we could improve our testing results in those patients who had a good acute PNE test but a technical failure in the chronic part of the test. We planned on performing a two-stage implant, whereby only the electrode would be implanted in the first stage and be connected to a temporary stimulator.

Material and methods In the present technique, neuromodulation treatment consists of two parts:

(I) Acute/chronic PNE with an external stimulator:

(2) Implant of a permanent electrode (lead) connected to a subcutaneous neurostimulator (6).

The PNE is divided into two separate episodes. In the acure phase, the parient is put in a prone position, with a pillow under the abdomen. A testing needle with isolation in the middle part-leaving the first and last centimeter nonisolated-is introduced in one of the sacral foramina of S-2, S-3, or S-4. The pelvic plexus and pudendal nerve run closely to the pelvic wall; therefore, the needle should iust enter the foramen. Stimulating the needle with an external stimulator will tell us if there is a good sensory reaction (in the perineal area) and motoric action consisting of levator contraction, as seen by an inpulling confraction of the anus. A concomitant confraction of the ipsilateral big toe indicates whether we have stimulated S-3. The foramen of S-2 usually shows a rotation of the leg. S-4 does not show any leg or toe movement. Because the optimal contraction of the levator is mostly seen in S-3. this is the foramen most often used.

If the response at this acute test is adequate, a stimulation wire that is also isolated over most of its length but leaves unisolated the last centimeter on both sides is introduced through the needle. If the response of the wire is similar to that of the needle, the needle is removed. The wire is then anchored to the skin with tape and connected to an external stimulator. The patient can now use the external stimulator, changing the voltage himself or herself so that the sensory sensation is felt without pain. The chronic phase consists of a period of 4 to 7 days in which the patient wears the wire and the external stimulator. keeping a micturition diary. After the wire is removed, the pretest. test, and posttest diaries are compared. To prevent psychogenic influences, a third diary is kept for another week after the test. in which a return to the baseline diary should be seen. 
Table 1. PNE testo done at tbe Chivervity Howpital

Maastrictur, 1990-1995

\begin{tabular}{|c|c|}
\hline & Total \\
\hline Patients & 99 \\
\hline Tests & 174 \\
\hline \multicolumn{2}{|l|}{ Patients } \\
\hline Implants: & 52 \\
\hline fiejected & 47 \\
\hline PNE score & $52 \%$ \\
\hline
\end{tabular}

Currently the criteria used for an implant of the permanent neurostimulator are as follows: A patient showing improvement of more than $50 \%$ overall of symptoms (either correcting the frequency, the number of pads, or the volume of urine voided) is called a responder, and he or she is a candidate for a permanent electrode implanted in the same foramen, now connected with a subcutaneous permanent neurostimulator:

In our clinic, we also had an average success of $52 \%$ on our PNE tests (Table I). We were convinced that for patients having an insufficient result of PNE, the positive success score would improve with a better testing method. The best electrode available is the permanent electrode used for the implant because this wire is fixed to the sacrum by fixation sutures: however: this would mean an operation to test the patient. Instead of waiting for improved hardware for the PNE, we decided to test our hypothesis that better selection is possible between nonresponders and technical failures by implanting a permanent electrode as a testing method. This was performed in those patients who failed on the present PNE test criteria, but whose success might be anticipated because of good objective parameters in the acute phase of the testing.

Of 47 patients who failed the chronic PNE test, 10 patients were carefully selected for the two-stage procedure. When we had a total of 25 failed PNE tests, we analyzed the data. When using the criterion of greater than $50 \%$ improvement over their pretest diaries during the chronic test. I5 had had an initial good response the first hours or days and then failed. Obviously, the electrode must have moved during that period. The other 10 had a good sensory feeling during the entire period, but did not show an improvement in their micturition behavior. These were the nonresponders. 
We then decided to do a prospective study of the two-stage implant; the theory was that the permanent electrode currently used is the only really stable electrode available. Patients who failed two chronic PNEs but who had a good initial response would be included. Of the next 22 patients who were not considered for permanent implant, 15 patients fulfilled this criterion. Some patients experienced immediate loss of sensation after moving from the table. All patients had a second PNE after the first failed. After the second PNE using the foramen that showed the best result, a two-stage implant was considered. Five patients lost their confidence and did not agree to the two-stage implant. Ten patients signed an informed consent.

In these 10 patients, the initial indications for neuromodulation were urge-incontinence ( 4 patients), retention ( 4 patients), and urgency/frequency (2 patients). The average age was 46 years (32 to 56 ). and there were eight women and two men. The average incontinence period was 3.6 years. All had undergone all possible treatments: for urgency/frequency and urge-incontinence, mostly anticholinergics; for mixed incontremce, suspension procedures in 3 patients; and for retention, prostate resection (2 patients), suprapubic catheter ( 1 patient), and intermittent catheterization ( 1 patient).

It is known that especially obese patients have a problem of movement of the electrode. In some centers, obesity is considered a contraindication. In our series, 5 patients were oyerweight and 5 were of normal weight.

A two-stage procedure consisted of the following procedures: the permanent PICE-QUAD electrode (Medtronic) was implanted in the best sacral foramen as was seen during the testing on the operating table, using a median incision over the sacrum. The lead was brought to the ipsilateral side, where a small additional incision was made. At rhat point, an extension wire was connected. This wire was brought subcutaneously to the contralateral side and left the skin through a second small incision. The extension wire was connected to an external stimulator (Fig. 1).

The transposition to the contralateral side was chosen to prevent infection. With a long subcutaneous tunnel, this danger was brought to a minimum.

In the next 5 to 7 days, patients filled in their diary as usual. Some went home and others stayed in the hospital as ambulant patients if they lived too far away. If the micturition diary showed more than a $50 \%$ improvement, the subcutaneous implant of the stimulator was performed in a second stage. The second stage followed 5 to 14 days after the first stage. During this procedure, the extension wire was removed and the permanent stimulator implanted subcutaneously (Fig. 2). 


\section{Chapter 6}

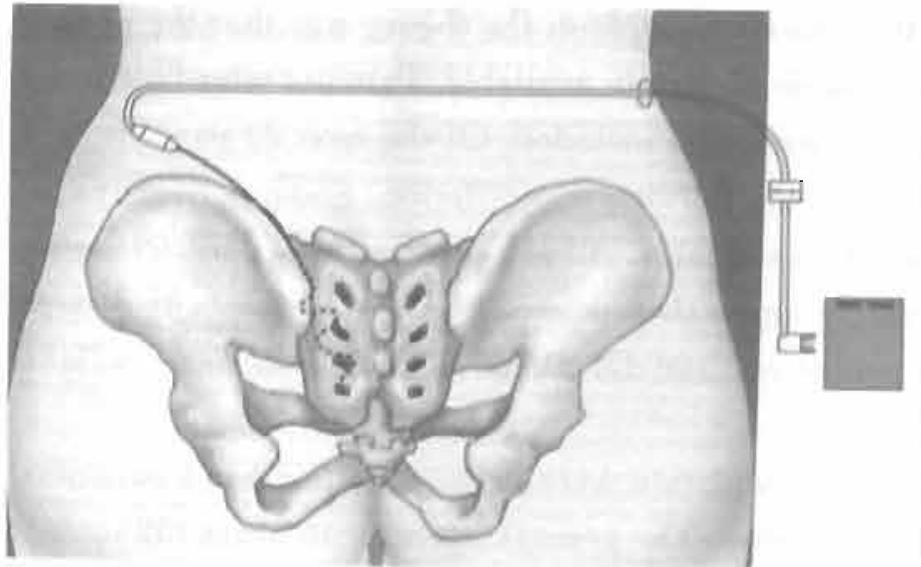

Fig. 1. Fint stage temperary externat win to fxternal simulatior.

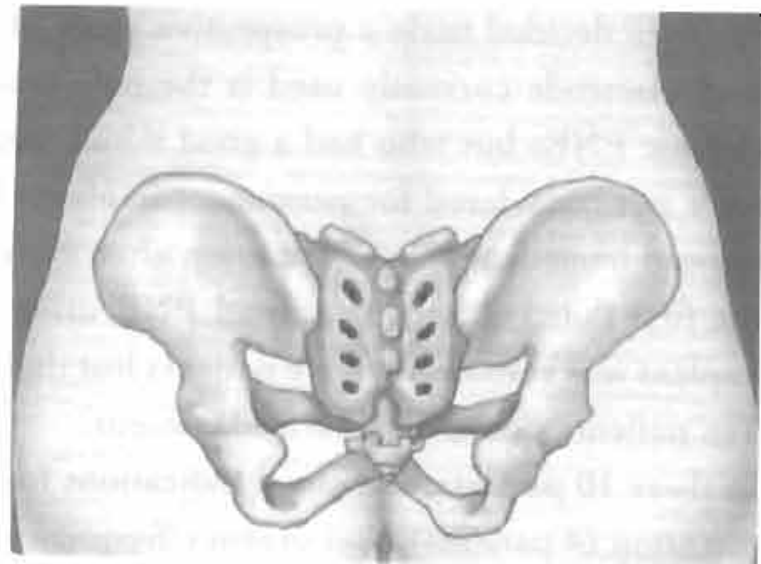

Fig. 2. Second stage: permanent implant.

Results During the chronic testing phase with the external stimulator, 8 of 10 patients had an improvement of more than $50 \%$ in their micturition diaries. Two of the 4 patients with retention had their micturition restored to normal. I patient had an average residue of $50 \mathrm{~mL}$, and I patient had no change in retention. In the patients with urge-incontinence, the incontinence disappeared from $60 \%$ to $90 \%$. One patient with urgency had a normal micturition frequency. Eight patients received the implantable stimulator (Itrel 11, Medtronic). After 6 months, pad use had diminished from 7.2 pads per day at baseline to 0.4 at month 6 in the urge-incontinence group (Fig. 3).

Tiwo patients failed to improve more than $50 \%$. Of these 2 patients, one woman had had the electrode implanted in S-4 but did not have a sensory response nor improvement in her micturition. Two months later, she was retested per PNE; we found a proper acute response in S-3. The electrode was changed from S-4 to S-3, and she had $90 \%$ improvement of her incontinence during a second first stage. She received the stimulator; this left only one failure (a patient with retention).

The follow-up is 4 to 36 months (average 16). No patients experienced infection because of the two stages.

Comment The hypothesis behind neuromodulation of the sacral roots (sensory and motor) is to correct, by the use of regulating electrical impulses, the dyssynergic activities of the cholinergic, adrenergic. and motor rellex pathways that initiate vesical storage and micturition (7). Although some 


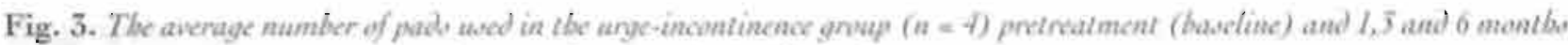
after permanent implant (steraing a lasting and significant dorewas).

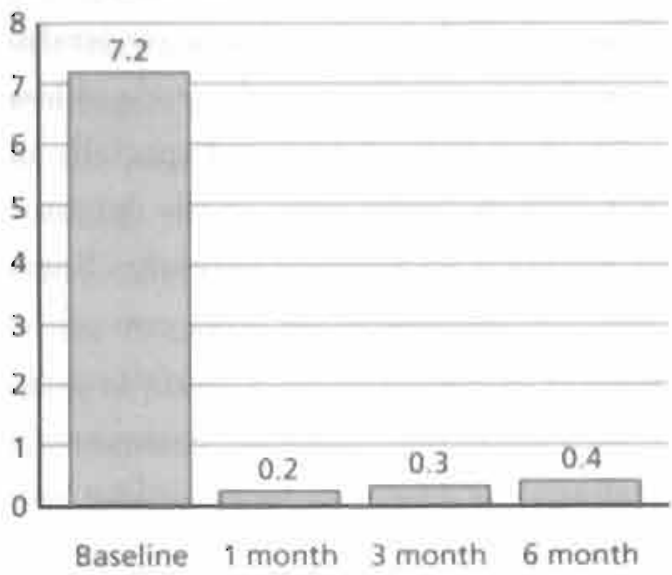

theories have been developed that explain the effects of neuromodulation, most of the results are based on empiric findings in human studies (3). Some animal experiments and electrophysiologic studies in humans show there is a spinal inhibitory action through the afferent branches of the pelvic and pudendal nerves (8). It is not clear whether neuromodulation primarily influences the micturition center located near the thalamus. Others maintain that there is a direct correction of the dyssynergia of the pelvic floor (pudendal nerve) by influencing the abnormal contractility of the pelvic floor. A. normal reflex pathway is induced, thereby decreasing bladder instability. Studies on the neurophysiologic aspects of this regulation by electrical interference must still be initiated.

In our first series, we performed 174 PNE tests on 99 patients. In those patients where we were not successful (less than $50 \%$ improvement), we repeated the procedure as often as four times. The average response is $52 \%$. We believed it troublesome that, with the same parameters, it could not be predicted who would be a responder. So far, no predictive parameters could be found when looking at urodynamics, age, history, and sex (9). Some patients do have a successful acute testing on the table and also sometimes during 1 or 2 days, but not enough for a permanent implant by our present standards. Especially obese patients have this problem, as do people who are very active. In some centers. therefore, obesity is regarded as a contraindication for testing. In our view, those patients were not nonresponders but technical failures. This is understandable when one realizes that there is a loose 


\section{Chapter 6}

wire in the foramen, passing a layer of subcutaneous fat that may move during walking, bending, or other activities, In addition, muscle contractions in active patients may dislodge the loose wire. It may also be postulated that a testing period of 4 days is arbitrary. If the patient has a successful acute testing, there is no reason why the patient should not respond to the permanent electrode unless there is an irreversible dyssynergic action between the pelvic floor and the detrusor. Especially in patients with retention, urodynamics cannot exactly tell whether enough contractility in the detrusor remains to restore normal micturition. In those patients, chronic testing is an absolute necessity. Some authors argue that only the acute needle testing is necessary. However, because of the large cost of the stimulator, most investigators want better proof of predicting success by including the chronic testing. It may be argued that this is also not an absolute proof, because the patient may influence (consciously or unconscious!y) the results by manipulating their micturition diary (for example, by recording longer intervals between micturitions or less loss of urine).

We wondered if the results of the present PNE method could be improved with a more permanent electrode in the loramen, thereby preventing dislodgment of the test wire. Of course, the disadvantage is that it involves an operative procedure as long as better testing wires are not available. Yet. we were convinced that patients with proper parameters should not be refused modulation just because of our present technical inabilities during the chronic testing phase.

In those patients who have successfully passed the PNE test and received a permanent implant of an internal pulse generator ( $1 \mathrm{PG}$ ), the success rate ranges from $83 \%$ to $90 \%(3-4)$. In the patients with urge-incontinence, we found a $50 \%$ to $90 \%$ decrease in pad use or in incontinence episodes. The patients with urgency/frequency also had a reduction of their frequency episodes by more than $50 \%$. In the retention group, there is an all-or-nothing effect, meaning that these patients achieve normal micturition without residue in $85 \%$ of cases. In $15 \%$, there was some residue, but an otherwise practically normal micturition. None of these patients had to rely on self-catheterization anymore. It, therefore, shows that the permanent electrode, in combination with the neurostimulator, is a reliable treatment form.

It should be assumed that the PNE test may include a larger percentage of success scores if more or less the same material was used as in the permanent implantation.

In our two-stage series, patients were all in the group of the so-called nonresponders to the PNE test, according to our present criteria, and were therefore excluded from permanent implant of an 1 PG. However, as they should be considered technical failures because the PNE technology at the present 
stage is not ideal, we therefore chose to perform the two-stage procedure to improve the overall success score for testing.

We have succeeded in eliminating the obvious technical failures in those patients who failed chronic PNE tests and have subsequently improved our overall testing results.

In the past 5 years, many technical details in the hardware or software were improved; the testing needles, the testing wire, the implanted electrode, and the stimulator have all been modified. Obviously, there is room for further improvement in the technology.

In the futures stiffer testing wires may reduce the amount of technical failures. Until then, the twostage implant is an alternative in those patients with a proper acute PNE test and an indication of proper response on the chronic test.

The selection of candidates for the two-stage implant should be made very carefully. First, repeated PNEs should be tried. It is easier to repeat a PNE than to perform a surgical procedure, especially when this procedure is meant as a test. There is no justification to go to a permanent implant as long as temporary testing has not separated the nonresponders from the technical failures. The indication for the two-stage implant is limited. The present study, however, shows that there is room for improvement of the PNE electrode and simultaneous improvement of the results of neuromodulation as at whole. 


\section{REFERENCES}

1. Schmidt RA, and Tanagho EA Feasability of controlled micturition through electrical stimulation. Urol Lut 34: $199-230,1979$.

2. Dijkema HE, Weil EH, Mijs PT, andlanknegt RA Neuromodulation of sacral nerves for incontinence and voiding dysfuncrions. Clinical results and complications. Eur U/rol 24:72-76, 1993.

3. Thon WF, Baskin LS, Jonas U. Tanagho EA, and Schmidt RA Neuromodulation of voiding dysfunction and pelvic pain. World / Crot 9:138-141, 1991.

4. Bosch J.HR, and Groen 1 Sacral (S3) segmental nerve stimulation as a treatment for urge incontinence in patient with detrunor instability: results of chronic electrical stimulation using an implantable neural pros dhesin. I/ / $\mathrm{rol}$ 154504-507, 1995.

5. Hassouna MM, and Elhilali MM Role of the sacral root stimulator in voiding dysfunction. Preliminary report. IItorld ./ I/mol 9:145-148, 1991.

6. Siegel SW Management of voiding dysfunction with an implantable neuroprosthesis. I Mol Clin Narth Am 19: 16.5-170, 1992.

7. Hohenfellner M. Thuroff JW, Schmidt PA, and ranagho EA Neurochirurgische Eingriffe zur Behandlung von Miktionsstorungen. Akt / / ral 23:47, 1992.

8. Lindstrom S, and Sudsuang R Functionally specific bladder reflexes from pelvic and pudendal nerve bran ches: an experimental study in the cat. Neurvard Unotynam 8:392, 1989.

9. Koldewijn EL, Rosier PF, Meuleman EJ, Koster AM, Debruyne FM, and van Kerrebroeck PE Predictors of success with neuromodulation in lower urinary dysfunction: results of trial stimulation in 100 patients. I/ / rv/ 152:20712075,1994 
CHAPTER 7 CLINICAL. RESULTS OF SACRAL NEUROMODULATION FOR CHRONIC VOIDING DYSFUNCTION USING UNILATERAL SACRAL FORAMEN ELECTRODES

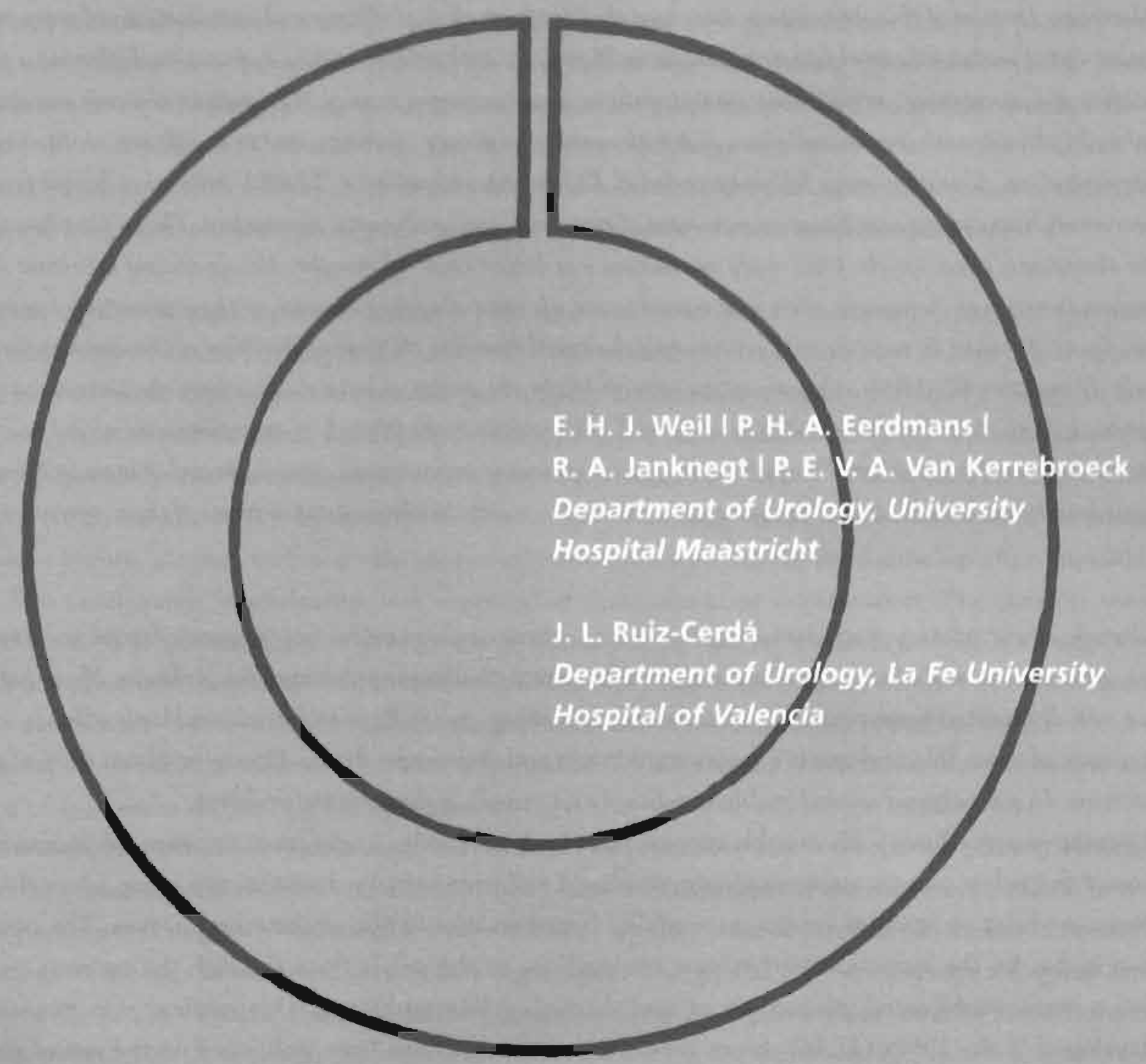

World J Urol 16:313-321, 1998 


\title{
Chapter 7
}

\section{CLINICAL RESULTS OF SACRAL NEUROMODULATION FOR CHRONIC VOIDING DYSFUNCTION USING UNILATERAL SACRAL FORAMEN ELECTRODES}

\begin{abstract}
The aim of ibus study was to determine tbe long-term elinical efficacy and complications of neuru-modulation wilb a unilateral saceal forwmen electrode in 36 patiente witb cbronie voiding dyefunction. Following a positive effat of a percutaneobe nerve cvaluation test, patients underwent open surgery. A permanent electrode was implanted in 24 patiente witb urge incontinence, in 6 witb uryency-frequency syndrome, and in 6 witb non-abstructive urinary recention. After an average follow-up period of 37.8 montbe, 19 patiente (52.8\%) continue to benefit from 1 be neturomodulatian witb a sigmificant improvement of symptome and urodynamic parameters. Tbe median duration of the Iberapeatie dfed for tbe lotal dudy population was longer than 60 montbs. No stgnificant defference in tbe median duration of tberapeutic effect with regand to sex, the type of volding disorder, or the implant pales generator

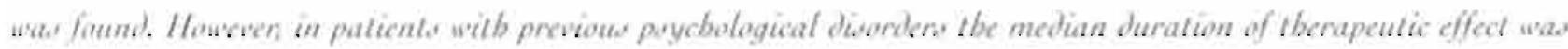
only 12 montbe (Peo.008). Complicatione ween mild. In the group of patiente in whom tbe therapeatic effect

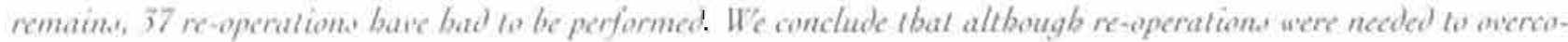

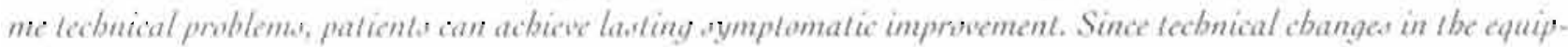
ment bave redued tbe number of complieations, cien better results can be cxpected in terma of tbe re-operation rate.
\end{abstract}

Chronic lower urinary tract dysfunction, such as motor urge incontinence, urgency-frequency syndrome, pelvic pain, and bladder evacuation problems are a challenging therapeutic problem. Most patients are initially treated conservatively with bladder retraining, pelvic floor exercises, and biofeedback. In the majority of cases this regimen is supplemented with anticholinergic drugs. However, about $40 \%$ of these patients do not achieve an acceptable condition and remain a therapeutic problem.

Alternative procedures with variable success rates such as bladder transection. transvesical phenol injection of the pelvic plexus, augmentation cystoplasty, and even urinary diversion are being advocated.

Neuromodulation is a new treatment modality based on stimulation of the sacral nerves. The postulation is that by the induction of rhythmic contractions of the pelvic floor through the nervous pudendus a more coordinated micturition occurs through reflex pathways. This method was empirically developed in the $1980 \mathrm{~s}(11,16)$. Since then, several reports have been published on the use of neuromodulation in the reatment of voiding dysfunction $(2,3,4,6,14,18-20)$. 
In 1991 the Department of Urology of the University Hospital Maastricht was the first in Europe to were carefully studied, a broad spectrum of difficulties arose as a result of the infrodmction into practice of this new treatment modality. The selection of patients and the means of dealing with complications and technical problems were the main challenges in the first period of our learning phase.

Some conclusions have been drawn from the experience obtained during these initial years, when neuromodulation was included as a therapeutic option for patients in whom no treatment other than urinary diversion could be considered. The aim of this study was to evaluate the resulis obtained in the first 36 patients with voiding dysfunction who had been treated by neuromodulation so as to investigate the long-term clinical eflicacy and to determine the rate of associated complicarions.

Patients and methods Between January 1991 and March 1993, 100 consecutive patients complaining of therapy-resistant voiding dysfunction were screened. Symptoms consisted of urgency. frequency, urine retention, urge incontinence, and pelvic pain. The inirial evaluation included a complete history and physical examination, urinalysis, urine cytology. a plain abdominal X-ray, ultrasound of the kidneys, cystoscopy, and a urodynamic investigation performed according to International Continence kidneys, cystoscopy, and a urodynamic investigation performed accorde
Society (ICS) standards (1). Symptoms were recorded in voiding/incontinence diaries for a minimum
of 4 days before, during, and after the neuromodulation test and during the follow-up after implantation. The urodynamic investigation was repeated at 6 months after implantation he pents were divided into three groups; those with urge incontinence due to bladder instability hose wissociated frequency syndrome, and those with nonobstructive urinary retention, with or without associated pain. The patients were first tested with the use of a percutaneous nerve evaluation (PNE) of the S2, S3, and S4 sacral roots. After a successful treatment period of $3-5$ days and a 2 -week interval to confirm the return of symptoms and to rule out spontaneous cure, they were scheduled for implantation. PNE was performed as previously reported $(3,13)$. The procedure has two separate phases, an acute phase for response confirmation and a subchronic phase for evaluation of the therapeutic effect. In the acute phase a test needle (Medtronic number 041828) was introduced into the S3 foramen. Sensory and motor responses to electrical stimulation were noted. The typical $\mathrm{S} 3$ responses are a tingling sensation in the genitals around the anus, with contraction of the deep pelvic floor muscles and flexion of the big toe $(11,14)$. If adequate responses are obtained during the acute testing, subchronic test stimulation is then conducted for a minimum of 3 days. The acure-stimulation needle is replaced by a 
Flexon 30 pacewire or temporary percutaneous lead (Medtronic, model 041830), which is connected to the external stimulator. After wound dressing and securing of the lead with tape the patients return to their homes. Stimulation parameters were as follows: unipolar monophasic, rectangular pulses, pulse width $210 \mathrm{~ms}$, pulse rate $15 \mathrm{pps}$, and amplitude $0.5-5 \mathrm{~V}$. If an improvement of more than $50 \%$ was seen in the main symptoms the test was called successful and the patient was selected as a candidate for implantation.

Implantarion was done as described elsewhere (14). The complete device consisted of a foramen electrode (PICE-QUAD, Medtronic, model 3886 or 3080 ) connected to a subcutaneously implantable pulse generator (IPG) via a lead extension (extension cable model 7495, Medtronic). In the first 15 patients an ltrel I IPG (Medtronic number 7421) was used, which enables telemetric resetting of the stimulation parameters only at the fixed contact point on the electrode (unipolar). In the rest of the patientu an Itrel II IPG (Medronic number 7424) was implanted. which enables telemetric switching between the four contact points (uni- and bipolar). Stimulation parameters were as follows: unipolar mono phasic, rectangular pulses, pulse width $210 \mathrm{~ms}$, pulse rate $15 \mathrm{pps}$, and amplitude $0.5-4 \mathrm{~V}$. Stimulation was either continuous or cyclic and daily use varied from a few hours to $24 \mathrm{~h}$. The criteria for success were as follows: good if the improvement in baseline symptoms was $>90 \%$, partial if it was $>50 \%$ and $<90 \%$, and poor if it was $<50 \%$.

The chi-square test was used to study the association between qualitative variables. Fisher's correction was used when needed. The mean values recorded for symproms and urodynamic parameters were compared using the Wilcoxon nonparametric test. The Kaplan-Meier product-limit estimate was used to calculate the median duration of the therapeutic effect of neuromodulation. The Breslow test was used for comparisons between groups. As a final event we considered the loss of therapeutic effect or the necessity for removal of the implant. A $5 \%$ level of statistical significance was used for all analyses.

Results After being screened with the PNE test, 36 patients were candidates for a permanent implant. All these patients were previously considered urological cripples, in whom no treatment other than urinary diversion could be considered. This series consisted of 27 women $(75 \%)$ and 9 men $(25 \%)$ of ages ranging from 23 to 67 (median 45 ) years. Overall, 24 patients $(66 \%)$ complained of urge incontinence: $6(17 \%)$, of urgency-frequency syndrome: and $6(17 \%)$. of nonobstructive urinary retention. In addition, 16 patients (44.4\%) felt perineal, hypogastric, or scrotal pain in association with their voiding complaints. 
The median duration of complaints of voiding dysfunction was 6 years. In all, $30(86 \%)$ of the patients had failed to respond to chronic oral medication. Anticholinergics were the drugs most frequently used $(80 \%)$, but alpha-adrenergic agonists and antagonists, analgesics, tricyclic antidepressants, musculotropic relaxants, desmopresin, and antibiotics were also used alone or in combination with anticholinergics. Of the total patient group, $16(44.4 \%)$ had a previous history of at least one operation on their lower urinary tract (Table 1). At the first visit, 8 patients used intermittent self-catheterization (median 4 times a day), 1 patient had a permanent urethral catheter, 2 had a permanent suprapubic

Table 1 Lit of previous turyery in patients considered wo be candidates for neuromedulation

\begin{tabular}{lc} 
Type of operation & Number (a) \\
Lower urinary tract surgery: & 12 \\
Urethrosuspension & 4 \\
Urethral dilatation & 7 \\
Bladder neck incision & 3 \\
Blind urethrotomy & 3 \\
Transurethral resection of the prostate & 1 \\
Teflon injection & 1 \\
Artificial sphincter & 4 \\
Clam ileocystoplasty & \\
Pelvic surgery: & 15 \\
Histerectomy & 4 \\
Herniorraphy & 1 \\
Ureter reimplantation & 1 \\
Epididymectomy & 3 \\
Oopherectomy & 3 \\
Uteropexy & 1 \\
Anus dilatation & 1 \\
Pelvic abscess secondary to Stamey procedure & 1 \\
Rectal amputation & 1 \\
Other: & 1 \\
Laminectomy L1-S4 & 1 \\
& 1 \\
\hline
\end{tabular}

Table 2. Final outcome of neurvmedulation Iratment after an average follow-up perial af 57.8 montbo

$\begin{array}{lr}\text { Outcome } & n(\%) \\ \text { Good } & 17(47.2) \\ \text { Partial(a) } & 3(8: 4) \\ \text { Failed: } & \\ \text { No effect } & 4(11.1) \\ \text { Explanted } & 12(33.3)\end{array}$




\section{Chapter 7}

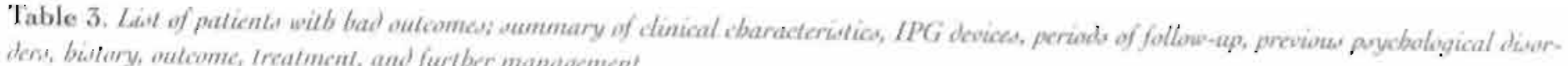
dens, butary, outeome, treatment, and further management

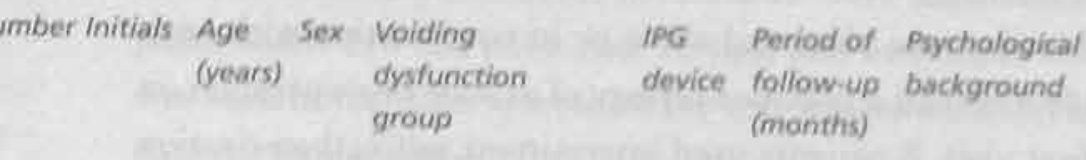

W $60 \quad$ M Urge incontinence $\quad$ I $\quad 36$

MS 25 f Urge incontinence I 24

CB 34 If Urge incortinence $\quad 36$

HP 39 F Urge incontinence I 10

KB 56 F Urinacy reterition । 6

$52 \quad 39$ F Urge incontinence $\quad$ । 3

5 $41 \quad \mathrm{M}$ Urge-frequency $\quad 1 \quad 24$

syndrome

$\begin{array}{llllll}R & 39 & \text { M } & \text { Urge incontinence } & \text { । } & 36 \\ \text { HS } & 66 & \text { F } & \text { Urge incontinence } & \text { II } & 12 \\ \text { R } & 34 & \text { M } & \begin{array}{l}\text { Urge-frequency } \\ \text { syndrome }\end{array} & \text { II } & 12 \\ & & & & \end{array}$

HS $42 \quad$ F Urge incontinence II 2

LR 41 F Urge incontinence II 2

SR

R M Urinairy retention II 12

$\begin{array}{lllllr}\text { BV } & 48 & \text { F } & \text { Urinary retention } & \text { II } & 36 \\ \text { P } & 58 & \text { F } & \text { Urge incontinence } & \text { II } & 6 \\ \text { N } & 44 & \text { M } & \begin{array}{l}\text { Urge-frequency } \\ \text { syndrome }\end{array} & \text { II } & 12\end{array}$

Hypermotilitysyndrome, stroke
Psychosocial problems, IPG
aversion

Persistent pain at implant site, Lost IPG aversion

Normal

Sexual trauma, incest, suicide attempts

\section{Lost:}

No

Outcome: Treatment

therapeutic

effect

Lost

Sexual abuse

No

Psychogenic erectile dysfunction, Lost

psychosomatic problems
Lost to follow-up
Incest
Lost
Lost
Anaphabet, several psychosomatic Lost diseases

No

Hypermotility syndrome.

primary enuresis

Normal

Lost:

Normal

Normal:

IPG aversion

Lost
No
Lost

Explanted

No

Explanted

No

Further

management

Explanted No
Explanted Heocystplasty
IPG still in place No

$\begin{array}{ll}\text { Explanted No } & \text { No } \\ \text { IPG stillin place } & \text { No }\end{array}$

IPG stillin place No

Explanted No

Explanted

Bladder

denervation

Explanted No

IPG stillin place No

Explanted

Cystectomy, Indiana pouch

Explanted

No

Explanted

Explanted

Indiana pouch

No 
catherer, 20 used diapers daily (median 6 pads a day), 2 were on biofeedback treatment, and 7 were undergoing physiotherapy of their pelvic floor muscles.

The final results, recorded after an average follow-up period of 37.8 months (range 12-60 months) according to the predefined criteria, are shown in Table 2. Altogether, 19 patients $(52.8 \%)$ remain in close follow-up at 5 years after the implantation. In two of them the result was considered partial. One patient (2.796) was known to have a partial improvement prior to being lost to follow-up because of death not related to neuromodulation treatment. In 16 patients $(44.4 \%)$ the result was insulficient because neuromodulation lost its effect or the implant had to be removed. Table 3 shows a summary of the evolution of this group of patients. In all, 12 of these patients (75\%) had some kind of previous psychological disorder. Five patients never showed a good response after the implantation. Although they had an excellent result when the PNE test was done, a stimulation response could not be reproduced and, after a short period, the result was considered poor.

Alogether, 11 patients had a secondary loss of therapeutic effect after a median period of $17 \mathrm{months}$ (range 4-36 months). Re-operations had to be done in 12 patients to remove the IPG due to a secondary loss of therapeutic effect and/or to a lack of satisfaction regarding the implant; afterward, major surgery was performed in 3 of them as treatment for the primary voiding dysfunction. In the rest of the patients, no further treatment was considered. Indeed, four patients currently have the stimulator in place without any therapeutic effect.

The influence of neuromodulation on symptomatology and urodynamic parameters is presented in Tables 4-6. Statistical analysis for the comparison of values obtained at baseline and at 6 months after implantation was done only in the group of patients complaining of urge incontinence. The sample size of the other two groups, urge frequency (six patients) and nonobstructive urinary retention (six patients), was too small to enable inferential testing.

In the group with urge incontinence, at 6 months after implantation a statistically significant improvement in all symptoms except urgency was observed. The total volume voided increased significant1y. Other positive side effects were found in 13 of the 16 patients with pain in combination with incon. tinence. The pain was reducedor no longer present. Furthermore, among five patiencs with defecation problems a normal defecation thythm was achieved in three cases, with regard to urodynamic parameters, statistically significant increases in total bladder capacity and in volume at first sensation were seen. The volume at the first unstable bladder contraction increased as well, but not enough to reach statistical significance $(P=0.0581)$. The maximal detrusor pressure at unstable contraction and post- 
Table 4. Distribution of patients by iex, woiding dysfunction group, IPG type, and previous birtory of porycbological disorders:

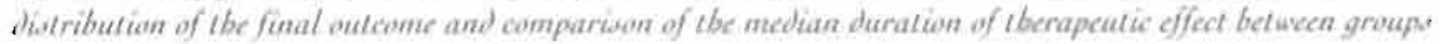

\begin{tabular}{|c|c|c|c|c|c|c|}
\hline \multirow[t]{2}{*}{ Variable } & \multirow[t]{2}{*}{$n(\$ 6)$} & \multicolumn{3}{|l|}{ Outcome } & \multirow{2}{*}{$\begin{array}{l}\text { Median period } \\
\text { of therapeutic } \\
\text { effect (b) }\end{array}$} & \multirow[t]{2}{*}{ P value (c) } \\
\hline & & $\begin{array}{l}\text { Good } \\
n(\%)\end{array}$ & $\begin{array}{l}\text { Partial } \\
n(\%)\end{array}$ & $\begin{array}{l}\text { Failed }(a) \\
n\left(x_{0}\right)\end{array}$ & & \\
\hline Sex: & & & & & & 0.2747 \\
\hline f & $27(75)$ & $17(82)$ & $3(100)$ & $10(42)$ & Not reached (d) & \\
\hline M & $9(25)$ & $3(18)$ & $0(0)$ & $6(38)$ & 24 & \\
\hline Group: & & & & & & 0.9793 \\
\hline Nonobstructive retention & $6(17)$ & $3(18)$ & $0(0)$ & $3(19)$ & 24 & \\
\hline Urge incontinence & $24(66)$ & $14(64)$ & $3(100)$ & $10(42)$ & Not reached (d) & \\
\hline Urgency-frequency syndrome & $6(17)$ & $3(18)$ & $0(0)$ & $3(19)$ & 36 & \\
\hline IPG device: & & & & & & 0.5359 \\
\hline 1 & $15(42)$ & $7(35)$ & i (33) & $8(50)$ & 36 & \\
\hline II & $21(58)$ & $13(65)$ & $2(67)$ & $8(50)$ & Not reached (d) & \\
\hline \multicolumn{7}{|l|}{$\begin{array}{l}\text { Previous psychological } \\
\text { disorders: }\end{array}$} \\
\hline No & $25(69)$ & $18(94)$ & $2(67)$ & $7(44)$ & Not reached $(d)$ & 0.008 \\
\hline Yes & 11 (31) & $1(6)$ & $1(33)$ & $9(56)$ & & \\
\hline \multicolumn{7}{|c|}{ (a) Patients in whom neutomodulation lost is therapestic effect or the ips had to be removed } \\
\hline \multicolumn{7}{|c|}{ (b) Patients with partiat improvement were induded in the group with good results. } \\
\hline \multicolumn{7}{|l|}{ (c) litesiow test } \\
\hline (1) At the end of the follow-up period. & more than 5 & Ss of the pati & Is the therat & tic effect of ne & edulation remains & \\
\hline
\end{tabular}

void residual volume showed a slighı decrease (Table 6). Nevertheless, in patients with urinary retention the average postvoid residual volume decreased from 217.7 to $57 \mathrm{ml}$, and in patients complaining of urge and frequency syndrome the average volume at lirst sensation increased from 102 to $221.7 \mathrm{ml}$. The median duration of the therapeutic effect for the entire group was longer than 60 months (Fig. 1). We could not demonstrate significant differences in the median duration of therapeutic effect with 
Table 5. Effect of ncuromodulation on symptoms and soiling wolume in ibe group of paliente witb urys involinence after 6 monibs of followisup

\begin{tabular}{|c|c|c|c|c|}
\hline Parameter & $\begin{array}{l}\text { Baseline } \\
\text { mean = SEM }\end{array}$ & $\begin{array}{l}\text { After ( } 6 \text { months) } \\
\text { mean = SEM }\end{array}$ & $\begin{array}{l}\text { Mean } \\
\text { change }\end{array}$ & $P$ value (a) \\
\hline Frequency & $13.7=1.37$ & $8.7 \pm 2.6$ & -5 & 0.0063 \\
\hline Major leakage episodes & $4.9 \pm 1.44$ & $1.1 \pm 0.7$ & -3.8 & 0.0039 \\
\hline Minor leakage episodes & $5.1=1.2$ & $1.3 \neq 1.5$ & -3.8 & 0.0111 \\
\hline Pads used per day & $6.6 \pm 1.1$ & $2.3 \pm 0.9$ & -4.4 & 0.0011 \\
\hline Utgency & $3.1=0.3$ & $3.1=0.2$ & $-0,83$ & 0.3911 \\
\hline Volume voided & $158.0 \neq 18.5$ & $228.0 \neq 26.2$ & 70.5 & 0.0117 \\
\hline
\end{tabular}

Table 6. Effect of neuronodulation on urodynamic paranctess in the group of patients witb urge incontinence afler 6 montbe of lollow-up

\begin{tabular}{|c|c|c|c|c|}
\hline Urodynamic parameter & $\begin{array}{l}\text { Baseline } \\
\text { mean } \pm \text { SEM }\end{array}$ & $\begin{array}{l}\text { After ( } 6 \text { months) } \\
\text { mean } \pm \text { SEM }\end{array}$ & $\begin{array}{l}\text { Mean } \\
\text { change }\end{array}$ & P value 9 (a) \\
\hline Bladder capacity (ml) & $187 \pm 29.3$ & $273 \pm 31.3$ & +85 & 0.0108 \\
\hline Volume at first sensation (ml) & $101=24.3$ & $194 \pm 28.2$ & +92 & 0.0025 \\
\hline $\begin{array}{l}\text { Volume at first unstable } \\
\text { contraction ( } \mathrm{ml})\end{array}$ & $114 \pm 78.7$ & $179 \pm 91$ & +178 & 0.0581 \\
\hline $\begin{array}{l}\text { Maximal detrusor pressure at } \\
\text { unstable contraction }(\mathrm{cm} \text { H20) }\end{array}$ & $56 \pm 10.5$ & $42 \pm 12$ & -15 & 0.3488 \\
\hline Postvoid residual & $110=57$ & $66 \pm 41.5$ & 44 & 0.9164 \\
\hline
\end{tabular}

regard to sex, the type of voiding dysfunction, or the IPG type (Table 4). However, the median duration of the rherapeutic effect in patients with a previous history of psychological disorder was 12 months, whereas in 18 of 25 patients $(72 \%)$ without these antecedents the effect lasted for more than 36 months ( $P=0.008$ : Fig. 2).

Complications were mild, but 56 operations were needed. In all, 37 reoperations (66\%) were perfor- 
med on the group of patients in whom the therapeutic effect remains. The rest were performed in attempts to improve the success rate for the group of parients in whom permanent neuromodulation had initially failed. The most frequent complication was lead problems (38\%); the lead had to be repositioned 19 times because of loss of therapeutic effect, pain at the site of the lead, isolation damage, and slippage. Complete replacement of the leadwas done three times, once because of a lead fracture and twice because of a technical problem. The Itrel I IPG was replaced by either the Itrel II or the Interstim IPG (Medtronic number 3023) to make the stimulation program easier.

Four patients (12\%) complained of pain at the site of the stimulator, which resolved after repositioning of the stimulator away from the scar of the previous incision. The stimulator was definitely removed when the patient required it, in cases of aversion, or when it was considered that the treatment had completely failed (Table 7).

Although the sample size is small, the trend of the number of reoperations is interesting. In patients

Table 7. Rechons for monervition

\begin{tabular}{|c|c|}
\hline Operation upon & $n(\%)(a)$ \\
\hline \multicolumn{2}{|l|}{ Lead: } \\
\hline Repositianed & $19(40)$ \\
\hline Replaced & $3(5)$ \\
\hline & $22(38)$ \\
\hline \multicolumn{2}{|l|}{ Stimulator: } \\
\hline Change Itrel $1 \rightarrow 11$ & 4 (9) \\
\hline Change Itrel I $\rightarrow$ III & $1(2)$ \\
\hline Change program stimulation (Itrel I) & $8(14)$ \\
\hline Repositioned & $7(12)$ \\
\hline Explanted & $12(21)$ \\
\hline & $33(58)$ \\
\hline \multicolumn{2}{|l|}{ Extension cable: } \\
\hline Replaced & 2 (2) \\
\hline & 2 (2) \\
\hline
\end{tabular}


without a previous history of psychological disorder the number of reoperations remained stable. However, in patients with a previous history of psychological disor der the number of reoperations gradually decreased. This observation reflects our reluctance to reoperate on this group of patients once the therapeutic effect of neuromodularion has been lost (Fig. 3).

Discussion The interaction between the autonomic and the somatic nervous system is an integral part of the neural control ofthe voiding mechanism as well as the stability of the bladder. Some of these interacting reflexes are inhibitory, whereas others are facilitative. A perfect balance between them is required for the accomplishment of normal voiding and the maintenance of bladder stability.

Dysfunctional voiding syndromes are associated with a degree of labile sacral reflex belavior. Therefore, by making use of the interacting reflexes we can modulate pelvic floor and detrusor instability. The main principles behind neuromodulation of voiding dysfunction and bladder instability are based on two factors: detrusor instability can be inhibited and pelvic floor and external sphincter instability can be controlled through neural stimulation of the somatic fibers of the sacral roots (15).

Unilateral sacral segmental stimulation with a permanent electrode at the level the sacral foramen $\mathrm{S} 3$ or S4 can offer an alternative non-destructive treatment for patients with dysfunctional voiding syndromes and chronic pelvic pain refractory to conservative measures.

Since 1989, when a clinical trial was started to evaluate the eflectiveness of this new treatment modality, experience has been gathered with regard to evaluation, surgery, and follow-up (11). !ndeed, although there is no longer any doubt about the possible effectiveness of neuromodulation in the relief of voiding symptoms, several points need further clariflcation before it can achieve the status of an established treatment modality. We lack a complete explanation of its mode of action. Long-term follow-up data and results from randomised studies to assess its efficacy properly are not available. The reason for the discrepancy between symptomatic improvement and urodynamic findings remains unknown. The mode of action of sacral neuromodulation remains unclear, but it has been hypothesised that the electrical current modulates reflex pathways involved in the filling and evacuation phases of the micturition cycle (17).

Stimulation of A- $\delta$ myelinated fibers of sacral roots S3 and S4 decreases the spastic behavior of the pelvic Hoor and enhances the tone of the urethral sphincter. The threshold of the somatic component of the spinal nerve that innervates the pelvic floor is lower than that of the autonomic component of the bladder. Thus, simultaneous bladder contraction is avoided during stimulation. In many subjects 


\section{Chapter 7}

Fig. 1. Duration of the therapeutic effect for tbe entire population of patients. One patient died during tbe follow-up period of a disease witbout any relation to the ireatmenc (+ Censored patients)

Probability (\%)

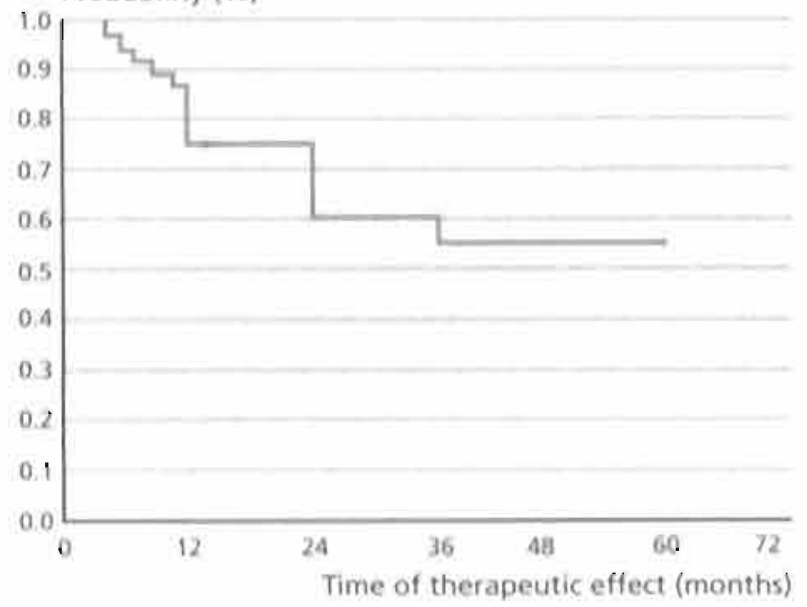

\begin{tabular}{|c|c|c|c|c|}
\hline 3 & 31 & 26 & 23 & 19 \\
\hline he 36 & 36 & 31 & 26 & 23 \\
\hline
\end{tabular}

Probability (\%)

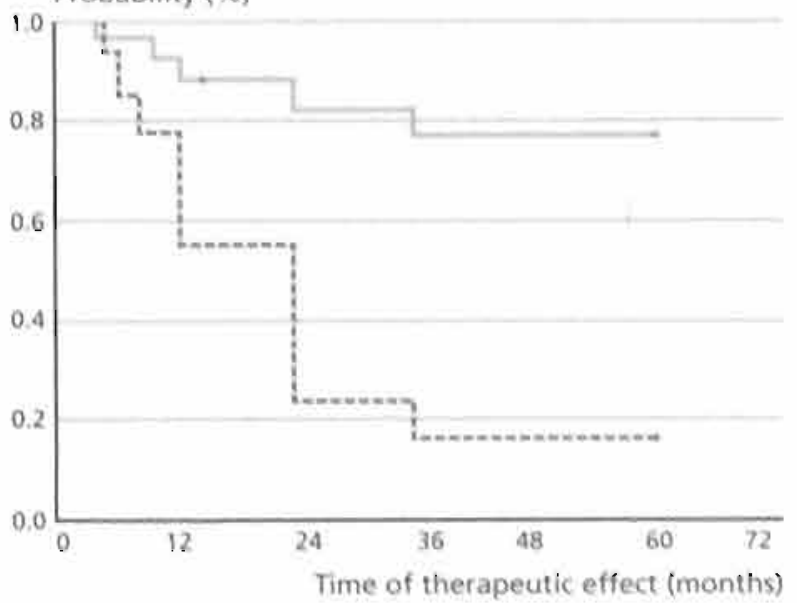

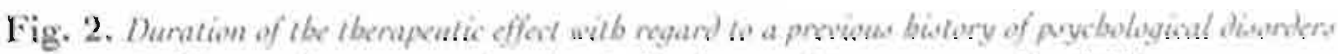

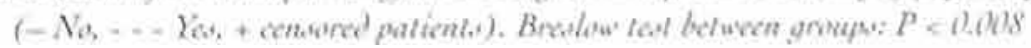


primary voiding dysfunction appears to begin with unstable urethral activity, which activates the voiding reflexes, leading to detrusor instability and associated urgency, frequency, and incontinence. The inhibitory effect of the enhanced urethral sphineter tone suppresses detrusor instability and sta bilises detrusor activity.

Bladder underactivity may be the result of an imbalance between excitatory and inhibitory reflex mechanisms. In patients with chronic urinary retention the aim of stimulating S3 is to recover voluntary control of the pelvic floor musculature to initiate voiding $(6,9)$. In the case of chronic pelvic pain. neuromodulation lessens the perceived intensity of the pain by exciting antinociceptive neuronal systems and masking or changing the nature of the pain through the sensation of the electrical stimulation (10),

It must be kept in mind that the therapeutic effectiveness of the stimulation is that of a modulatory influence on the reflexes controlling micturition and its related dysfunction. Similar parameters of stimulation can be applied to seemingly paradoxical clinical problems, a urinary retention disorder as well as one of urinary incontinence; both can be secondary to a dysfunction of the neural reflexes and, as such, respond to the same modulation input to the CNS obtained from neurostimulation (12).

After subchronic stimulation about 13-62\% of patients are possible candidates for definitive implantation $(5,7,8,11)$. We believe that this figure could be increased if we could overcome some technical problems. We observed an early lead displacement in almost $20 \%$ of parients showing normal S3 responses when screened by PNE. This is an outpatient test. In some patients the resistance of the lead against displacement is insufficient. For this reason we have started to test a new lead designed to increase resistance against displacement. According to previous reports, about $25 \%$ of the patients. who respond well to a percutaneous trial fail to respond to a permanent implant $(8,11,13,18,19)$, In our study, $7 \%$ of the patients never had a good response after the implantation.

The data suggest that one could improve the results if more stringent screening were undertaken. A patient should not be offered permanent implantation unless there has been a significant improvement of symptoms during the subchronic test. In an attempt to decrease this high number of failures a logistic regression analysis has been carried out to determine predictive factors of success in neuromodulation (9). As explanatory variables the investigators used clinical and urodynamic parameters, but, unfortunately, none of these provided enough significant independent information to predict success. Different approaches have been used to make implant decisions more reliable. 


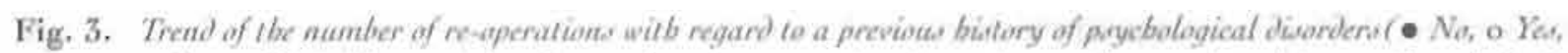
- No, +... Xes). Tbe trend for the number of ne-operatione in patiente witb a previow bitory af puycbological

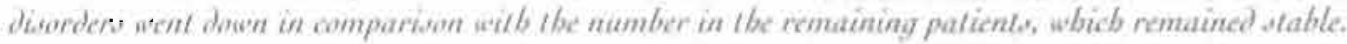

Patient I wat convidered an outlier and was cotchod

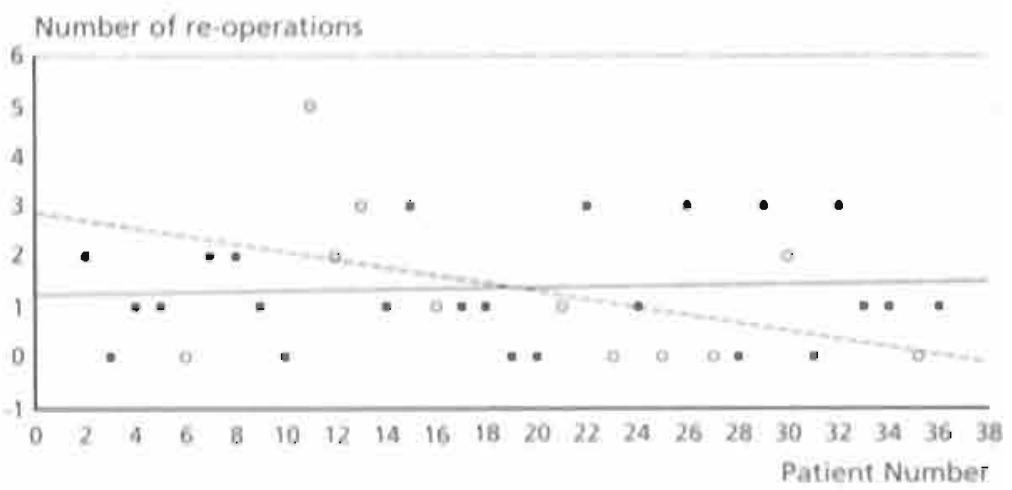

More than one subchronic test can be undertaken if there is any doubt or reluctance on the part of the parient or if there is any doubt as to the technical success achieved in the initial outpatient trial. A twostage procedure has been proposed as well as a longer test stimulation using urodynamics as an objective measure of improvement $(5,7)$. In those patients who fail to achieve relief with a permanent implant, the lack of maintaining an efficient contact with the nerve could be the explanation.

The high numbers of operations undertaken to reposition the lead in patients in whom the therapeutic effect persists reaffirm this assumption (up to five repositions of the lead being done in a single patient). Special attention is needed with regard to patients with a previous history of psychological dysfunction and/or sexual abuse. Furthermore, it is noteworthy that all these patients had a good response to temporary stimulation and their symptoms returned to baseline thereafter. Our data indicate that $82 \%$ of these patients showed poor results as compared with $28 \%$ of the patients withour at history of psychological disorders $(\mathrm{P}=0.002)$.

Moreover, $25 \%$ of all reoperations were done in patients with psychological disorders. In most of these patients the reoperations had no effect. Since we had our doubts about the effectiveness of reoperations in this group, the number decreased slightly during this sfudy (Fig. 3). In our experience this group of patients is hard to deal with, and it is extremely important that one be alert so as to identify them.

Data about the psychological backiground of the patients were obtained after a thorough and careful inves. tigation (Table 6). At the time of the initial contact, most of the patients were reluctant or refused to talk: 
about former traumatic events that could explain or influence their present behavion. Some of these data were obtained from their general practitioners since is was impossible to get them directly from the patients. In the future a more restricted indication for a permanent implant must be adopted. Psychological tests or psychiatric evaluation at the beginning of the study may help to identify these patients.

Permanent electrode stimulation obtained a $52.8 \%$ efficacy rate among a group of patients who, by definition, were refractory to all presently available conservative forms of treatment. This percentage is in the same range as that reported previously $(14,17)$, although success rates of up to $83 \%$ have been published $(2,3,11)$. When the voiding groups are taken into consideration separately, our success rate is slightly lower than those reported before. Elabbady and colleagues (4) obtained practically a $100 \%$ success rate in both patients with urinary retention and patients complaining of pain, frequency. and/or urge incontinence.

In a homogeneous group of patients with urge incontinence due to bladder instability. Bosch and Groen (2) obtained an 83\% success rate, and Vapnek and Schmidt (19) achieved an $85 \%$ rate in patients with urinary retention. However, our results were influenced by several decisive factors. First, the patients belonged to an indication linding study done during the first period of our learning phase (1991-1993). Second, psychological disorders were found a posteriori in $30 \%$ of the patients. which clearly influenced our final results. Finally. the patients selected for permanent implantation had undergone 64 different kinds of operations in the pelvic region. which caused concomitant disorders of the lower urinary tract that were not cured by neuro-modulation. Nevertheless, the therapeutic effect of neuromodulation remains present in the majority of patients as evidenced by the long-term follow-up. Although the average period of follow-up was $37.8 \mathrm{months}, 52.8 \%$ of the patients continue to benefit from the neuromodulation effect after 5 years of follow-up.

Furthermore, the median duration of the neuromodulation treatment effect for the entire population was longer than 60 months, indicating that lasting symptomatic improvement is possible. On the other. hand. we realise that our study lacks a control arm. However, we noticed that when the stimulation was decreased below a certain level or became too slight to be felt, the symptoms recurred. In 1993 a new randomised multicenter study was initiated to compare neuromodulation with existing conservative treatment using a 6-month-delay arm (8).

The discrepancy between the symptomatic improvement and the urodynamic findings continues to need an answer.

Some studies have been capable of measuring the neuromodulation effect objectively by the perfor- 


\section{Chapter 7}

mance of urodynamics studies during temporary stimulation (5.18), whereas others have not found a complete correlation $(2,6)$. Ambulatory urodynamic investigation can help us to understand better the neuromodulation effect on lower urinary tract function. However, variability is inherent in all urodynamics studies and renders the reproducibility difficult (2).

The number of re-operations was higher than those reported previously. However, this figure was influenced by two factors. In the ltrel I group, each change to another stimulating point required a reoperation using local anaesthesia ( 8 times, 14\%), and our first implanted patient needed 12 re-operations to overcome various kinds of technical problems. Indeed, most re-operations were performed because of technical failures (Table 7). Revisions performed because of loss of stimulation or deterioration of response were also common, but the majority of these occurred because of poor selection criteria. In conclusion. on the basis of the results we obtained using neuromodulation and a long period of follow-up, it is evident that the therapeutic benefit is a result of the modulation of neural reflex excitability rather than of a direct change in muscle behavior or in the integrity of neural conduction. The eflect is immediate and voluntary muscle contraction is not inhibited by the stimulation. Although results from randomised studies are not available, enough information has been gathered for neuromodulation to be considered an effective treatment modality in patients with severe voiding dysfunction. Since historic studies were done in not-well-defined groups of patients and since there have been considerable advances in the development of neuromodulation devices, a higher success rate may be achieved in the future. 


\section{REFERENCES}

1. Abrahms P, Blaivas JG, Stanton SL, Anderson JT (1988) The standardisation of terminology of lower urinary tract function. Scand J Und Nepbod 1 14:5-19

2. Bosch JLHR, Groen 1 (1995) Sacral (S3) segmental nerve stimulation as a treatment for urge incontinence in patients with detrusor instability: results of chronic electrical stimulation using an implantable neural pron. thesis. JUmo/ 154:504-507

3. Dijkema HE, Weil EHJ, Mį̣s PT, Janknegt RA (1993) Neuromodulation of sacral nerves for incontinence and voiding dysfunctions. Eur Urol 24:72-76

4. Elabbady AA, Hassouna MM, Elhilali MM (1994) Neural stimulation for chronic voiding dysfunctions, J Chol' $152: 2076-2080$

5. Everaert K, Plancke H, Levere F, Oosterlinck W (1997) The urodynamic evaluation of neuromodulation in patients with yoiding disorders. Br J C rol 79:702-707

6. Hassouna MM, Elhilali MM (199I) Role of the sacral root stimulator in voiding dysfunction. Wortd J U ho/ 9 : $145-148$

7. Janknegt RA, Weil EHJ, Eerdmans P (1997) Improving neuromodulation technique for relractory voiding dys functions: two stage implant. Cralegy 49:358-362

8. Janknegt RA, Van Kerrebroeck PhEV, Lycklama a Nijeholt A, Schmidt RA. Hassouna MM, Siegel SW, Gajewski JB, Weil $\mathrm{EHJ}$, Oleson KA (1997) Sacral nerve modulation for urge incontinence: a multinational, multicenter randomised study. J Urol 157:317

9. Koldewijn EL, Rosier PFWM, Meuleman EJH, Koster AM, Debruyne FMJ, Van Kerrebroeck PEV (1994) Predictors of' success with neuromodulation in lower urinary tract dysfunction: results of trial stimulation in 100 patients. J Lrol 152:207]-2075

10. Meizack R, Wall P (1965) Pain mechanisms: a new theory. Sicience 150;971-979

11. Schmidt RA (1988) Applications of neurostimulation in urology. Neuroural Crondyn 7:585-592

12. Schmidt RA (1992) Implantable neuroprosthesis in urology. Tradynamica 1: 29-38 13. Schmidt RA, Senn E: Tanagho EA (1990) Funcrional evaluation of sacral nerve root integrity. Urolugy 35:388-392

14. Siegel SW (1992) Management of voiding dysfunction with an implantable neuroprosthesis. Uiol Clin Norlb Am 19:163-170

15. Tanagho EA (1992) Neuromodulation in the management of voiding disorders in children. / Uto/ 148:65565.7

16. Tanagho EA, Schmidt RA (1988) Electrical stimulation in the clinical management of the neurogenic bladder: J Lirol 144:1331-1339 


\section{Chapter 7}

17. Thon WF, Baskin LS, Jonas U, Tanagho EA, Schmidt RA (1991) Neuromodulation of voiding dysfunction and petvic pain, Wirld d Clool 9:138-141

18. Van Kerrebroeck PEV, Noland W, Rosier P, Wijkstra H, Debruyne f (1996) Is percutaneous sacral nerve stimulation a screening tool in lower urinary tract dysfunction? Eur Und 30:236

19. Vapnek JM, Schmidt RA (1991) Restoration of voiding in chronic urinary retention using a ocuroprosthesis. Ifirld I Utol 9:142-144

20. Weil EHJ, Eerdmans PHA, Janknegt RA (1996) 5 Year treatment of patients with severe voiding disorders; so called urological cripples, by neuromodulation: the facts. Fur Unol 30:236 
CHAPTER 8 SACRAL ROOT NEUROMODULATION IN THE TREATMENT OF REFRACTORY URINARY URGE INCONTINENCE:

A PROSPECTIVE RANDOMIZED CLINICAL TRIAL

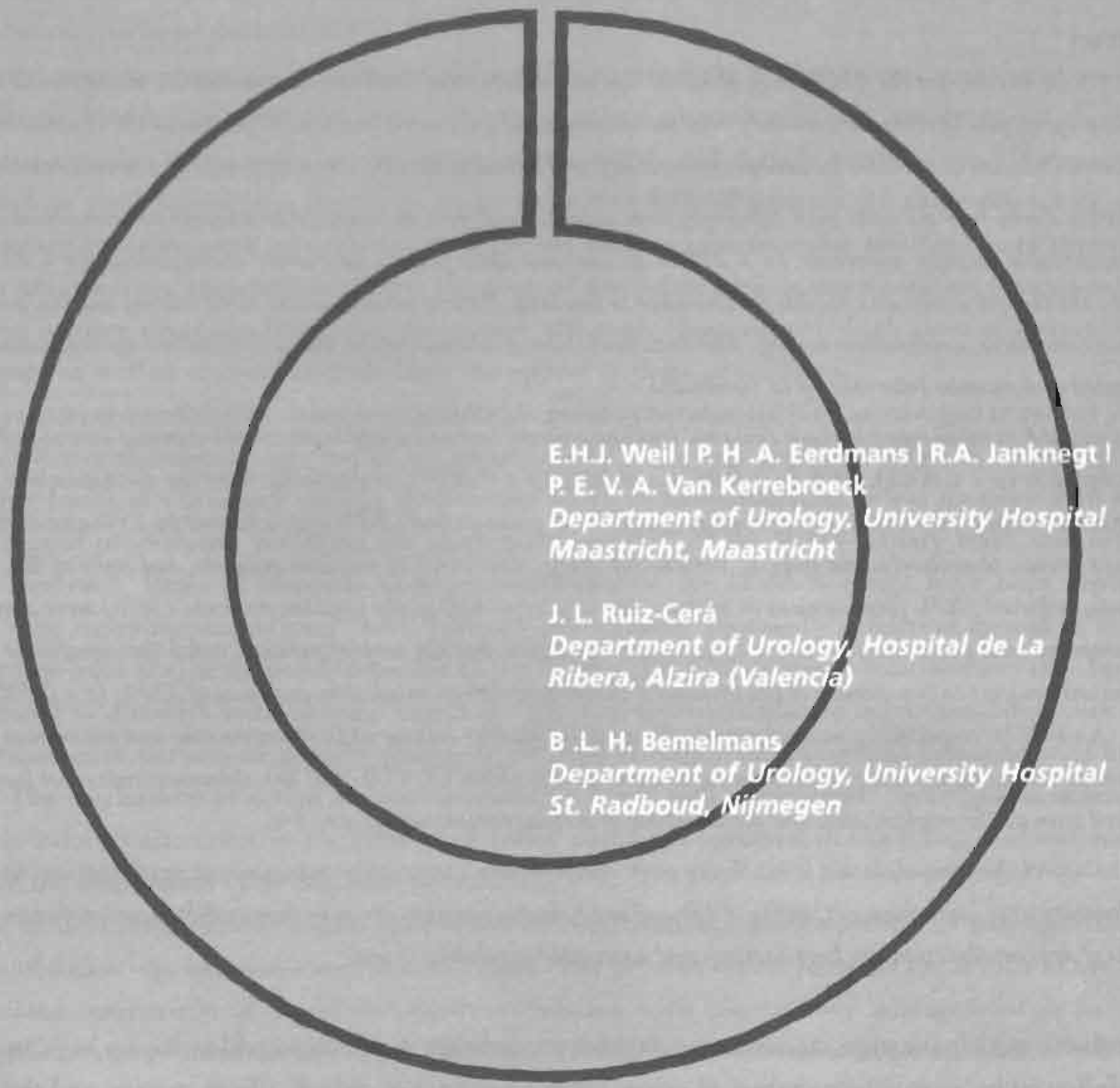

Eur Urol 37:161-171, 2000 


\title{
SACRAL ROOT NEUROMODULATION IN THE TREATMENT OF REFRACTORY URINARY URGE INCONTINENCE:A PROSPECTIVE RANDOMIZED CLINICAL. TRIAL.
}

\begin{abstract}
DB.AC TIVES Tit compare tbe effectivenes of wacral root neuromodulation witb that of conservative management in ameliomating, symptoms of reffactory urinary urge incontinence and enbancing quality of life; awew lbe objective response

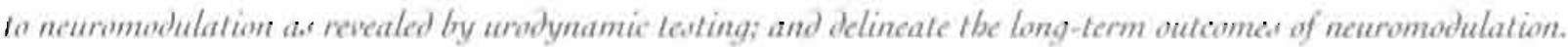

Mhrthons Forty-four patients wilb sefractory urge incontinence were randomized to undergo ncuromodulation with an implantable impule generator $(n=21)$ or to cantimue their prior conservative management $(n=25)$. At 6

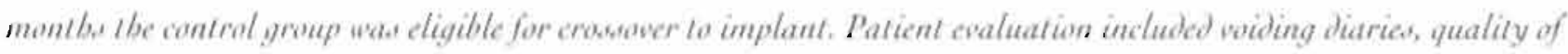
life quetionnairs, urodynamic lesting, and decumentation of adserse coents. Lang-term follow-up evaluations were conducted at 6 montbo intervals up to 56 montbus.

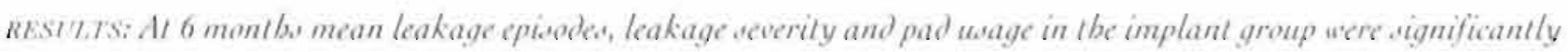
bower by $88 \%$, $p<0.0005)$. 24\% $(p=0.0-47)$ and $90 \%(p<0.0005)$, reapectively, than the correaponding control

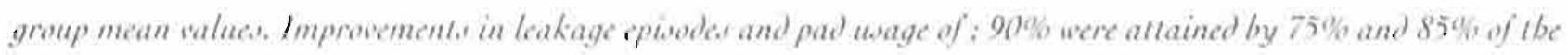

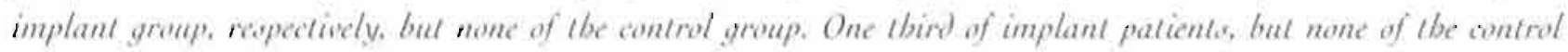
patientw, arbieved: $50 \%$ improvement in leakage weverity. Oeer balf of tbe implant patiente (56\%) were completely

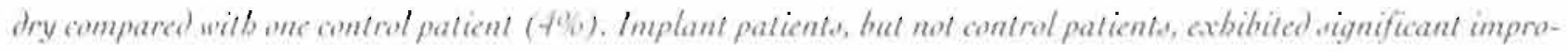

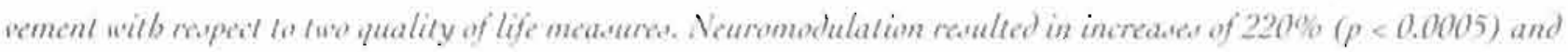

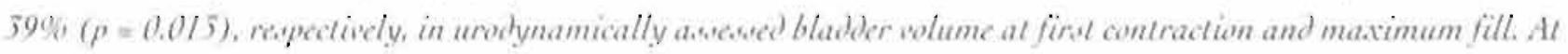

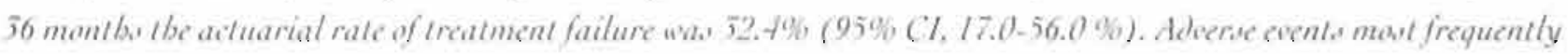

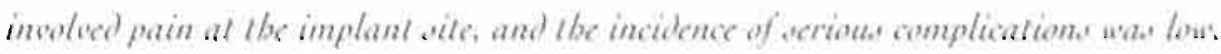

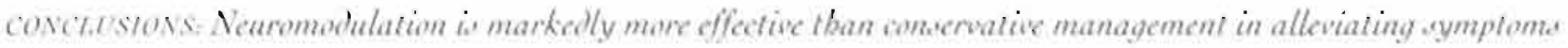
of refiratory urge incontinence. Qualily of life and urodynamic function are abo impreved by neuromodulation. Tbe

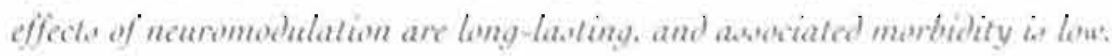

Ineroduction Urinary urge incontinence denotes a condition in which a sudden strong urge to urinate is followed by an involuntary loss of urine. Urge incontinence, which affects women and the elderly disproportionately, is disconcerting to patients, adversely affecting their quality of life, and imposes 
substantial economic costs (1). The condition is classified as detrusor hyperreflexia in the presence of a precipitating neurologic abnormality and detrusor instability in its absence (2). Neither the epidemiology nor the pathophysiology of urge incontinence has been well delineated, though available evidence suggests that subclinical neurologic disease or primary smooth muscle disease may contribute to the disorder in some patients (1).

Currently, urge incontinence is typically managed conservatively by behavioral techniques such as biofeedback, bladder retraining or pelvic muscle exercises: pharmacotherapy involving anticholinergic, antispasmodic, or tricyclic antidepressant medications; and dietary modification. These approaches fail to yield satisfactory outcomes in an estimated $40 \%$ of patients. In these refractory urge incontinence cases invasive procedural interventions such as intravesicular instillations of capsaicin, bladder transsection, rransvesical phenol injection of the pelvic plexus, augmentation ileocystoplasty and even urinary diversion have been advocated, although comparatively high rates of incontinence recurrence as well as of complications limit the appeal of these procedures.

Sacral root neuromodulation using an implantable pulse generator (IPG) has emerged in recent years as an attractive therapeutic alternative for patients with refractory urge incontinence. as well as certain other forms of refractory voiding dysfunction $(3,4)$. Neuromodulation is less invasive than available surgical procedures, preserves the anatomical integrity of the lower urinary tract, and can be readily reversed. Rates of response to neuromodulation in the $52-83 \%$ range have been reported among urge incontinence patients (5-8). Patients with urgency-frequency syndrome as well as urinary retention have also been found to benefit (7.9-12). The effects of neuromodulation have thus far not been found to diminish with chronic use (13). Nor has neuromodulation been associated with any reported cases of permanent adverse change in perineal sensation or micturition behavior or of nerve injury. The mechanism of action of neuromodulation is not well understood; nevertheless, neuromodulation-induced alteration in the activity of reflex pathways involved in the filling and evacuation phase of the micturition cycle has been postulated.

Studies of neuromodulation to date have involved comparatively small numbers of patients, limited periods of follow-up, and non-randomized designs. The present report presents the results of the first randomized comparison of sacral root neuromodulation with conservative management in pafients with refractory urge incontinence. This controlled clinical trial involved a larger number of patients than that in any previously reported study. and patients were followed for up to 36 months after commencement of neuromodulation. 


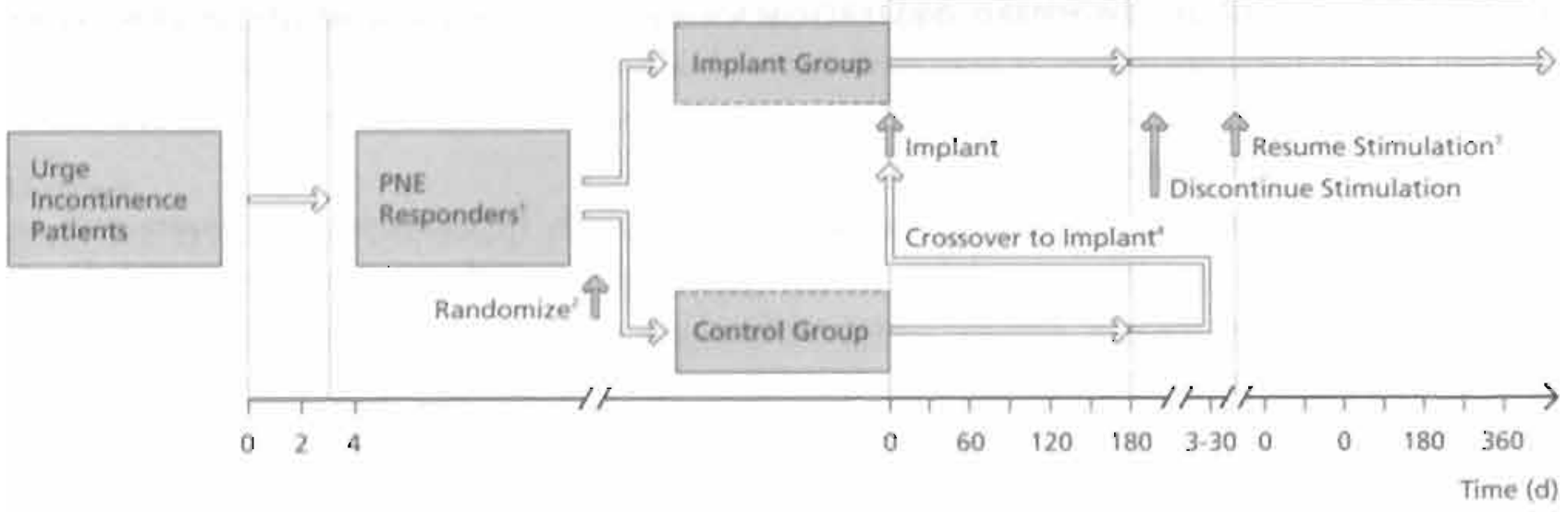

1. Based upon $50 \%$ improvement in one of more symptoms 2 . Upon regression to baseline symptoms following PNE 3. Upon partial or complete regression to baseline symptoms 4 . If still suitable candidate for implant

Material and Methods This prospective randomized clinical trial was conducted at the University Hospital Maastricht, Maastricht, The Netherlands and the University Hospital St. Radboud, Nijmegen. The Netherlands. During the period from December 1992 through January 1997, 123 consecutive patients with refractory voiding dysfunction rendered their informed written consent to undergo evaluation as potential study participants, including percutaneous nerve evaluation (PNE). Refractory voiding dysfunction included any of the following conditions that had proven unresponsive to standard currently available treatments: (a) urge incontinence; (b) urinary retention or voiding dysfuncrions, such as hesitancy or intermittency: due to an acontractile detrusor or obstruction due to urethral overactivity; or (c) severe or protracted urgency/frequency syndromes in the absence of incontinence. Although only the urge incontinence patients were the subject of the present study, the patients with the other types of refractory voiding dysfunction were also potential candidates for neuromodulation and therefore also underwent PNE.

The design of the study is depicted in Fig. 1. Patient selection criteria included: age > 16 y: normal upper urinary tract function, muscular and sensory responsiveness as demonstrated by PNE; detrusor storage capacity : $100 \mathrm{~mL}$; and absence of sphincter pathology. Patients were excluded on the basis 
Fig 2. Patient disposition

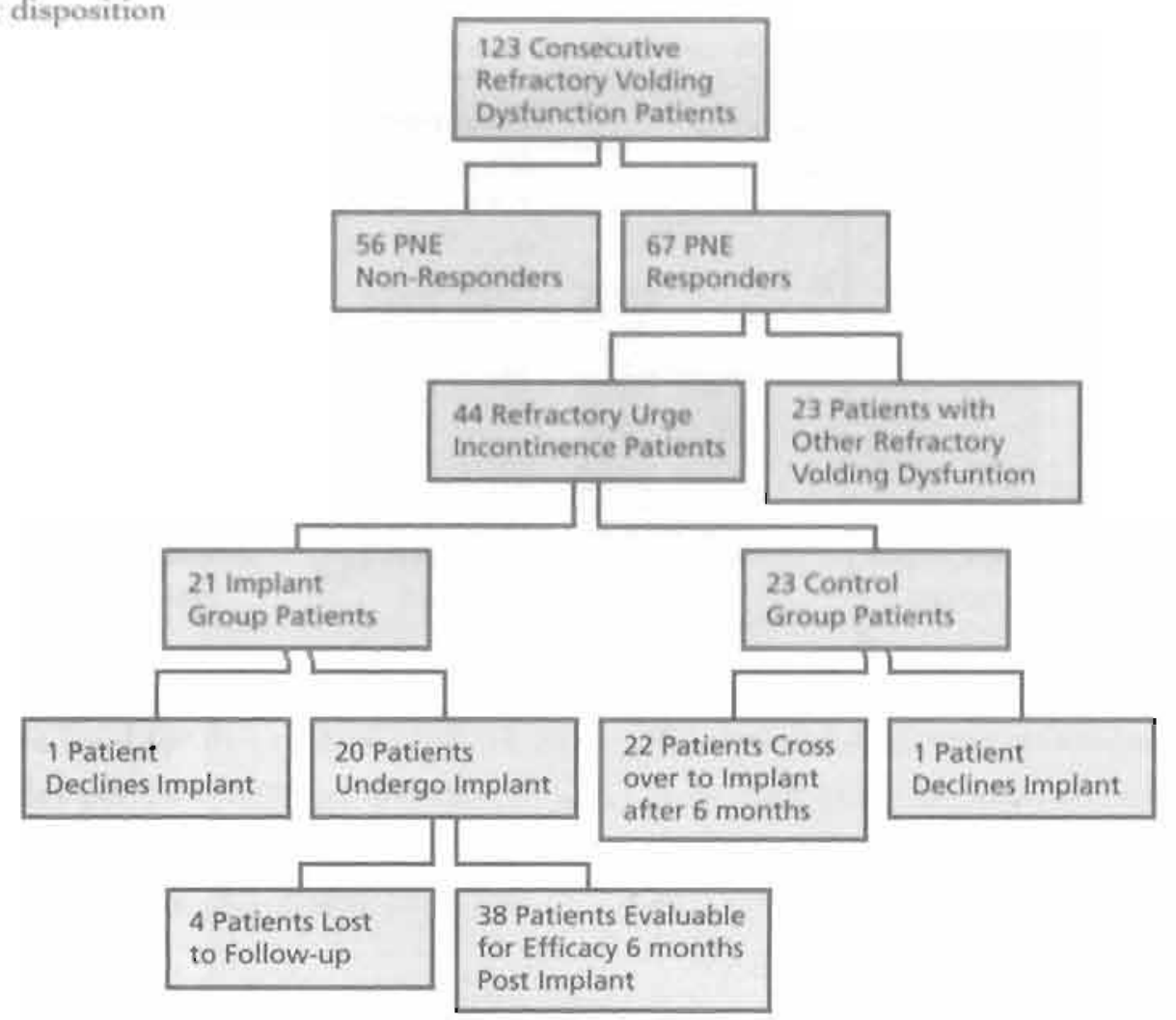

of: stress incontinence; multiple sclerosis; Reiter=s syndrome; severe or uncontrolled diabetes or diabetes with peripheral nerve involvement; pregnancy; anatomical features that would preclude successful placement of an IPG; concomitant medical conditions limiting the prospects for successful neuromodulation such as spinal cord injury or cerebrovascular accident within the preceding 6 months period, active degenerative disc disease, or bleeding complications; moderate to severe ureteral reflux or moderate to severe hydronephrosis; symptomatic urinary tract infection; and pelvic pain of unknown etiology.

Patient Evaluation Patients' general and urological history was documented, and physical examination, urinalysis, including cytology, uroflowmetry and urodynamic evaluation were performed. Patients completed a voiding diary as well as an SF-36 quality of life questionnaire (14). The voiding 
Chapter 8

Tabie 1. Bactine parient dala

\begin{tabular}{|c|c|c|c|c|}
\hline \multirow[t]{2}{*}{ Parameter } & \multicolumn{2}{|c|}{$\begin{array}{l}\text { Contral Group } \\
(n=23\end{array}$} & \multicolumn{2}{|c|}{$\begin{array}{l}\text { Implant Group } \\
(a=21)\end{array}$} \\
\hline & $n$ & $\%$ & $n$ & 96 \\
\hline \multicolumn{5}{|l|}{ Gender } \\
\hline Female & 21 & 91.3 & 19 & 90.5 \\
\hline Male & 2 & 8.7 & 2 & 9.5 \\
\hline \multicolumn{5}{|l|}{ Body weight } \\
\hline$<80 \mathrm{~kg}$ & 19 & 82.6 & 17 & 81.0 \\
\hline $280 \mathrm{~kg}$ & 4 & 17.4 & 4 & 19.0 \\
\hline \multicolumn{5}{|l|}{ Detrusor function } \\
\hline Unstable: & 17 & 73.9 & 16 & 76.2 \\
\hline Stable & 6 & 26.1 & 5 & 23.8 \\
\hline \multicolumn{5}{|l|}{ Number of PNEs } \\
\hline 1 & 17 & 73.9 & 16 & 76.2 \\
\hline$>1$ & 6 & 26.1 & 5 & 23.8 \\
\hline \multicolumn{5}{|l|}{ Prior disorders } \\
\hline Musculoskeletal (a) & 5 & 21.7 & 5 & 23.8 \\
\hline Neurological (b) & 6. & 26.1 & 4 & 19.0 \\
\hline Psychiatric (c) & 2 & 8.7 & 2 & 10.0 \\
\hline General gynecologic (d) & 12 & 52.2 & 6 & 28.6 \\
\hline Gastrointestinal (e) & 9 & 39.1 & 4 & 20.0 \\
\hline Recurrent urinary tract infection & 9 & 39.1 & 5 & 23.8 \\
\hline \multicolumn{5}{|c|}{ (a) Including dronic back pain, arthrosis artiritis and cendinits } \\
\hline \multirow{2}{*}{\multicolumn{5}{|c|}{$\begin{array}{l}\text { (b) Including herniated nucizus pulposus. eqilepny. tension headache } \\
\text { and carpal tunnel syndrome }\end{array}$}} \\
\hline & & & & \\
\hline \multicolumn{5}{|l|}{ (c) insloding depresuion and hoperventitation } \\
\hline (d) Including bysterectomy irregular nomtei & dome & & & \\
\hline
\end{tabular}




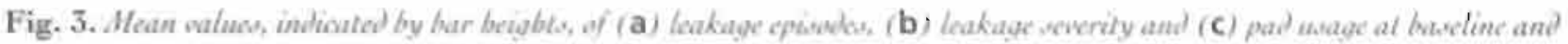

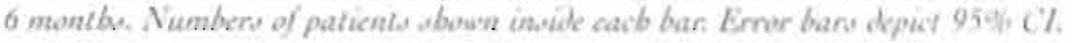
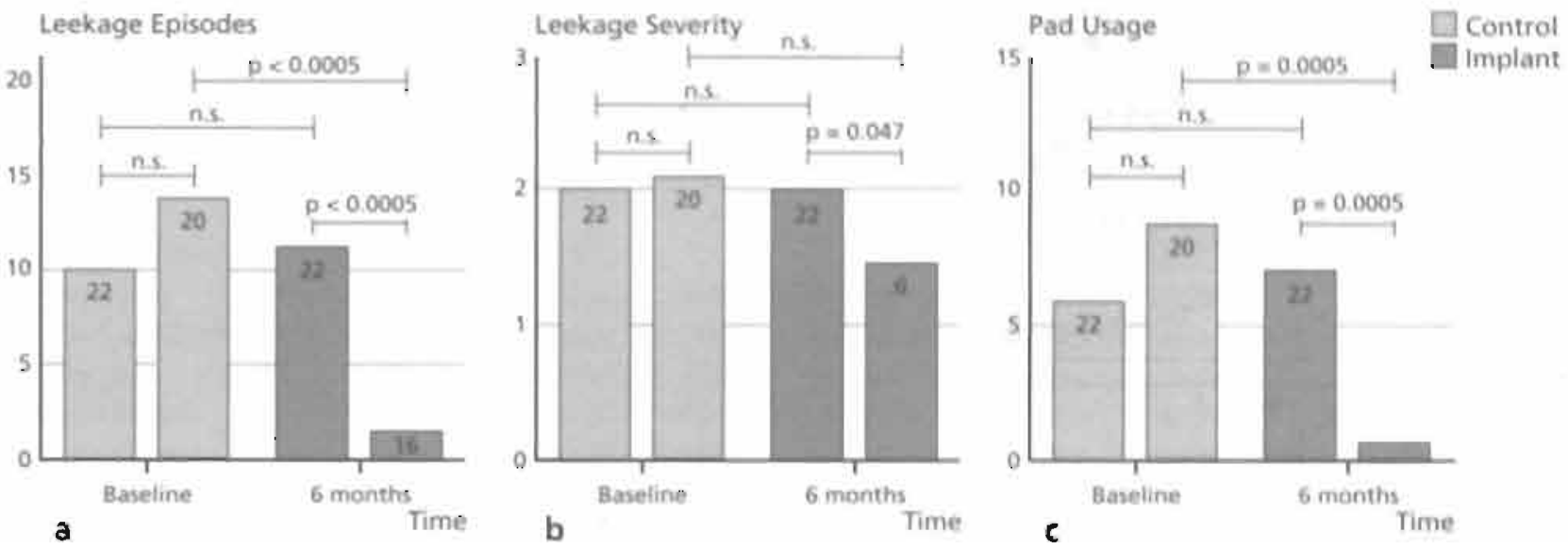

diary data were used for determination of the three primary study outcome measures, viz, number of leakage episodes per $24 \mathrm{~h}$. leakage severity on a 0-3 scale. and usage of pads, including diapers, per $24 \mathrm{~h}$. The leakage severity scale was: 0 for dry. I for loss of a few drops of urine, 2 for loss of $1-2$ lablespoons of urine and 3 for complete wetting.

Percutaneous Nerve Evaluation PNE, which consisted of an acure phase and a sub-chronic phase, was performed as previously described $(5,15)$. In the acute phase percutaneous electrical stimulation was applied by the attending investigator to the ventral ramus at the level of the S3 foramen, or atter natively S2 or S4, using insulated needles and an external, hand-held neurostimulator (Model 3625 Screener, Medtronic, Inc., Columbia Heights, Minnesota. USA). Patients exhibiting satisfactory responsiveness proceeded to the subchronic phase, in which stimulation was applied via a temporary percutaneous lead wire for a minimum of $72 \mathrm{~h}$ under patient control. Patients completed daily voiding diaries during the sub-acute phase and again at least $72 \mathrm{~h}$ thereafter upon regression to baseline symptoms. Patients exhibiting : 50\% improvement in at least one of the three primary outcome measures during PNE, upon granting their further informed written consent to undergo implantation, were enrolled in the study. 


\section{Chapter 8}

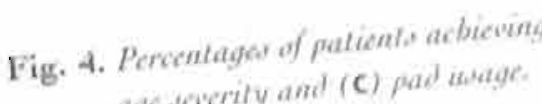

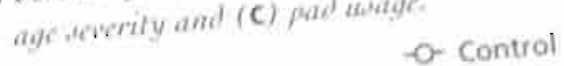

- Implant

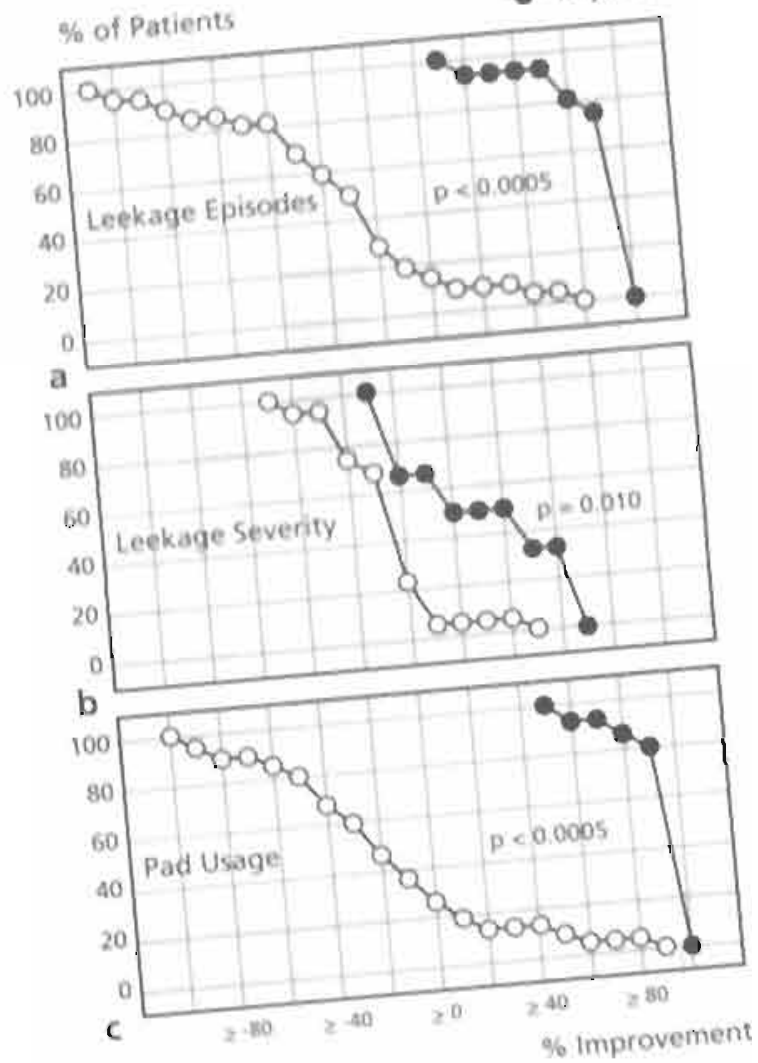

Randomization Patients were randomly assigned to the implant group and the control group in a bil target ratio. Treatment assignments were based upon numbers the proceded the placement and neuro dom number generator. implant group patients proced to receive their previous conservative management with modulation. Control group patients continte for the ensuing 6 months controlled phase of the study, at oral medication or pelvic floor exercises for the enplant provided they remained suitable candidates for which time they were eligible for crossoverto instituted in the control group during the controlled this form of treatment. No new therapies were institutedingen 
Chepter 8

Table 2. Quality of life

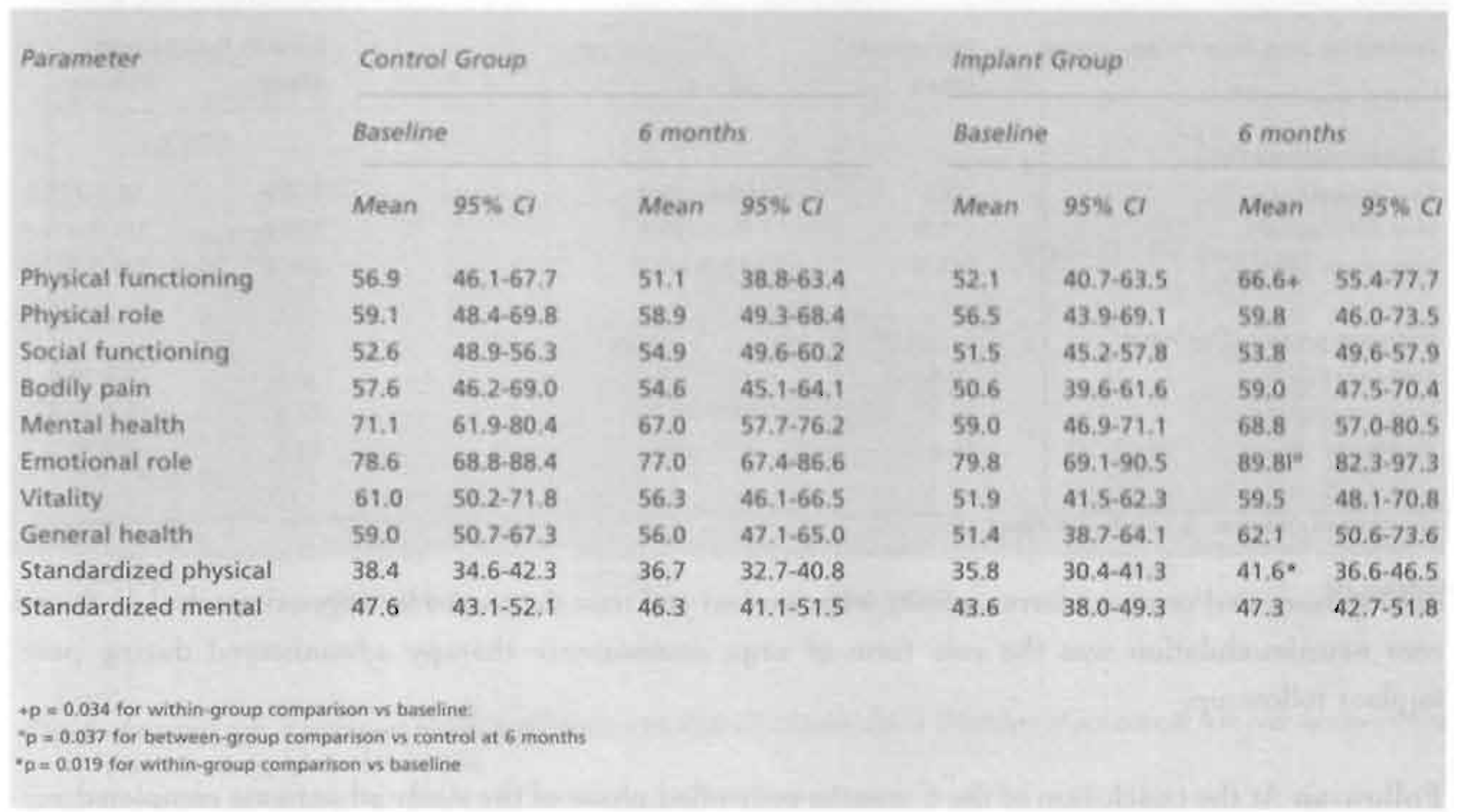

phase of the study. Twenty-two of 23 control patients $(96 \%)$ underwent implantation at the conclusion of the 6 months controlled phase.

Implantation IPG placement procedures were performed between January 1994 and May 1997 by previously described methods (10). Briefly, with the patient under general anesthesia, acute testing of responsiveness was repeated after surgical exposure of the same sacral foramen previously successfully stimulated during PNE. The lead (Model 3886 PISCES-Quad Lead, Medronic, Inc., Columbia Heights, Minnesota, USA) was positioned and secured by fixation to the sacral periosteum or bone. The IPG (Model 7424 ITREL7 II Implantable Pulse Generator, Medtronic, Inc., Columbia Heights, Minnesota, USA) was implanted in a lower abdominal pocket and connected to the lead by an extension (Model 7495 Extension. Medtronic, Inc., Columbia Heights, Minnesota, USA) threaded through a subcutaneous tunnel. Stimulation wascommenced on the following day with initial pulse width of $210 \mu \mathrm{s}$, rate of $15 \mathrm{~s}^{-1}$, and amplitude of $0.1 \mathrm{~V}$. Amplitude was thereafter increased in $0.1 \mathrm{~V}$ increments 
Table 3. I/ndynamic function

\begin{tabular}{|c|c|c|c|c|}
\hline \multirow[t]{2}{*}{ Parameter and Time Point } & \multicolumn{2}{|c|}{ Preimplant } & \multicolumn{2}{|c|}{6 moth Postimplant } \\
\hline & Mean & $95 \% \mathrm{Cl}$ & Mean & $95 \% \mathrm{Cl}$ \\
\hline \multicolumn{5}{|l|}{ Bladder volume (mi) } \\
\hline First sensation & 92.6 & $66.6-118.6$ & 167.2 & $59.2-275.2$ \\
\hline First contraction & 115.8 & $75.7-155.8$ & $370.2+$ & 324.9 .415 .4 \\
\hline Maximum fill & 265.9 & 218.0 .313 .8 & $370.2^{*}$ & 324.9 .415 .4 \\
\hline \multicolumn{5}{|l|}{ Detrusor pressure $(\mathrm{cm} \mathrm{H2O})$} \\
\hline First sensation. & 9.5 & 4.1-15,0 & 6.6 & $2.3-10.8$ \\
\hline First contraction & 26.9 & $18.1-35.7$ & 32.5 & $15.4-49.6$ \\
\hline Maximum fill & 16.6 & 11.0 .22 .2 & 13.8 & $6.9 \cdot 20.8$ \\
\hline
\end{tabular}

until sensory and/or muscularres ponses were evoked and then decreased by approximately I V. Sacral root neuromodulation was the sole form of urge incontinence therapy administered during postimplant follow-up.

Follow-up At the conclusion of the 6 months controlled phase of the study all patients completed voiding diaries and quality of lile questionnaires and were assessed by uroflowmetry and urodynamic testing. The same evaluation procedures were also followed by the control group 6 months after crossover to implant. After evaluation at 6 months, post-implant stimulation was discontinued at least $72 \mathrm{~h}$ until regression to baseline symptoms, at which time patients completed additional daily voiding diaries for a 72 h period. At this juncture, stimulation was resumed, and a further diary was completed at least 72 h later when patient response to stimulation stabilized. Subsequent long-term followup consisted in all patients of completing voiding diaries at 6 months intervals.

Data Analysis Descriprive staristics were calculated and inferential statistical analyses performed using SPSS 8.0 statistical software (SPSS, Ine, Chicago, 1llinois. USA). Mean values and $95 \%$ confidence intervals $(95 \%, \mathrm{Cl})$ were calculated for parametric data. Inferential statistical tests were performed on a two-tailed basis with an a level of 0.05 . Between - groupcomparisons of nonparametric baseline patient attributes were made by Fisher exact test. Within - and between - group comparisons 


\section{Chapter 8}

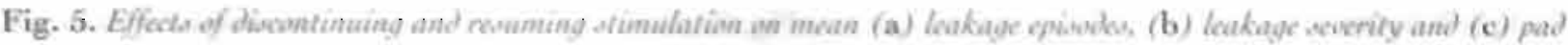

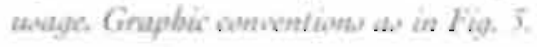
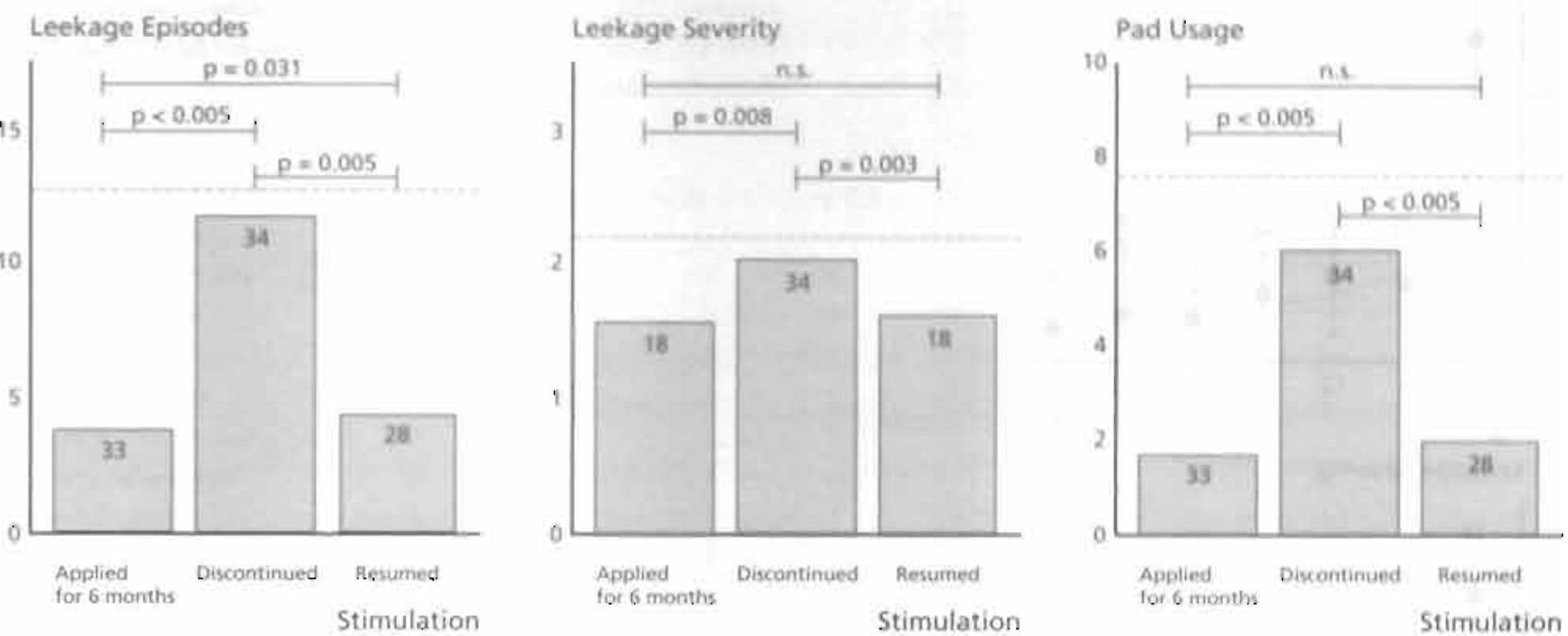

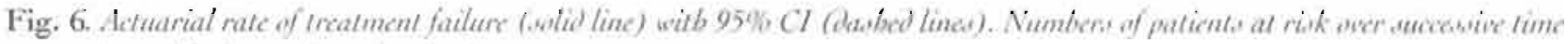

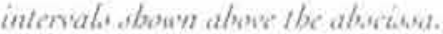

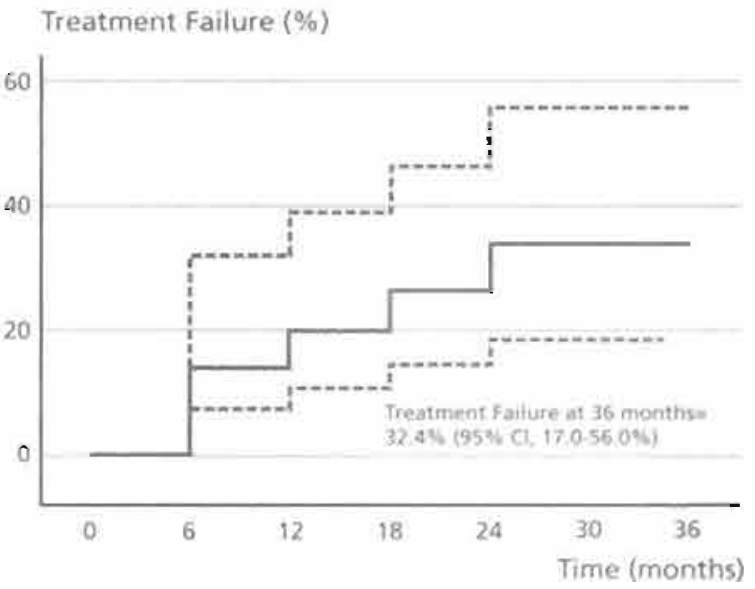




\section{Chapter 8}

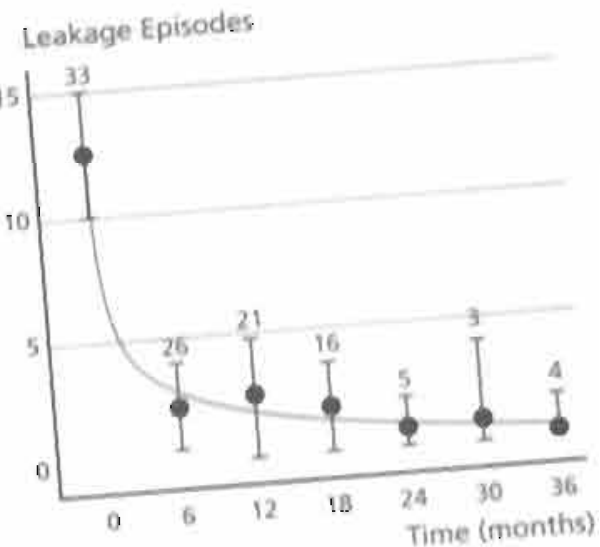

Fig. 7. Mean (a) Leakage epteods, (b) Leakaye weverity and (c) pad usage during long-term follow ap in nen-facture patient. Dote indicate empirival mean values, and error bars

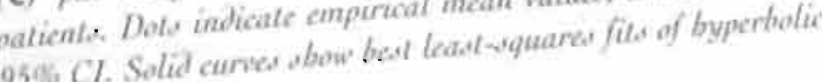
decay functions.

a

Leakage Severity

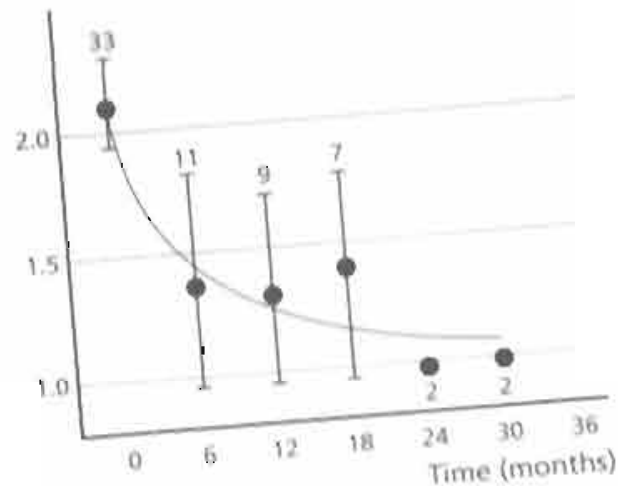

b

Pad Usage

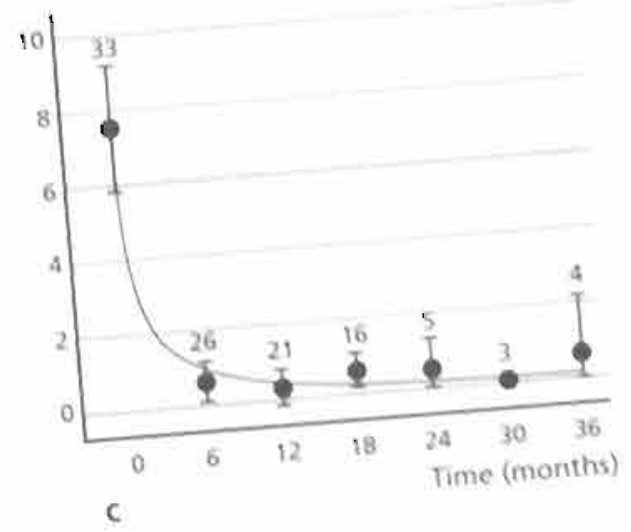




\section{Chapter 8}

\section{Table 4. Adwense cirnts}

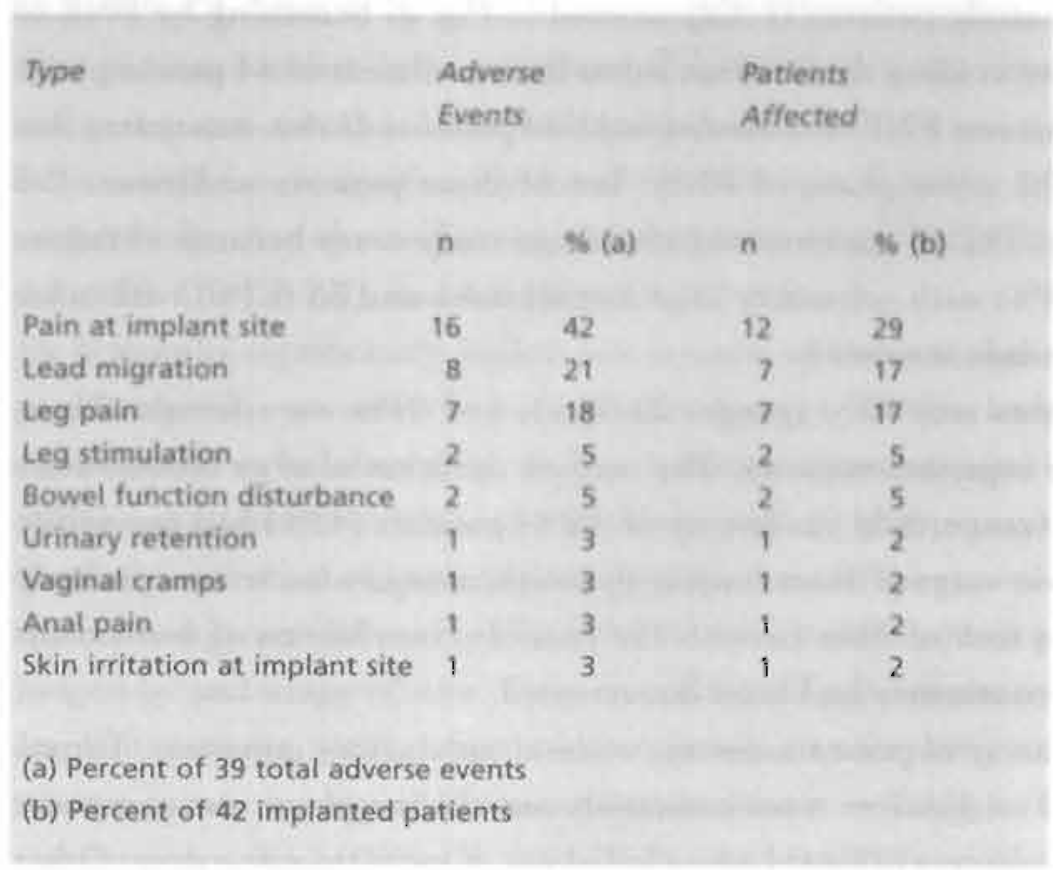

of parametric results during the 6 months controlled phase of the study were conducted by Student's test for paired and grouped data, respectively. Percentage improvement at 6 months ys baseline was calculated in cumulative decile increments (e.g., $\geq 40 \%$, $\geq 50 \%$, $\geq 60 \%$, etc.), and between-group differences in apportionment across cumulative deciles of improvement were evaluated by Mann-Whitney $\mathrm{U}$ test. Post-crossover phase results from the implant and control groups were pooled. In the analysis of the pooled results, baseline for the control group was defined to be the time point just prior to implant, i.e., after the 6 months controlled phase. Within-group comparisons for post-crossover phase data were conducted using repeated measures analysis of variance with simple contrasts or Student's paired test. Nonparametric correlations between changes in primary study outcome measures and those in urodynamic data were assessed by the Spearman rank method. The actuarial rate of treatment failure was determined by the Kaplan-Meier product-limit method. For purposes of this analysis, patients were declared to be failures at the time they (1) first failed to exhibit ; $50 \%$ improvement vs baseline in at least one of the three primary outcome measures or (2) underwent IPG explantation. Variables potentially predictive of treatment failure were evaluated by logistic regression. 


\section{Results}

Patient Atributes The disposition of study patients is diagrammed in Fig. 2. Screening by PNE of 123 consecutive patients with refractory voiding dysfunction led to the enrollment of 44 parients with refractory urge incontinence. More than one PNE was needed in 11/44 patients (25\%), most often due to lead displacement subsequent to the acute phase of PNE. Ten of these patients underwent 2-3 PNEs, while one patient required five, The 56 patients excluded from study entry because of failure to respond to PNE consisted of 21 (38\%) with refractory urge incontinence and $35(62 \%)$ with other urgency/frequency syndromes without incontinence).

The median age of the enrolled parients was 43 y (range, 20-66 y), and $91 \%$ were female. These parients presented with long-standing urge incontinence. The median duration of urge incontinence symptoms prior to enrollment was 9 y (range, $2-34$ y). Twenty of the 44 patients $(45 \%)$ had previously undergone lower urinary tract or pelvic surgery, most frequently urethrosuspension to treat urinary stress incontinence or hysterectomy. In four of these parients the possible contribution of urethrosuspension to the development of urge incontinence had been documented.

The enrolled patients had received an array of prion treatments without satisfactory outcomes. Thirtysix of 44 patients $(82 \%)$ had received medication, most commonly anticholinergic or antispasmodic agents, and prior treatment in half the patients $(22 / 44)$ had included use of more than one drug. Other unsuccessful previous trearments included biofeedback, various forms of external electrical stimula. tion. intermittent self-catheterization, psychological counseling and denervation.

Upon randomization 23 patients were assigned to the control group and 21 to the implant group (Fig. 2). At baseline there were no statistically significant differences between the groups with respect to any of the three primary outcome measures (leakage episodes, leakage severity and pad usage) or to an array of other patient attributes (Table 1). Detrusor instability was not evident in 6 control group and 5 implant group patients. In some or all these cases it is possible that ambulatory urodynamic eva. luation might have revealed detrusor instability or that urge incontinence was due to urethral instability. Neither possibility was investigated as part of the present study.

Controlled Phase Results One patient randomized to the implant group declined to undergo implantation due to desire to initiate a pregnancy. The remaining 20 patients in this group received implants. As shown in Fig. 3, at 6 months mean leakage episodes (1.4: 95\% CI, 0.0-3.2) and pad usage $(0.7: 95 \%$ CI, 0.0-1.3) in the implant group had signiticanty declined ( $p<0.0005$ ) by $90 \%$ and $92^{\circ} 0_{0}$, respectively. compared with the respective baseline values of $13.5(95 \%, \mathrm{C} 1,10.3-16.7)$ and $8.7,95 \%$ CI, 5.8 - 
11.6): Mean leakage severity at 6 months (1.6; 95\% CI, 0.7-2.4) was also lower than that at baseline (2.1: $9596 \mathrm{CI}, 1.9-2.4)$ by $249 \%$; however, this difference was not staristically significant. No significant change from baseline in mean values of the three primary outcome measures was evident in the control group at 6 months. Mean leakage episodes, leakage severity and pad usage in the implant group at 6 months were significantly lower by $88 \%(p<0.0005) .24 \%(p-0.047)$ and $90 \%(p<0.0005)$, respectively, than the respective control group mean values at 6 months of $11.2(95 \% \mathrm{Cl}, 8.9-13.5)$, $2.1(95 \% \mathrm{CI}, 1.9-2.4)$, and $6.8(95 \% \mathrm{Cl}, 5.2-8.5)$.

By 6 months significantly higher percentages of implant than control patients had achieved greater percentage improvements in leakage episodes $(p<0.0005)$, leakage severiry $(p=0.010)$ and pad usage ( $\mathrm{p}<0.0005)$ vs baseline (Fig. 4). For instance, improvements in leakage episodes and pad usage of ; $90 \%$ were attained by $75 \%$ and $85 \%$ of the implant group, respectively, but none of the control group. Similarly, one third of implant patients achieved : $50 \%$ improvement in leakage severity, while none of the control group did so. By 6 months $9 / 16$ evaluable implant patients (56\%) were completely dry, as judged by pad usage of zero. Only one of the 22 control patients (4\%) was dry at 6 months.

Implant patients, unlike their control group counterparts, exhibited significant improvement with respect to two quality of life measures, as shown in Table 2. Thus, at 6 months mean physical functioning score $(66.6 ; 95 \% \mathrm{Cl}, 55.4-77.7)$ and standardized physical component scale (41.6; 95\% C1. $36.6-46.5)$ in implant patients were greater by $28 \%(p=0.034)$ and $16 \%(p=0.019)$, respectively, than the corresponding baseline mean values of 52.1 ( $95 \% \mathrm{Cl}, 40.7-63.5)$ and $35.8(95 \% \mathrm{Cl}, 30.4-41.3)$. Additionally, mean score for role limitations due to emotional problems at 6 months in the implant group (89.8; 95\% CI. 82.3-97.3). though not significantly different from the baseline mean, was nevertheless significantly higher by $17 \%(p=0.037)$ than the 6 months mean value for the control patients (77.0; 95\% Cl, 67.4-86.6). No significant between-group differences were apparent at baseline in any of the quality of life measures. Nor were any significant improvements demonstrable in the control group at 6 months vs baseline. The absence in the implant group of significant improvement with regard to a broader array of quality of life measures may be at least partly ascribable to the lack of disease specificity in the SF-36 health status scales used to evaluate quality of life (16).

At the conclusion of the controlled phase of the study, one control group patient elected not to proceed with implantation. This patient's decision was prompted by the need to undergo a neurosurgical intervention for herniated nucleus pulposus. 
Post-Crossover Phase Results After neuromodulation for 6 months study patients underwent urodynamic evaluation (Table 3). At both first contraction and maximum fill mean bladder volume at 6 months was significantly higher by $220 \%(\mathrm{p}<0.0005)$ and $39 \%(\mathrm{p}=0.013)$, respectively, compared with the respective baseline means. Mean values of bladder volume at first sensation and of detrusor pressure were not significantly different at 6 months than at baseline. Changes at 6 months vs baseline in mean bladder volume at maximum fill were weakly $(r=0.424)$ but significantly $(p=0.028)$ correlated with corresponding changes in leakage episodes. No other significant correlations could be demonstrated between changes in urodynamic bladder volume parameters and those in any of the three primary outcome measures.

At the conclusion of the 6 months period following implant the dependency of treatment effects on active stimulation were evaluated by temporarily discontinuing and then resuming stimulation. As indicated in Fig. 5. upon discontinuation of stimulation a significant rebound was observed in mean leakage episodes ( $p<0.0005)$, leakage severity $(p=0.008)$ and pad usage $(p<0.0005)$ to levels comparable with those prior to implant. With the resumption of stimulation these three outcome measures decreased significantly $(\mathrm{p}<0.0005, \mathrm{p}=0.003$ and $\mathrm{p}<0.0005$, respectively). Mean values of leakage severity and pad usage after stimulation was resumed were not significantly different from those prior to discontinuation of stimulation. However, mean leakage episodes remained $33 \%$ higher $(p=0.031)$ than the pre-discontinuation level.

The median duration of follow-up for the study patients was 18 months (range, 6-36 months). Over the course of follow-up 9 patients were declared to be treatment failures: 8 because of deterioration in the primary outcome measures and one due to explantation (Fig. 6). The actuarial rate of treatment failure at 36 months was $32.4 \%(95 \% \mathrm{Cl}, 17.0-56.0 \%)$. Among the non-failures mean leakage episodes, leakage severity and pad usage exhibited marked decline at 6 months post implant vs preimplant values and remained stable at low levels throughout the duration of follow-up (Fig. 7). Logistic regression analysis failed. to reveal any significant predictors of treatment failure. Variables evaluated by logistic regression were: body weight; number of PNEs; detrusor instability: baseline leakage episodes; and history of muscular, neurological, general gynecologic or gastrointestinal disorders or of recurrent urinary tract infection.

Adverse Events Table 4 summarizes treatment-related adverse events. A total of 39 adverse events were encountered in the -12 implanted patients. Twelve patients experienced a single adverse event. while 8 patients experienced $2-5$ adverse events, and 2 patients 4 adverse events. Most frequent was 
pain at the implant site, accounting for $42 \%$ of all treatment-related adverse events, followed by lead migration $(21 \%)$ and leg pain (18\%). No intra- or perioperative complications accompanied the implant procedure. Twenty-one post-implant surgical procedures were performed to resolve adverse events, including 8 surgical revisions to correct lead migration and 8 to ameliorate pain at the implant site. One patient accounted for 3 of the 8 procedures to relieve implant site pain, and the final proce. dure in this patient was IPG explantation due to intractable implant site pain.

Discussion The present investigation exrends the available evidence supporting the efficacy and safety of neuromodulation for treatment of refractory urge incontinence and provides the first randomized demonstration of superior outcomes with neuromodulation compared to conservative management. At 6 months mean leakage episodes, leakage severity and pad usage were substantially and sig. nificantly lower in implant than control patients, and significantly higher percentage improvements vs baseline in all three primary outcome measures were observed in implant than control patients. The magnitude of improvement in leakage severity was lower than that in leakage episodes and pad usage. It should however be remembered that, unlike the other two outcome parameters, leakage severity was recorded on a non-linear scale and was subjecrively assessed: hence, smaller improvement in leakage severity may be a reflection of the rype of data recorded, although a relatively modest effect of neuromodulation on detrusor contraction force could also at least partly account for this finding.

More than half of the implant group patients were completely dry after neuromodulation for 6 mo. Unlike their control group counterparts, implant patients also achieved significant improvement in two quality of life measures. It is noteworthy that these results were achieved in a population of patients with comparatively severe urge incontinence of long standing. Half the study parients experienced 10 or more daily leakage episodes at baseline and had endured symptoms of urge incontinence for nearly a decade or longer.

PNE, which assesses nerve root integrity and subjective response to stimulation, is essential in patient selection for long-term neuromodulation. The rate of treatment failure during long-term follow-up in the present study was comparatively low. Nevertheless, despite responding satisfactorily to stimulation during PNE some recipients of permanent implants did not experience long-term benefit from neuromodulation. for reasons that remain unclear. The explanation for treatment failure in many cases may be technical problems in the delivery of electric stimulation to the target sacral nerves, for exam- 


\section{Chapter 8}

ple, because of lead displacement (7). A novel distensible lead design currently under investigation may offer one approach to reducing or eliminating treatment failure due to lead displacement. In other cases the cause of failure may reside in inappropriate patient selection. For instance, patients with psy. chiatric disorders may be at high risk of failure (7). Since only four of the patients participating in the present study presented with a history of psychiatric disorder, it was not feasible to evaluate the role of this factor as an outcome predictor. Evaluation of an array of other baseline patient variables failed to reveal any significant outcome predictors, and this observation is consistent with the findings of an earlier study $(17)$.

In addition to its superior effectiveness compared with conservative management as observed in the present study, neuromodulation also offers the advantage of immediate onset of action, as well as absence of systemic side effects. For instance, maximal effects of tolterodine and oxybutynin require $5-8$ wk to develop [18), and systemic side effects of pharmacotherapy can be treatment-limiting.

The present results serve to confirm earlier findings that neuromodulation is a safe therapy. Adverse effects, most frequently pain at the implant site, were generally manageable, and the incidence of serious complications was low. Only one patient required explantation. Nevertheless, the need for surgical revisions is not infrequent and remains a significant limitation of neuromodulation in its current form. Lead displacement necessitating revisions could be more likely in obese or highly physically active patients. As has been reported in earlier studies, no clinical evidence of nerve damage resulting: from neuromodulation was noted in the present investigation.

Major significant improvements in bladder volume upon first contraction and maximum fill were documented during urodynamic evaluation at 6 months. Increases in urodynamically assessed bladder volume at maximum fill were weakly but significantly correlated with reduction in leakage episodes. Nevertheless, no other correlations were apparent in urodynamic bladder volume parameters and the three primary study outcome measures. The present observations of significant improvements in certain urodynamic parameters but limited correlarions with symptom changes are consistent with those of earlier neuromodulation studies (6.13). Plausibly. firmer correlations between subjecrive and objeclive parameters may emerge from the use of ambulatory urodynamic evaluation methods.

The effects of netromodulation were found to be associated with continuing stimulation rather than the presence of the IPG per se, Upon discontinuation of stimulation symptoms regressed to baseline and thereafter improved again with resumption of stimulation. The prompt loss of symptom improvement in cases of lead migration further underscores the importance of continuing stimulation. These 


\section{Chapter 8 .}

observations affirm the reversibility of neuromodulation effects and also suggest that long-lasting and significant alteration of muscular function or the integrity of endogenous neurotransmission resulting from neuromodulation is unlikely.

The techniques and technology of neuromodulation continue to evolve (19). For instance, new lead technology currently under clinical investigation holds promise for reducing the likelihood of lead displacement, as well as enhancing the sensitivity of PNE. The potential utility of bilateral electrode placement is also under investigation. Such technical advances may promote higher treatment success. rates and make the need for surgical revisions less frequent. Improved technology for PNE may also ultimately broaden the population of patients considered suitable candidates for neuromodulation. In the present study $25 \%$ of patients failed PNE and were thus excluded as candidates for neuromoduLation. A two-stage implant approach has recently indicated that a substantial proportion of patients failing conventional PNE may in fact be responsive to neuromodulation (19). While technical refinements will likely improve further the results of neuromodulation in the future, this form of therapy is. already proving to be effective and well-tolerated in patients with refractory urinary urge incontinence, as well as certain other types of refractory voiding dysfunction. 


\section{REFERENCES}

1. Payne CK: Epidemiology, pathophysialogy, and evaluation of urinary incontinence and overactive bladder. Urolegy 1998;51:3-1

2. Abrams PH, Blaivas JG, Stanton SL. Andersen JT: Standardization of terminology of the lower urinary tract func lion. Ncurnumol thodyn 1988:7:403-427.

3. Tanagho EA, Schmide RA: Electrical stimulation in the clinical management of the neurogenic bladder. $J$ Chol 1988:140:1331-1339

4. van Kerrebroeck PE: The role of electrical stimulation in voiding dysfunction. Fur / fol 1998:34 (suppl I):2730

5. Dijkema HE, Weil EH, Mijs PT, Janknegt RA: Neuromodulation of sacral nerves for incontinence and voiding dys functions. Clinical results and complications. Eur l'nol 1993:24:72-76.

6. Bosch Il. Groen J: Sacral (S.3) segmental nerve stimulation as a treatment for urge incontinence in patients with detrusor instability: resulfs of chronic electrical stimulation using an implantable neural prosthesis. / / $\mathrm{ir} / 1995 ; 154: 504-507$.

7. Weil EH, Ruiz-Cera. JL, Eerdmans PH, Janknegt RA, van Kerrebroeck PE: Clinical results of sacral neuromodulation for chronic voiding dysfunction using unilateral sacral foramen electrodes. Hordd . / frol 1998:16:313-321.

8. Shaker HS, Hassouna M: Sacral nerve root neuromodulation: an effective treatment for refractory urge inconlinence. I lind 1998:159:1516-1519.

9. Vapnek JM, Schmidt RA: Restoration of voiding in chronic urinary retention using a neuroprosthesis. II:

10. Siegel SW: Management of voiding dystunction with an implantable neuroprosthesis. Lirol Clin Nortb Am $1992: 19: 163.170$.

11. Hohenfellner M, Schultz-Lampel D, Dahms S, Matzel K. Thuroff JW: Bilateral chronic sacral neuromodulation for treatment of lower urinary tract dystunction. I/ frol 1998:160:821-824.

12. Shaker HS, Hassouna M: Sacral root neuromodulation in idiopathic nonobstructive chronic urinary retention. J C/rol 1998;169:1470\% 1478.

13. Bosch JL, Groen J: Neuromodulation: urodynamic effects of sacral (S.3) spinal nerve stimulation in patients with detrusor instability or detrusor hyperflexia. Bebur Broun Ro 1998:92:141-150.

14. Ware JE, Sherbourne CO: The MOS 36-item short-form health survey (SF-36). I. Conceptual framework and

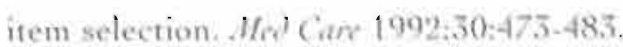

15. Schmidt RA, Senn E, Tanagho EA: Functional evaluation of sacral nerve root integrity, Report of a technique. l'noliggy 1990:35:388-392. 
16. Jackson S: The patient with an overacrive bladder-Symptoms and quality-of-life issues. Undegry 1997;50:18-22.

17. Koldewijn EL, Rosier PF, Meuleman EJ, Koster AM, Debruyne FM, van Kerrebroeck PE: Predictors of success with, neuromodulation in lower urinary tracs dysfunction: results of trial stimulation in 100 patients. I L/nol 1994:152:2071-2075.

18. Appell RA: Clinical efficacy and safety of tolterodine in the treatment of overactive bladder: a pooled anaty sis. Unology 1997;50 (6A suppl):90-96.

19. Janknegt RA, Weil EH, Eerdmans PH: Improving neuromodulation technique for refractory voiding dysfunc tions: two-stage implant. (Inthyg 1997:-49:358-362. 

CHAPTER 9 NOVEL TEST LEAD DESIGNS FOR SACRAL NERVE STIMULATION: IMPROVED PASSIVE FIXATION IN AN ANIMAL MODEL.

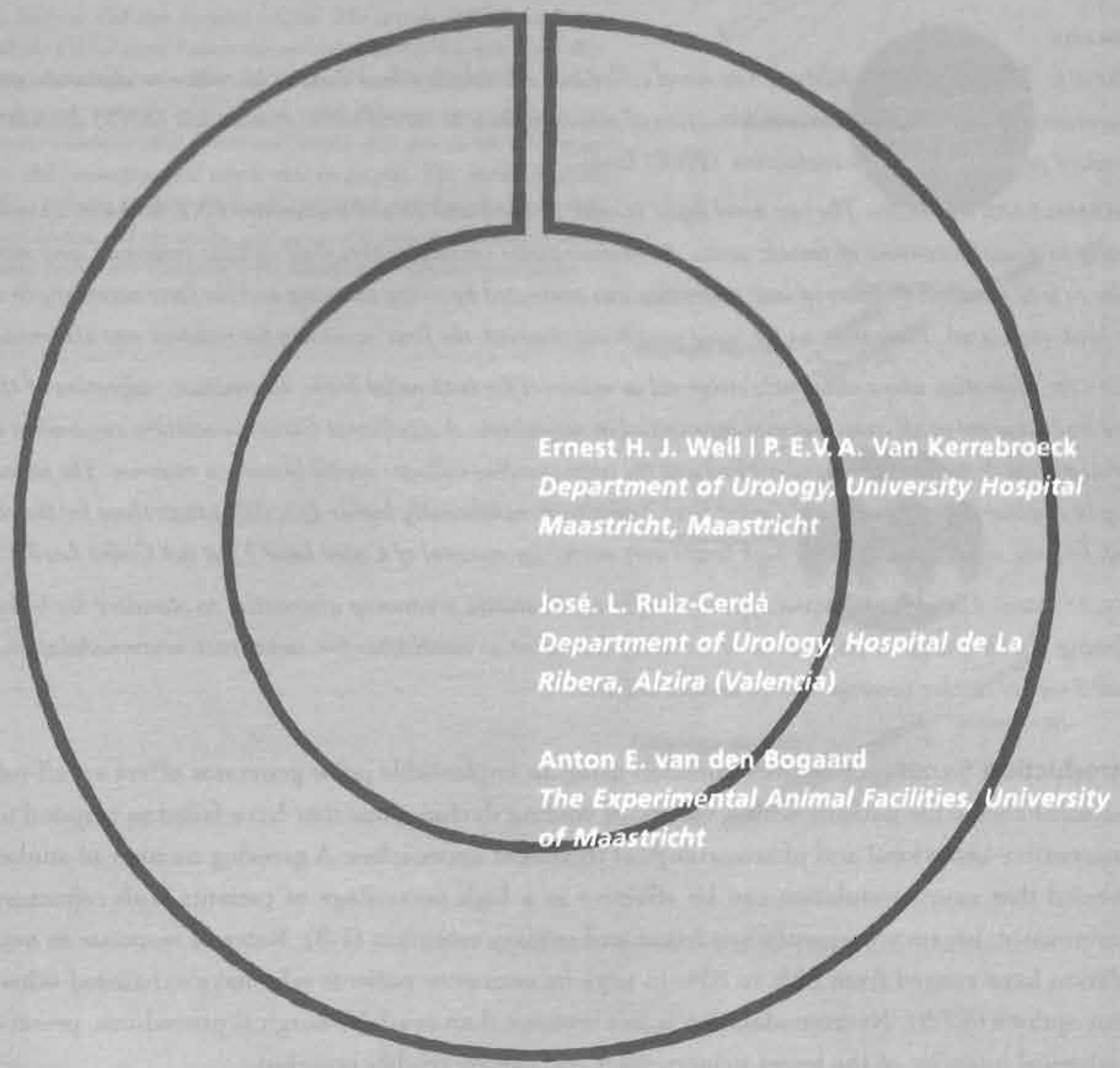

The Journal of Urology 1645551-555, 2000 


\title{
NOVEL TEST LEAD DESIGNS FOR SACRAL NERVE STIMULATION: IMPROVED PASSIVE FIXATION IN AN ANIMAL. MODEL
}

\begin{abstract}
Abstraci

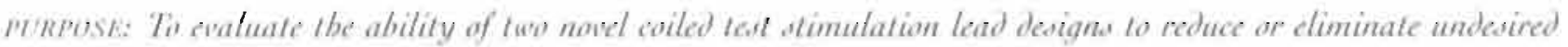

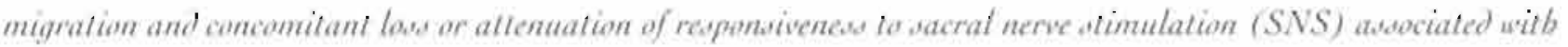

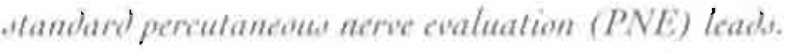

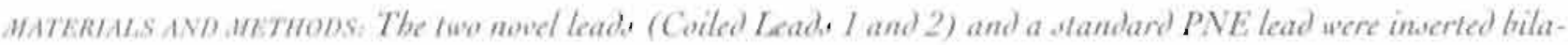

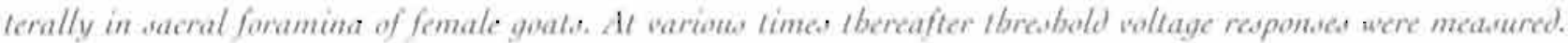
Prior to lead remeval, dustance of lead migration was cvaluated by .r-ray imaging and tbe force mecasary to dieplace

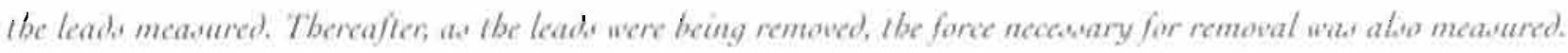

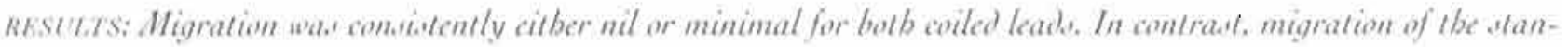

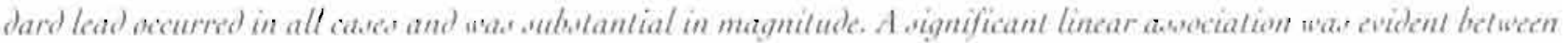

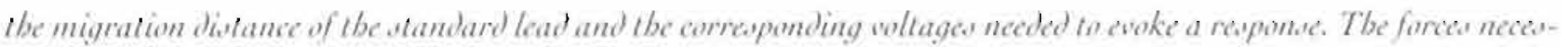

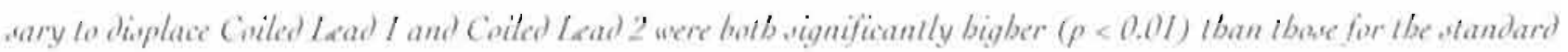

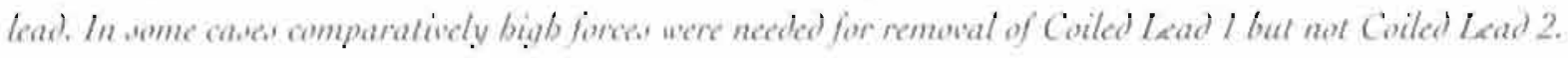

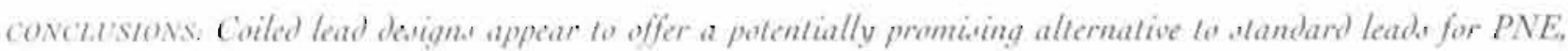
allowing a wider range of patienes to be correctly identified as candidater for sacral root neuromodulation. Coiled Lad 2 meribe furber inverligafion in buman ablects.
\end{abstract}

Introduction Sacral root neuromodulation using an implantable pulse generator offers a well-tolerated treatment choice for patients with a variety of voiding dysfunctions that have failed to respond to more conservative behavioral and pharmacological treatment approaches. A growing number of studies have revealed that neuromodulation can be effective in a high percentage of patients with refractory urge incontinence, urgency/frequency syndrome and urinary retention (1-8). Rates of response to neuromodulation have ranged from $52 \%$ to $83 \%$ in urge incontinence patients who have exhausted orher treatment options $(3,7,9)$. Neuromodulation is less invasive than available surgical procedures, preserves the anatomical integrity of the lower urinary tract and can be readily reversed.

The high success rates of neuromodulation are to an important degree attributable to the identification 
Fig. 1 (a) Standand PNE lead, (b) Coiled Lead I and (c) Coilw Loud

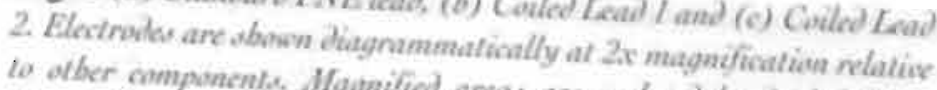

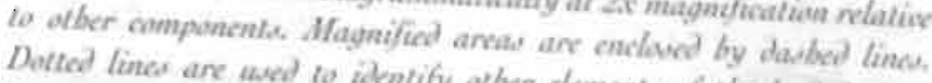

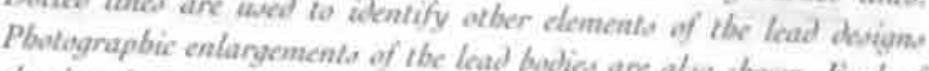

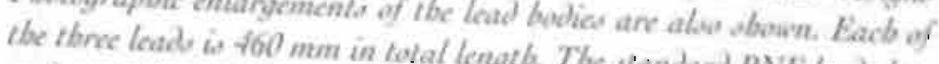

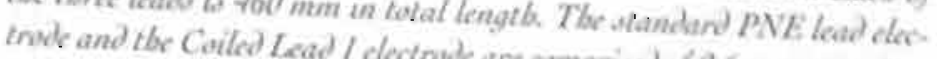
metes straigbl-strand wine forming ane comprivol of 0.6 mm euter diaLoad 2 electrote convists of 0.25 min ang 6 mm in lengrb. The Coiled esenall auter diameler of $0.4 \mathrm{~mm}$ sater dameter wine aviled bo an

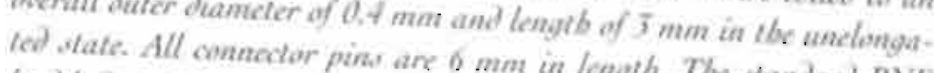

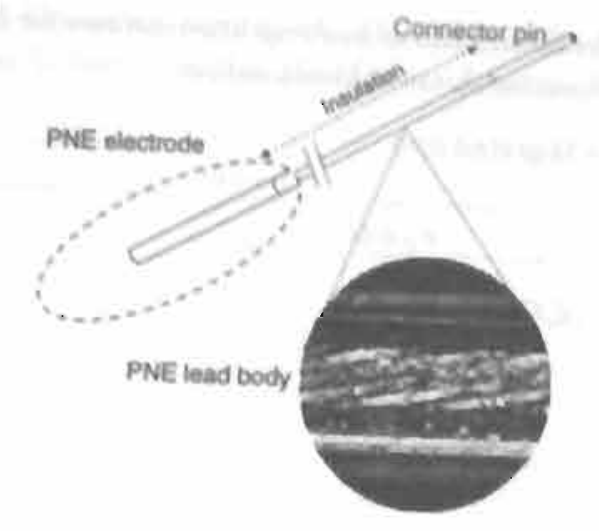
coiled Lad both in outer diameler companed witb $0.6 \mathrm{~mm}$ for vbe tav

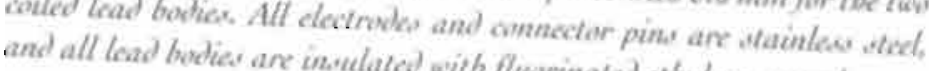

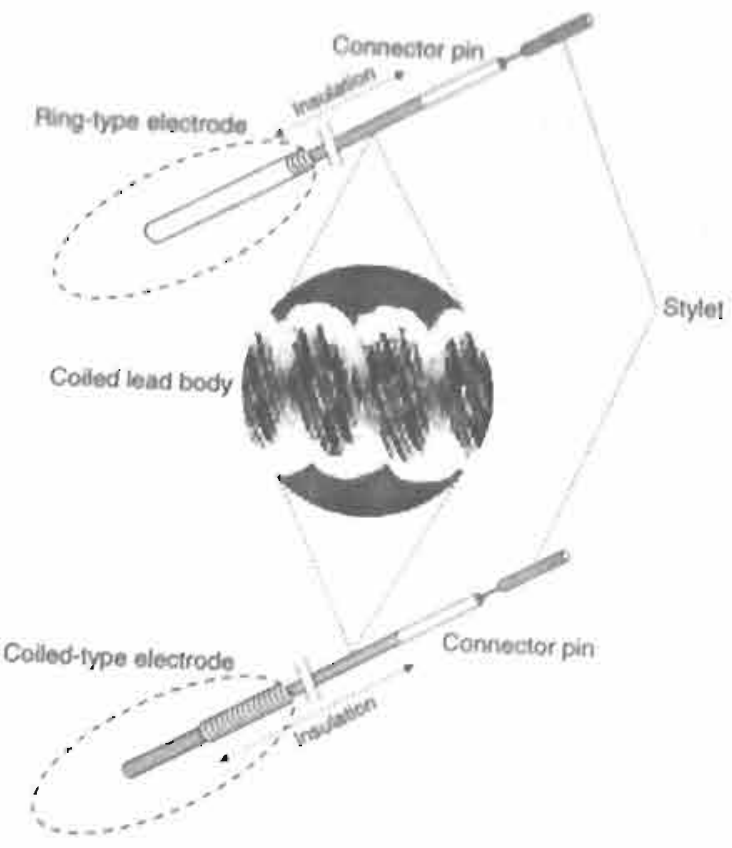




\section{Chapter 9}

Fig. 2. Dot density plot of lead mignation distance for cacts of tbe tbree tested lead derigns. Each apen circle indivater a single migration distance deternumal ion.

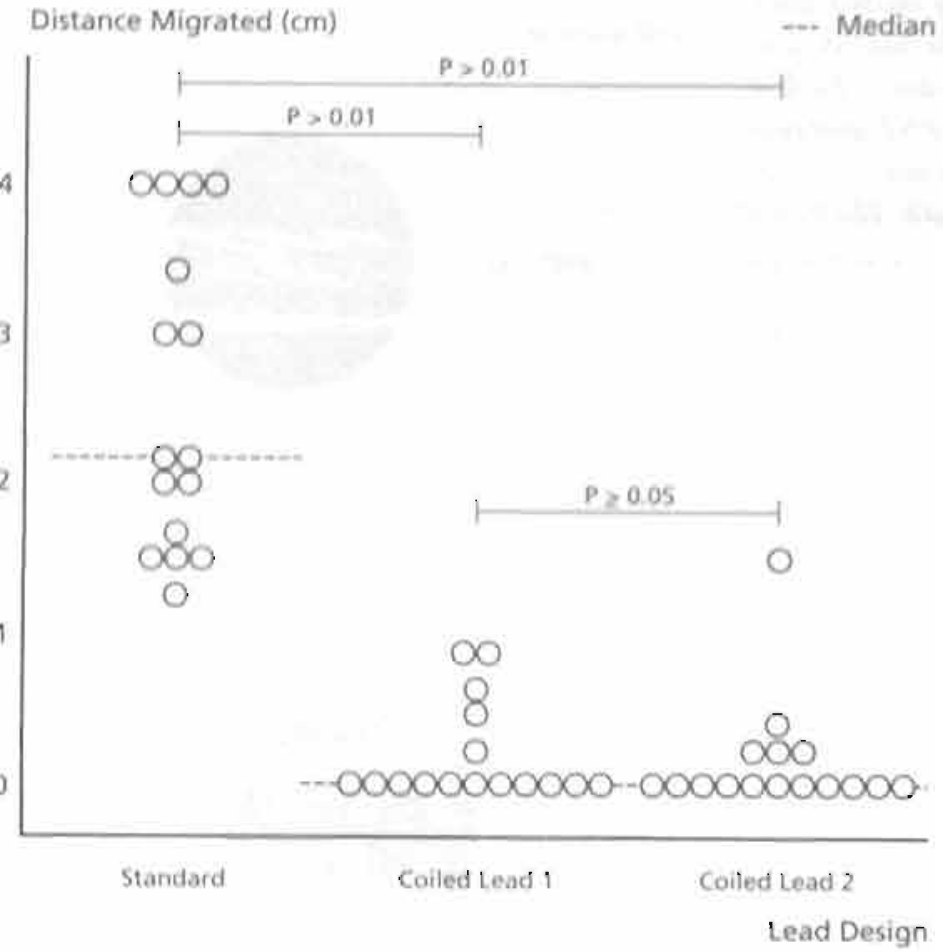

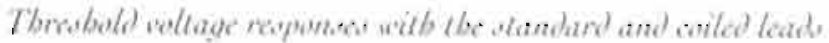

\section{Threshold Response (vo/ts)}

Lead

\begin{tabular}{lllr} 
& $n$ & Median & \multicolumn{1}{c}{ Range } \\
& & & \\
Standard & 42 & 1.0 & $0.5-10.0$ \\
Coiled Lead 1 & 42 & 1.0 & $0.5-3.5$ \\
Coiled Lead 2 & 42 & 1.0 & $0.5-2.0$
\end{tabular}




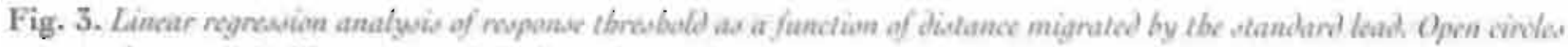

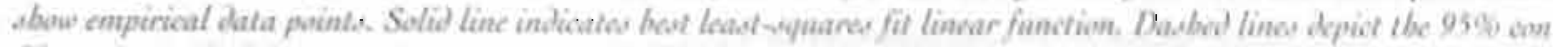
fidence interval of the regrewion.

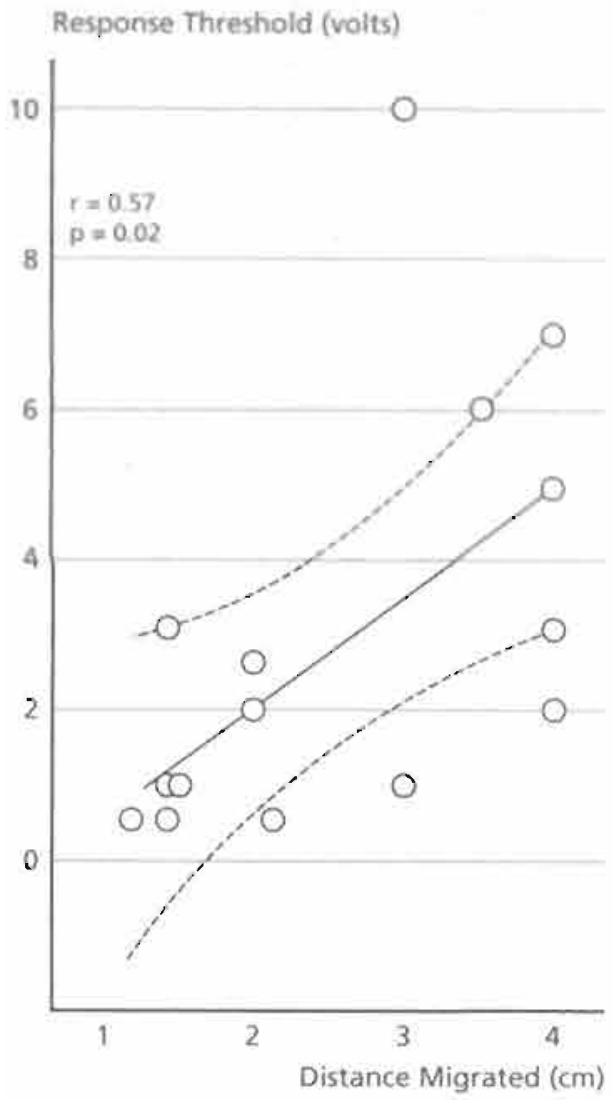

of suitable candidates during a pre-implant percutaneous nerve evaluation (PNE) procedure (10). PNIE entails the use of a temporary sacral foramen lead coupled to an external stimulator. PNE affords the only predictor of success available to the clinician and is an integral part of neuromodulation therapy. Fifty to sixty percent of candidates are usually judged to have responded sufficiently during PNl: ( $>50 \%$ decrease in symptoms) to be considered for implantation. 1 I-13 Failure to respond to the PNE stimulation test can be due to a number of factors. One known cause of unsatisfactory test stimulation results is the migration of the test leads away from the optimal position for stimulation in the sacral foramina.11 In a standard PNE stimulation test, a lead with an electrode at its distal end is inserted 


\section{Chapter 9}

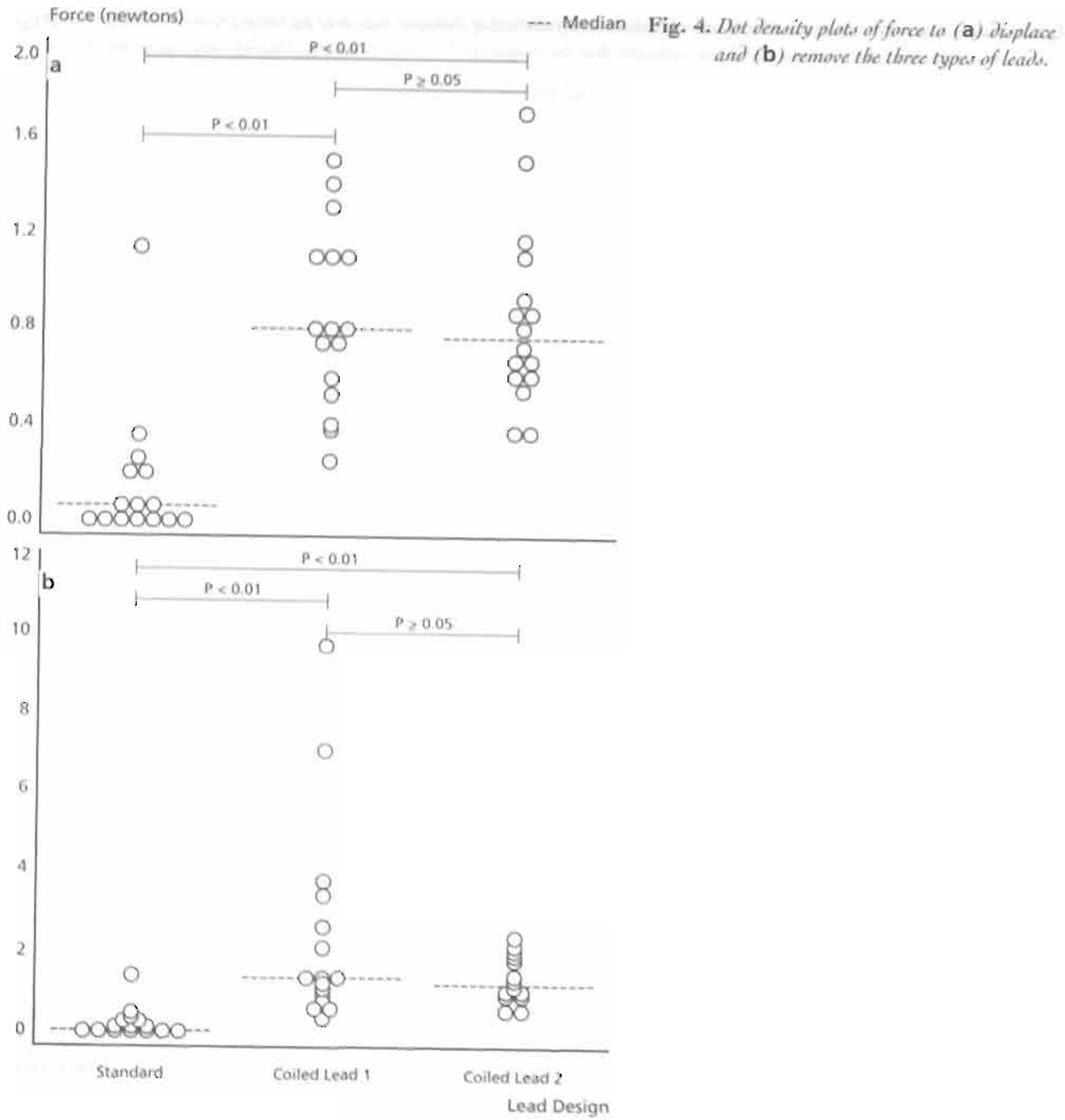


and positioned by threading through a testing needle. Once the needle is removed, the lead is secured to the skin with adhesive tape and then connected to the external stimulator. The unanchored electrode end of the lead is vulnerable to migration resulting from movements in the tissue between skin and bone. In a recent study 8 of 10 patients initially failing to achieve more than a $50 \%$ reduction in symptoms during PNE with standard leads responded satisfactorily after substitution of leads that were anchored to the sacrum with fixation sutures. (11)

Current PNE temporary screening leads embody a straight-wire design. Two novel test stimulation leads with a coiled, pliable design have been developed. The present study evaluated in a goat model system the ability of these novel designs to provide superior passive fixarion compared with standard leads. A comparison of the forces necessary for lead displacement and removal was also conducted.

\section{Materials and methods}

Animals Leads were evaluated in 8 female adult Dutch Landrace goats of average weight $40 \mathrm{~kg}$ under. an experimental protocol approved by the Ethical Committee for Animal Experimentation of the University of Maastricht, Maastricht. The Netherlands. Goats were housed individually in indoors pens at $20^{\circ} \mathrm{C}$ with a 12 hilight cycle and received food and water ad libitum. Goats were judged to provide a suitable experimental model because of the similarity of caprine and human sacral size and anatomy .

Lead Designs The ability of three lead designs to apply s a cral nerve stimulation (SNS), resist migration and allow easy removal were compared: two novel coiled !eads (Coiled Leads 1 and 2) obtained from Medtronic Bakken Research Center: Maastricht. The Netherlands, and a standard PNE lead (Model 041830, Medtronic, Inc., Minneapolis, MN, USA). The standard lead is an insulated straightstrand wire design (FIG. I(a)). Coiled Leads 1 and 2 are composed of pliant insulated coiled-strand wire, differing only with respect to the distal electrode type: namely, ring-type (FIG, l(b)) and coiltype (FIG. 1(c)), respectively. Both coiled lead designs include a stylet in the center of the lead in order to facilitate initial positioning of the lead in the foramen.

Lead Insertion and Stimulation Leads were inserted bilaterally in sacral foramina S2, S3 and S4, two leads of each type per goat. In each goat, the standard PNE lead was inserted in the left S2 and S3 


\section{Chápter 9}

foramina, Coiled Lead 1 in the right S2 and left S4 foramina, and Coiled Lead 2 in the right S3 and S4 foramina. For lead insertion and periodic monitoring of lead position by $x$-ray imaging, goats were anesthetized with $0.5 \mathrm{~mL}$ of $20 \mathrm{mg} / \mathrm{mL}$ xylazine IM. At the end of the procedure xylazine anesthesia was reversed by injecting $0.5 \mathrm{~mL}$ of $5 \mathrm{mg} / \mathrm{mL}$ atipamezole hydrochloride IM.

A $9 \mathrm{~cm}$ long 20 gauge insulated needle (Model 041828, Medtronic, Inc.) was initially inserted in each foramen for acute stimulation testing. Electrical current was applied with an external test stimulator (Model 3625 Screener, Medranic, Inc.) to the needle in increments until a visible muscle motor response was obtained. In goats, visible motor responses upon SNS are comprised of an upper leg response for foramen S2, an anal and tail response for S3 and primarily a tail response for S4. Stimulation was applied at $15 \mathrm{~Hz}$ and a pulse width of $210 \mu \mathrm{s}$. A $1 \mathrm{~cm}$ vessel dilator was positioned in the rectum as a ground.

Afer suecessful acute stimulation confirmed that the needles were properly positioned, the coiled and standard leads were inserted intot the foramina through the needles. Each lead was initially tested with the needle still in situ. Thereafier, the needles and, in the case of the coiled leads, also the stylets. were carefully removed so as to avoid lead displacement. The external sections of leads were attached with adhesive tape to a cotton drape secured to the skin with sutures. The leads were then fully enclosed in the cotton drape to protect them from damage during the post-insertion period of the study. A lateral $x$-ray image was obtained to establish the initial positions of the leads in the foramina to a line. ar precision of $0.1 \mathrm{~cm}$.

Post-Insertion Follow-up Evaluations The inserted leads remained indwelling for 1,3,7 and 21 days in 1,3,2 and 2 goats, respectively, and at each of these time points threshold voltages to achieve reflex motor responses at all indwelling leads were determined using the external test stimulator. After induction of anesthesia but prior to lead removal, distance of lead migration was evaluated by $\mathrm{x}$-ray imaging and the force necessary to displace the leads measured by Chatillon* Digital Force Gauge (Mode! DFGS, AMETEK, Inc., Largo, Florida, USA). Larger displacement forces are indicative of greater potential resistance to migration. Thereafter, as the leads were being removed, the force necessary for removal was also measured. Because in clinical PNE testing leads are intended solely for temporary use, it is important that they be easily removable with minimal porential for rissue damage. Smaller removal forces suggest comparative ease of lead removal. 


\section{Chapter 9}

Data Analysis Data were analyzed using SPSS 9.0 statistical software (SPSS, Inc., Chicago, 11linois, USA) and SigmaStat 2.03 (SPSS, Ine.). The significance of differences in migrarion distance and force of lead displacement and removal was evaluated by Kruskal-Wallis one-way analysis of varian* ce on ranks with multiple pairwise comparisons using Tukey test. The relationship between migration distance of the standard lead and threshold response voltage was evaluated by linear regression.

\section{Results}

The study procedures were generally well-tolerated. No serious complications, infections or deaths occurred among the experimental animals, and all experimental determinations were completed as planned.

No statistically significant differences could be demonstrated in measurements of lead migration. threshold response voltage, displacement force or removal force as a function of time over the study follow-up period of 1-21 d. Accordingly, measurements made at various study rime points were pool. ed for analysis.

Lead Migration As shown in FIG. 2, the standard PNE lead migrated in all 16 test determinations (median, $2.1 \mathrm{~cm}$; range, $1.3-4.0 \mathrm{~cm}$ ). In contrast, the median migration of both Coiled Lead I and Coiled Lead 2 was zero. Migration was nil in $69 \%$ of the determinations (11/16) for both coiled leads. Moreover, when migration could be detected, it was minimal in magnitude, as revealed in FIG. 2. Maximum migration was $0.8 \mathrm{~cm}$ for Coiled Lead I and $1.5 \mathrm{~cm}$ for Coiled Lead 2. The standard lead migrated significantly farther than either of the coiled leads ( $p<0.01$ ). There was no significant difference in migration between the two coiled leads.

Threshold Response Voltage The TABLE summarizes the threshold response voltages measured with each of the three leads. With the standard lead up to 10.0 volts were needed to evoke a response, compared with 3.5 and 2.0 volts for Coiled Leads 1 and 2 , respectively. Nevertheless, the median values were the same for the three leads, and no statistically significant differences associated with lead type were evident in threshold response voltages. As indicated above, the standard lead, but neither coiled lead, was subject to frequent and substantial migration. As shown in FIC. 3, larger distances migrated by the standard lead were significantly linearly associated with higher threshold respon- 
se voltages. This observation is consistent with the hypothesis that lead migration can result in lack of response during PNE. The data in FIG. 3 reveal that higher voltages were necessary to evoke a response in cases of greater lead migration. However, 9/16 voltage measurements were made in cases of srandard lead migracion $\$ 2.1 \mathrm{~cm}$, and in these cases the median measured threshold voltage was 1.0 volts, likely accounting for the lack of overall significant between-lead voltage difference as indicated in the TABLE.

Displacement Force As shown in FIG. 4(a), the standard lead was compararively easily displaced. In $44 \%$ of the determinations (7/16), displacement was observed at forces below the limit of detection. The median force required for displacement of the standard lead was 0.05 newton (range, 0.00-1.10 newtons). In contrast, both Coiled Lead 1 and Coiled Lead 2 exhibited significantly greater resistance $(p<0.01)$ to displacement than did the standard lead, with median displacement forces of 0.80 newton (range, 0.25-1.50 newtons) and 0.78 newton (range, 0.35-1.70 newtons), respectively. The two coiled leads did not, however, differ significantly from each other in displacement force. The comparative difficulty of displacing the coiled leads provides evidence of their capacity for passive fixation and is consistent with the observation that their migration from the initial insertion site was nil or minimal.

Removal Force Significantly greater force $(p<0.01)$ was required to remove the two coiled leads compared with the standard lead, as indicated in FIG. 4(b). The removal force of the standard lead (median 0.05 newton; range, 0.00-1,10 newtons) was in no case measurably different from the displacement force. There was no statistically significant difference in removal force between Coiled Lead 1 (median 1.05 newtons; range 0.25-9.80 newtons) and Coiled Lead 2 (median 0.98 newton; range: 0.35-1.85 newtons). However, removal forces were more variable for Coiled Lead 1 wirh the ring-type electrode than Coiled Lead 2 with the coil-type electrode (FIG. 4(b)).

\section{Discussion}

Both coiled leads evaluated in the present study exhibited a capacity for passive fixation significantly superior to that of the standard lead. The number of leads that migrated and the distance migrated were both greater with the standard lead. Such lead migration can result in malpositioning of the distal elec. 


\section{Chapter 9}

trode in relation to the spinal nerve, which could require retesting with its attendant expense and inconvenience or could result in false-negative PNE results depriving potentially responsive parients of the benefits of neuromodulation.

Lead displacement from the optimal position for stimulation has been cited by clinical investigators as a major reason for unsatisfactory PNE results. The electrode and lead have been observed to be completely displaced outside the foramen after 1-2 days of sub-chronic testing in some cases (11). In a recent multicenter clinical trial of sacral root neuromodulation for the treatment of urinary voiding dysfunction involving more than 600 patients, frank evidence of lead movement during PNE as reve* aled by $x$-ray imaging was present in approximately $9 \%$ of patients.

In the present study a significant linear correlation was apparent between distance migrated by the standard lead and loss of responsiveness to stimulation, as reflected by comparatively high measured threshold response voltages. This finding provides further support for the conclusion that lead migra* tion can contribute to inaccurate PNE results.

A third of the standard leads required stimulation at $>2$ volts to achieve a response. Generally a perineal muscle response in the range of $0.5-2.0$ volts is preferred for clinical PNE testing (14). This voltage range ensures an adequate space between the nerve and the electrode and minimizes pressure on the nerve, maintaining patient comfort during stimulation. In the present study only a single coiled lead required a threshold voltage $>2$ volts.

Although the average time of sub-chronic testing is generally 3-5 days, temporary testing has been reported over a period of weeks (15). With increased time, the possibility of displacement or local fibrosis between the electrode and target nerve could be expected to increase. However, no significant relationship between time of implantation and either displacement or threshold stimulation voltage could be demonstrated in the present study.

The advantage of superior passive fixation afforded by the coiled lead designs needs to be considered in light of the possible limitation of difficult removal after PNE testing or even unintended tissue damage while attempting removal. The standard PNE lead requires very little force to remove: > 60\% of the standard leads required $<0.05$ newton. Both coiled leads require significantly more force to remove. However, the median removal force for these novel leads was less than I newton, and it appears unlikely that this magnitude of removal force would pose difficulties of clinical significance. Nevertheless. Coiled Lead I appeared to be associated with greater variability in removal force needed and possibly greater potential for tissue damage or other complications. Consequently. Coiled 
Lead 2 appears to hold greater promise as a practical alternative to standard leads.

Another potential disadvantage of the coiled leads is that, because of their pliancy, they cannot be repositioned once the stylet is removed. Moreover, after removal the stylet cannot be re-inserted into the lead. Therefore, care must be taken to position the coiled leads precisely at the optimal site for stimulation and avoid displacing them during stimulation procedures. The relatively stiff standard leads can be repositioned to a limited extent in the foramen should the need arise.

Other approaches such as bilateral stimulation, tunneled temporary leads or surgical implantation of the lead used in chronic SNS have been advocated as alternatives to the current methods of PNE testing $(11,15,16)$. These approaches are unfortunately considerably more invasive than conventional PNE. Coiled leads such as those investigated in this study might allow PNE testing to be improved in accuracy without recourse to more involved, invasive or costly alternatives.

\section{Conclusions}

Coiled lead designs appear to hold promise for improving the ability of PNE resting to identify correctly patients likely to benefit from sacral root neuromodulation. These novel leads can be effective in applying SNS via the sacral foramina with reduced likelihood of subsequent loss of responsiveness to stimulation resulting from lead migration. One of the two novel leads evaluated in the present study could also be consistently removed without difficulty. This new lead merits further investigation in human subjects.

\section{Acknowledgement}

The technical assistance of Joyce Suyck and May Bost of the University of Maastricht. Maastricht, The Netherlands, is gratefully acknowledged. Also acknowledged with appreciation are the contributions of Diederik Keizer, Ubi van den Hombergh, Antoine Camps and Victor Duysens of the Medtronic Bakken Research Center, Maastricht. The Netherlands, who participated in many helpful discussions regarding the design and conduct of this investigation and supplied the leads evaluated in the study. This work was supported by a grant form the Urologic Scientific Foundation of the University of Maastricht, Maastricht. The Netherlands (WAMU1. 


\section{REFERENCES}

1. Tanagho, E. A Principles and indications of electrostimulation of the urinary bladder. Umolege (A), 29:185. 1990.

2. Thon, W. F., Baskins, L. S., Jonas, U., Tanagho, E. A. and Schmidt, R. A. Neuromodulation of voiding dysfunction and pelvic pain. Werld / l'nol, 9:138, 1991.

3. Dijkema, H. E., Weil, E. H., Mijs, P. T. and Janknegt, R. A: Neuromodulation of sacral nerves for incontinence and voiding dysfunctions. Clinical results and complications. Eur U/nol, 24:72, 1993.

4. Hohenfellner, M., Matzel, K. E., Schultz-Lampel, D., Dahms, S., Schmidt, R. A., Tanagho, E. A. and Thuroff, J. W. Sacral neuromodulation for treatment of micturition disorders and fecal incontinence. In: Intwation in l'molagic Saryery. Edited by R. Hohenfellner, A. Novick and J. Fitchner: Oxford: ISIS Medical Lid., Pp, I30 (Chapter 3), 1997.

5. Goodwin, R. J., Swinn, M. J. and Fowler, C. J. The neurophysiology of urinary retention in young women and its treatment by neuromodulation. World f U rol, 16:305, 1998.

6. Shaker, H. S. and Hassouna, M. Sacral root neuromodulation in idiopathic nonobstructive chronic urinary retention...) (Trol, 159:1476, 1998.

7. Weil, E. H., Ruiz-Cerd, J. L., Eerdmans, P. H., Janknegt, R. A. and Van Kerrebroeck, P. E. Clinical results of sacral neuromodulation for chronic voiding dysfunction using unilateral sacral foramen electrodes. Ilorld f l/wol, [6:313. 1998.

8. Weil, E. H. J., Ruiz-Cerd., J. L., Eerdmans, P. H. A., Janknegt, R. A., Bemelmans, B. L. H. and van Kerrebroeck, P. E. V. Sacral root neuromodulation in the treatment of refractory urinary urge incontinence; a prospective ran domized clinical trial. Eur Uml, in press.

9. Bosch, R. and Groen, J. Unilateral sacral (S3) segmental nerve stimulation (neuromodulation) in patients with urge incontinence due to detrusor instability or hyperreflexia: correlation between symptomatic and uro dynamic results. Lur Ltol, 33 (suppl 1):61, 1997.

10. Schmidt, R. A., Senn, E. and Tanagho, E. A.: Functional evaluation of sacral nerve root integrity. Report of a technique. Uraleggy, 35: 388, 1990.

I1. Janknegt, R. A., Weil, E. H. and Eerdmans, P. H. Improving neuromodulation technique for refractory voiding dysfunctions: two-stage implant. Cirology, 49:358, 1997.

12. Bosch, 1. L and Groen, 1.: Sacral (S3) segmental nerve stimulation as a treatment for urge incontinence in patients with detrusor instability: results of chronic electrical stimulation using an implantable neural pros thesis. I Cirol, 154:504, 1995.

13. Van Kerrebroeck, P. E. V., Noland, W., Rosier, P., Wijkstra, H. and Debruyne, F. Is percutaneous sacral nerve stimu- 


\section{Chapter 9}

Lation a screening tool in lower urinary tract dysfuncrion? Eur Unol, 30: 236, 1996.

14. Schmidt, R. A. Clinical value of neuromodulation: a urological viewpoint. In: Female Urology. Edited by S. Raz. Philadelphia: W. B. Saunders Company. pp. 643, 1996.

15. Everaert, K., Plancke, H., Lefevere, F. and Oosterlinck. The urodynamic evaluation of neuromodulation in patients with voiding dysfunction. Br.J Urol, 79:702, 1997.

16. Hohenfellner, M., Schultz-Lampel, D., Dahms, S., Matzel, K. and Thuroff, I. W. Bilateral chronic sacral neuromodu tation for treatment of lower urinary tract dyafunction. J Urol, 1602821, 1998. 


\section{CHAPTER 10 BUTTOCK PLACEMENT OF THE IMPLANTABLE PULSE GENERATOR: A NEW TECHNIQUE FOR SACRAL NERVE STIMULATION}

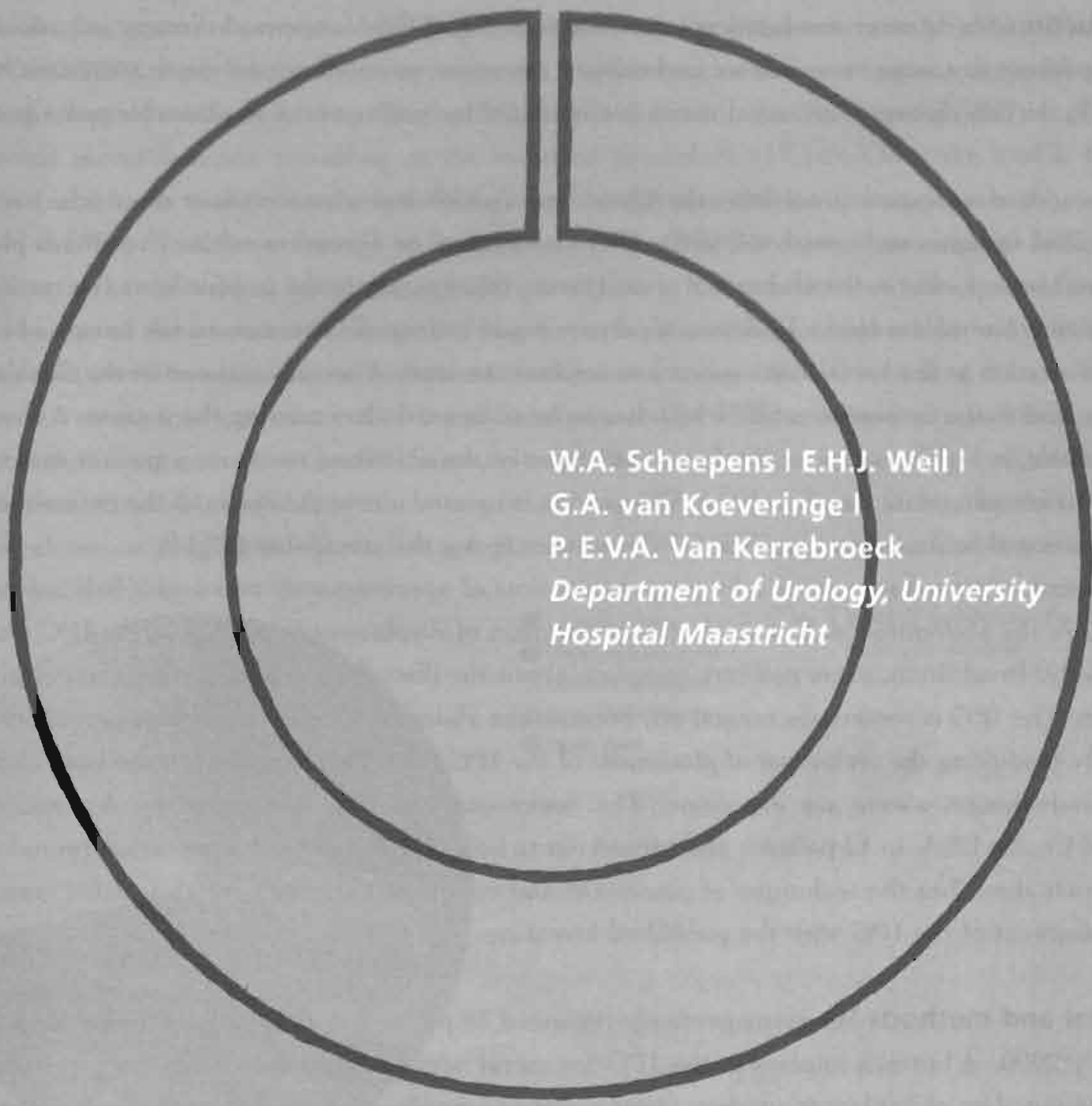

Submitted for publication 


\section{BUTTOCK PLACEMENT OF THE IMPLANTABLE PULSE GENERATOR: A NEW TECHNIQUE FOR SACRAL NERVE STIMULATION}

Introduction Sacral neuromodulation is an established and FDA approved therapy in patients with urgency-frequency, urge incontinence and urinary retention, in whom conservative treatment has failed $(1-12)$. In this therapy: the sacral nerve is stimulated by means of an implantable pulse generator (IPG).

In the standard operation procedure, the Quad-lead (which is a wire with four electrodes) is placed in the sacral foramen and connected to the IPG by means of an extension cable. The IPG is placed in a subcutaneous pocket in the abdominal area. During this operation, the patient has to be turned from a prone to a lateral decubitus position, reprepared and redraped. Three incisions have to be made. First an incision at the level of the sacrum to implant the lead. A second incision in the flank to connect the lead to the extension cable, which has to be re-opened after turning the patient. A third incision is made in a skin crease in the lower quadrant of the abdomen to create a pocket that is large enough to accommodate the stimulator. This pocket is created above the fascia of the external oblique muscle, using this fascia as an anchor for the sutures fixing the stimulator $(13,14)$.

This operation procedure entails a long operation time of approximately two-and-a-half hours. With the IPG in the abdominal wall, some patients complain of displacement or pain at the IPG site postoperatively. In addition, some patients complain about the disturbing magnetic fields at certain shop counters. The IPG is sometimes turned off, because the abdominal region is in close proximity to this field. By modilying the technique of placement of the IPG from the abdominal to the buttock region. the disadvantages above are overcome. This technique was first performed by A. Das, Albany Medical Centre USA, in 13 patients and turned out to be a safe technique for sacral neuromodulation. This article describes the technique of placement and compares the results of abdominal versus buttock placement of the IPG with the published literature.

Material and methods We retrospectively reviewed 39 patients undergoing, between August 1999 and July 2000, a buttock implant of the IPG for sacral nerve modulation. Birth-date, indication for implantation, date of implantation, direct postoperative complications, late complications, current status and the patients' satisfaction with their IPG's were obtained during postoperative consultation by 
their urologist. All patients were implanted using the same technique. The implantation is performed under general anaesthesia, in different hospitals (see acknowledgements) by the same surgical team. After administration of prophylactic intravenous antibiotics, the patient is positioned in a prone decubitus position, with 30 degrees anteflexion of the hips and 30 degrees flexion of the knees. The lower back, flanks, buttocks are prepared and draped sterile, using a transparent vertical sheet (Molnlycke model 826020-21). Both feet and the perineum are exposed under this transparent drape in order to observe the typical motor reactions. The lead (Medronic quadripolar lead, model 3080 ) is placed in the selected sacral foramen according to the standard procedure $(13,14)$. Once the lead is fixed, a transverse incision is made over the lateral-superior quadrant of the buttock approximately $5-10 \mathrm{~cm}$ caudal to the iliac erest, large enough to accommodate the IPG (Medtronic quadripolar IPG, model 3023). The pocket is created by means of blunt dissection in the subcutancous fat, below Camper=s fascia. The size of the pocket is sufficient if 3 digits can be inserted. The lead is then tunneled subcutaneously, between the sacral wound and the buttock wound using a special tunneling device. The lead is connected to the lead extension of $10 \mathrm{~cm}$ (Medtronic, model 3095) mechanically and isolated. The lead-extension is connected to the IPG mechanically. The surplus wire is coiled up behind the IPG, which is then inserted into the subcutaneous pocket, with the inscripted part facing the skin, in order to allow telemetric programming. In buttock placement of the IPG only a short lead extension of 10

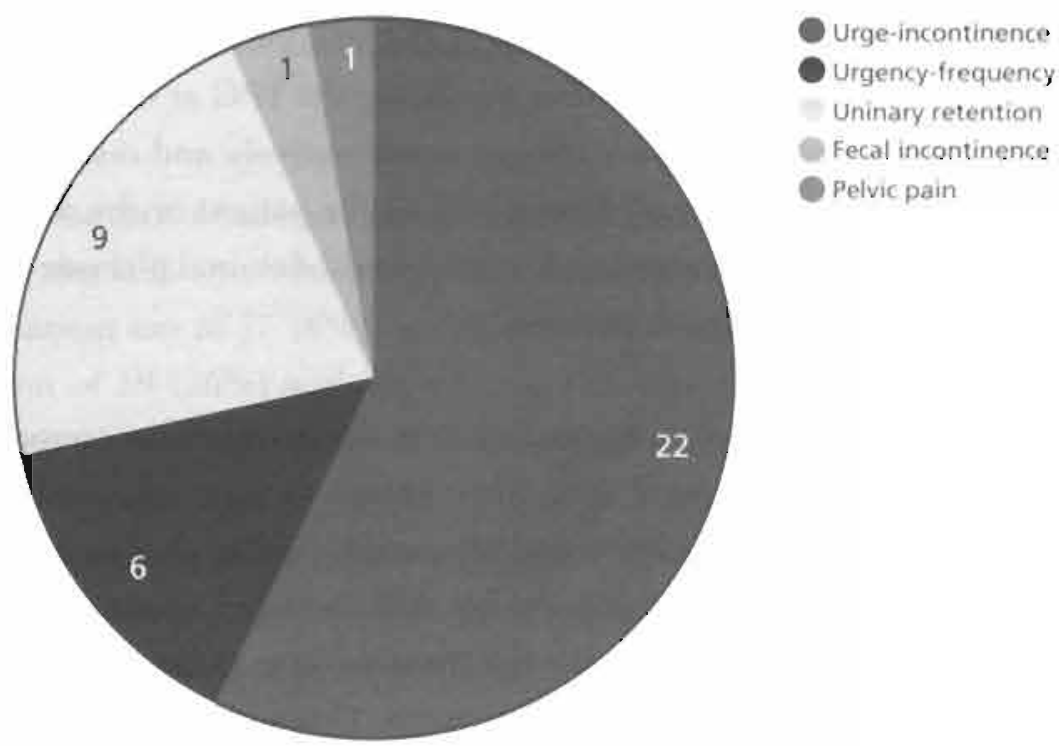

Fig. I Palient indicationd for ataial nenvestimalation 
$\mathrm{cm}$ is used to reduce coiling of the wire behind the IPG. The IPG is connected to the extension cable and placed into this pocket. The wound is flushed with antibiotics and carefully closed in two layers.

Results The average age of the patients was 51 years (range $33-72$ years). Of these 39 patients, 22 were diagnosed with urge-incontinence, 6 with urgency-frequency syndrome, 9 patients with urinary retention, I with pelvic-pain syndrome and I with faecal incontinence (fig. I). In two of these patients, the IPG was repositioned from the abdominal position to the buttock on account of abdominal discomfort. The average follow-up time was 5.3 months (range $1-10$ months). Operation time for the implantation of the neuromodulation system with the IPG in the buttock was approximately $1-1.5$ hours. No repositioning of the patient is required during surgery using the buttock implant technique with respect to the IPG. Only two instead of three incisions have to be made, i.e. an incision in the flank is not needed anymore. Merely a short subcuraneous runnel is required to connect the lead at the level of the sacrum to the IPG at the level of the buttock.

During follow-up, ranging from 1 to 10 months, 4 patients had some pain/discomfort at the level of the IPG implant site (11\%), which was treated with simple oral analgesics (e.g. paracetamol) postoperatively, if necessary. In none of them a re-operation was required to replace the IPG. After 6 months, follow-up 3 out of 18 patients $(17 \%)$ had some pain/discomfort at the level of the IPG, which needed no further treatment. This accounts for $8 \%$ of the total group of 38 patients. Two patients were seen with a postoperative hematoma $(5 \%)$. One hematoma was located at the level of the IPG in the buttock, the other hematoma was scen at the abdominal region after removing the IPG at that level and placing it at the level of the buttock. These hematomas were treated conservatively and resolved completely. In this study, no infections were seen. No problems were noted by the patient or the physician concerning the programming of the IPG. The two patients with a previous abdominal placement of the IPG, reported no complaints and preferred the buttock position.

Discussion Sacral nerve stimulation is an exciting method for urologists as it offers treatment opportunities for patients for whom no treatment was available until now. This therapy is especially useful in patients with urge incontinence which is resistant to medication and idiopathic voiding dysfunction (15). As has been described by Siegel (13), the implantation technique for this therapy had some disadvantages that were mentioned previously. Weil et al. showed that the main adverse event of sacral nerve stimulation is pain at the implantation site of the IPG in $29 \%$ of patients. This accounts for $42 \%$ 


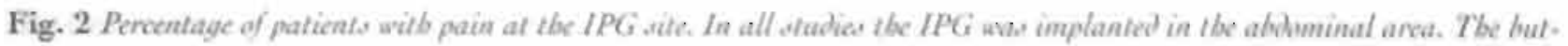

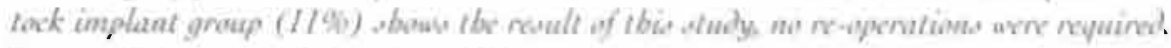

*'e-epenations requined te replace IPG

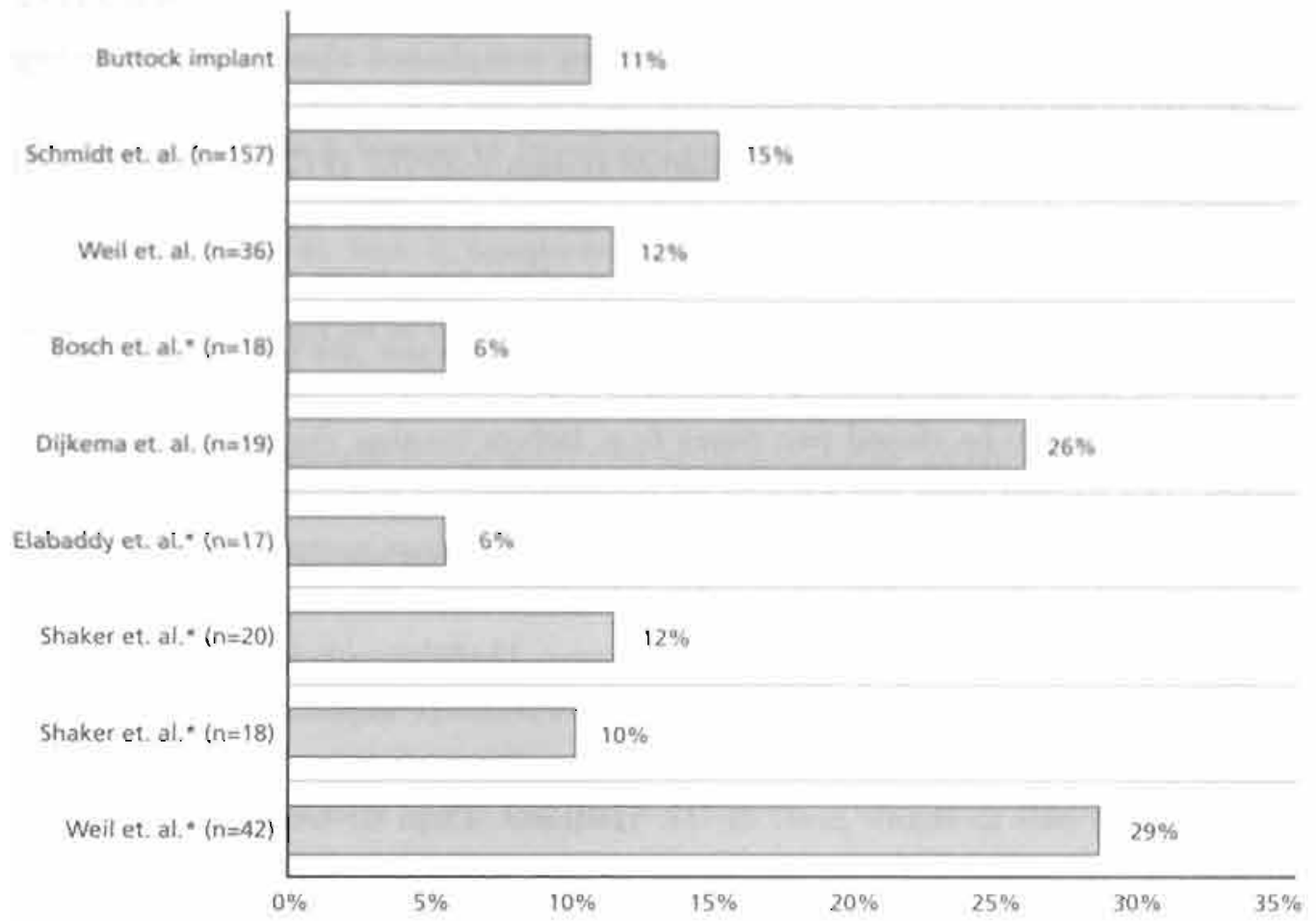

of the total of adverse events noted in that study (16). Shaker and Hassouna noted $10 \%$ and $12 \%$ pain at the IPG site, which resulted in re-implantation of the IPG $(6,9)$. Elabaddy et al, showed pain in 1 patient out of $17(6 \%)$, which resulted in removal of the IPG (7). Dijkema et al, presented 5 patients. out of $19(26 \%)$ with pain at the IPG site. Bosch and Groen showed that ! out of 18 patients $(6 \%)$ experienced pain at the IPG site, which resulted in re-implantation of the IPG (8). Weil et. al. showed in 4 patients out of $36(12 \%)$ with pain at the IPG site, resulting in re-operation (15). Schmidt et al. presented in 83 of 157 patients adverse events, 23 of the patients $(15,9 \%)$ reported pain at the implantation site of the IPG. This resulted in 22 surgeries to reposition the IPG (17).

When these data were combined (fig. 2), a mean of $17 \%$ of patients with pain at their abdominal IPG site was found, which led to a considerably high re-operation rate. In this study, after implantation of 
the IPG in the buttock, 11\% of patients complained about pain at the IPG site. None of these patients needed to be re-operated because of pain at the IPG site over time. The pain at the IPG site seemed to decrease, as at 6 months only $8 \%$ of the patients noted some pain/discomfort at the level of the IPG. Also in these cases no further treatment was needed. One patient complained about a numb feeling around the location of the IPG (3\%) that was not recovered after six months.

The operation time of the implantation of the neuromodulation system with the IPG in the abdominal region is approximately 2.5 hours. Implantation of the neuromodulation system with the IPG in the buttock takes approximately 1.1 .5 hours. This reduction in operation time from approximately 2.5 hours to 1.1 .5 hours is mainly due to the fact that the patient does not have to be turned from a prone to a lateral decubitus position. Only two incisions are needed in this technique in stead of three. The incision in the flank, which needed to be closed two times (e.g. before turning the patient and after surgery), is not necessary. The patient does not have to be reprepared and redraped. In this technique, a short subcutaneous tunnel is needed to connect the IPG to the lead, as compared to the abdominal implantation. Leaving out these factors also teduces the risk of infection. The buttock implantation technique provides advantages to both the patient and to the urologist. Therefore in our opinion this can be considered an improvement for sacral nerve stimulation and the first choice implantation technique.

Aknowledgements We would like to thank prof. dr. H. Hedlund, Dept of Urology, University Hospital, in Oslo, Norway; dr. B. Schurch, Swiss paraplegic centre 'Paracare', Zurich, Switzerland; dr. A. Garbeglio and dr. E. Ostardo, Dept of Urology, Ospedale S. Maria degli Angeli Porderone; dr. A. Molon and dr. M. Pastorello, Dept of Urology, Ospedale Sacro Cuore Don G. Calabria Verona; dr. C. Ratto, Dept of Surgery, Catholic University Largo A. Gemelli. Rome, Italy: prof. dr. J. Nordling. Dept of Urology. Herlev Hospital, Copenhagen, Denmark. Prof. dr. G. Jakse and dr. D. Rohrman, Urologische Kilinik der RWTH-Aachen. Germany.

Conclusion Butrock placement of the IPG in sacral nerve stimulation involves less pain at the IPG implantation site, shorter operation rime, wo instead of three incisions and a shorter subcutaneous tunnel. Patients seem to prefer the buttock position of the IPG. Applying this technique for sacral nerve stimulation is advantageous for the patient and the urologist. 


\section{Chapter 10}

\section{REFERENCES}

1. Kerrebroeck van PEV A treatment algorithm for the overactive bladder. Br.J Und 1999; 83 Suppl. 2:29. 30.

2. Schmidt RA Applications of neurostimulation in urology. Neurourol Urodyn 1988: 7: 85-592.

3. Schmidt RA, Senn E, Tanagho EA Functional evaluation of wacral root integrity: Report of a technique. Urolegy 1990; 35(5):588-392.

4. Thon WF, Baskin LS, Jonas U, Tanagho EA, Schmidt RA Neuromodulation of voiding dysfunction and pelvic pain. World ) Urol 1991: 9:158-141.

5. Dijkema HE, Weil EHJ, Mijs PT, Janknegt RA Neuromodulation of sacral nerves for incontinence and voiding dysfunctions. Clinical results and complications. Eur Uno/ 1993; 24(1):72-6.

6. Shaker HS, Hassouna M Sacral nerve root neuromodulation: an effective treatment for refractory urge incontinence. J Lind 1998; 159(5):1516-9.

7. Elabaddy AA, Hassouna MM, Elhilali MM Neural stimulation for chronic voiding dysfunctions, J Uro/ 1994; 1.52: 2076-2080

8. Bosch JL, Groen J Sacral (S.3) segmental nerve stimulation as a treatment for urge incontinence in patients with detrusor instability: results of chronic electrical stimulation using an implantable neural prosthesis. J Crol 1995; 154(2 Pt 1):504-7.

9. Shaker HS, Hassouna M Sacral root neuromodulation is idiopathic non-obstructive chronic urinary retention. J Thel 1998: 159(5):1476-8.

10. Vapnek J, Schmidt RA Restoration of voiding in chronic urinary retention using the neuroprosihesis, Whild.J Urol 1991: 9: 142-144.

11. De Ridder D, Van Cleynenbreugel B, Baert L Sacral nerve stimulation for female urinary retention: a two year follow-up. Eur lhol 1999; 35:17.

12. Swinn M, Goodwin R, Fowler C Sacral neuromodulation for young women in urinary retention, Fur liwol 1999; 35:17.

13. Siegel SW. Management of voiding dysfunction with an implantable neuroprosthesis. Urol Clin Nortb Am 1992; 19(1):163-70.

14. Thon WF, Baskin LS, Jonas U, Tanagho EA, Schmidt RA Surgical principles of sacral foramen electrode implantation. Wharld J lirol 1991; 9:153-1.37.

15. Weil EHJ, Ruiz Cerda JL, Eerdmans PH, Janknegt RA, Van Kerrebroeck PEV Clinical results of sacral neuromodulation for chronic voiding dysfunction using unilateral sacral foramen electrodes. World f Urol 1998: 16(5): 313-21. 


\section{Chapter 10}

16. Weil EHI, Ruiz Cerda I, Eerdmans PH, Janknegt RA, Bemelmans BL, Van Kerrebroeck PEV Sacral root neuromodu lation in the treatment of refractory urinary urge incontinence: a prospective randomized clinical trial. Eur Ural 2000; 37(2):161-71.

17. Schmidt RA, Jonas U, Oleson KA, et al. Sacral nerve stimulation for treatment of refractory urinary urge incon tinence. Sacral Nerve Stimulation Study Group. J Urol 1999; 162(2):352-7. 
Color illustrations of PNE procedure and implantation of sacral nerve stimulator 


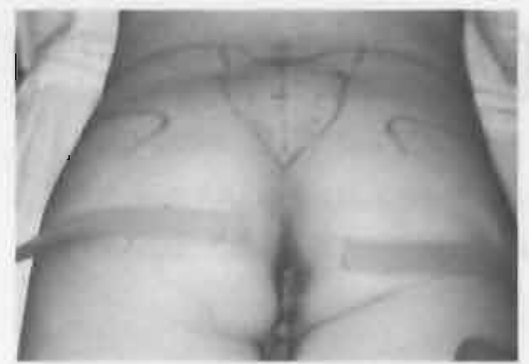

Location of puncture site

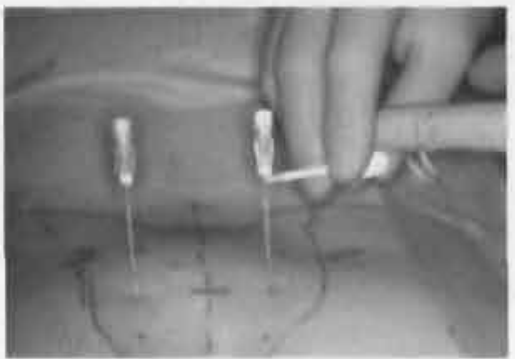

Stimulation of nermo

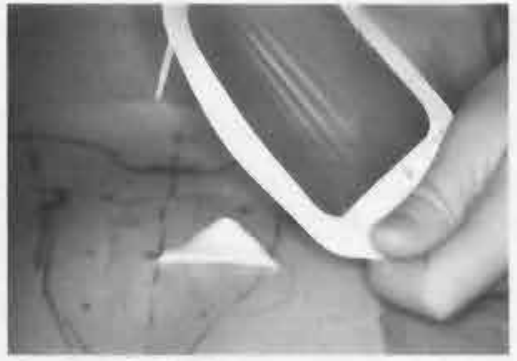

Draping with Tegadlrom

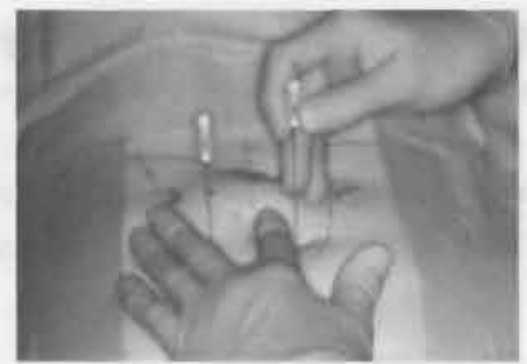

Puncture of fantmicn

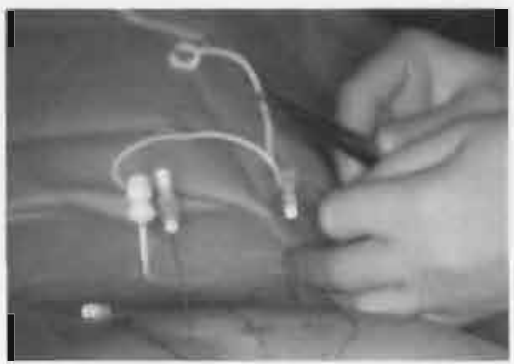

Flactinat inertion

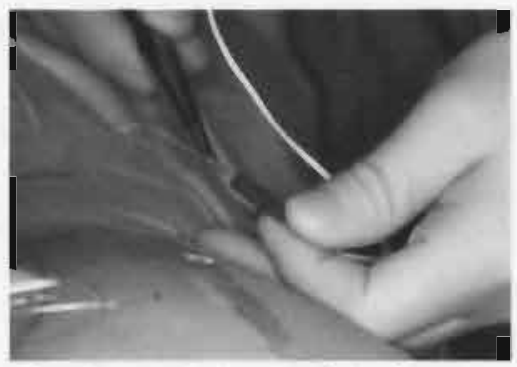

Flowtnot conentiven in external wimulatior

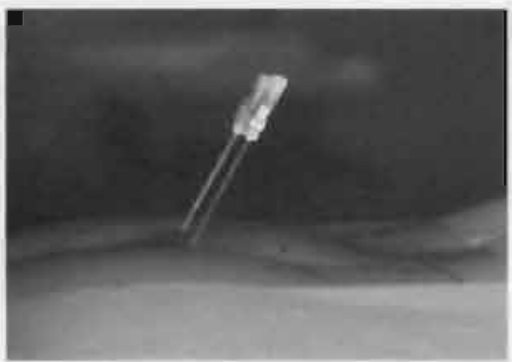

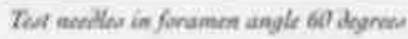

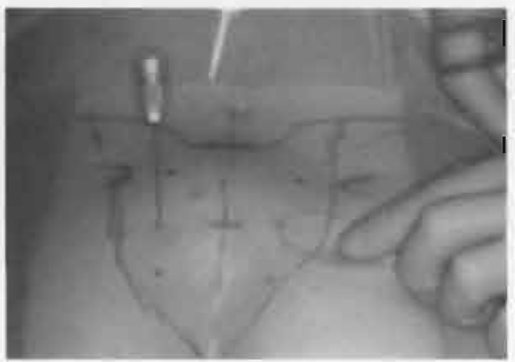

Fixation of eloctront

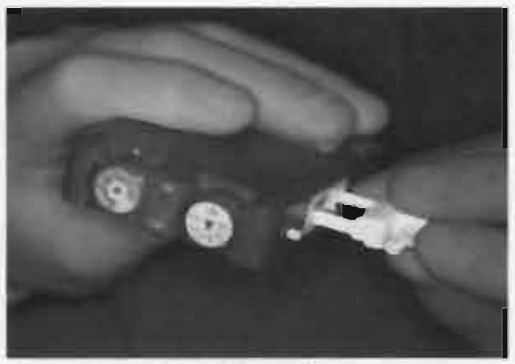

Connection te erternel stimulator 


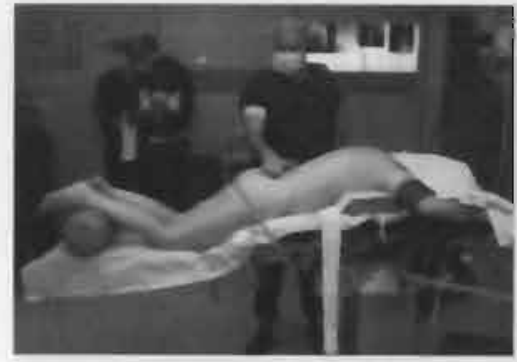

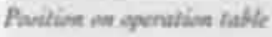

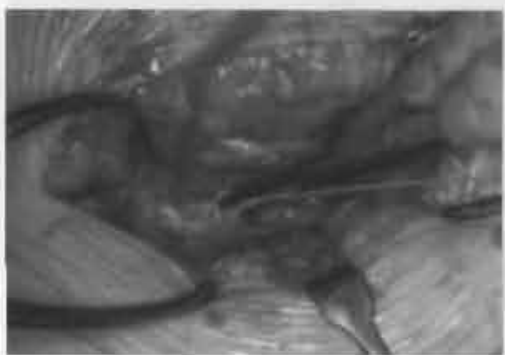

Inerrien of toud in fonamon

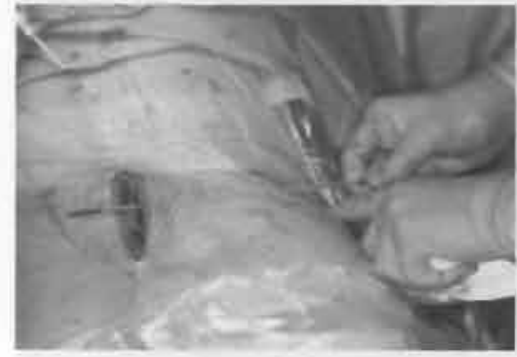

Tannding of latal from milline to buttonk poskd

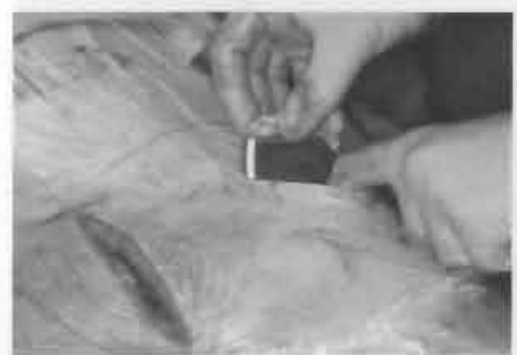

Implantatiar of simalabir in suhvotannow pusted

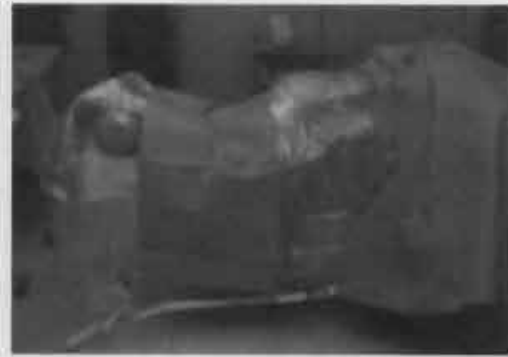

Deapuay of parian!

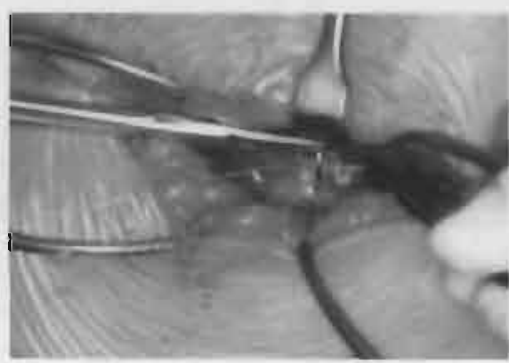

Fination of lead wilb notating nowile

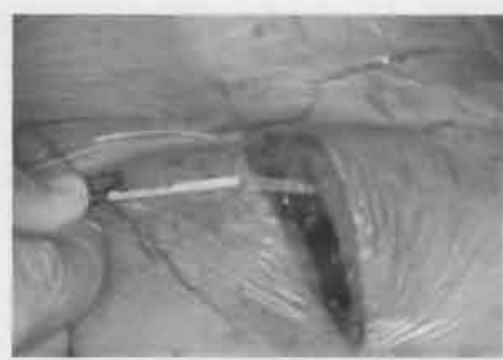

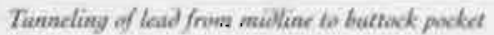

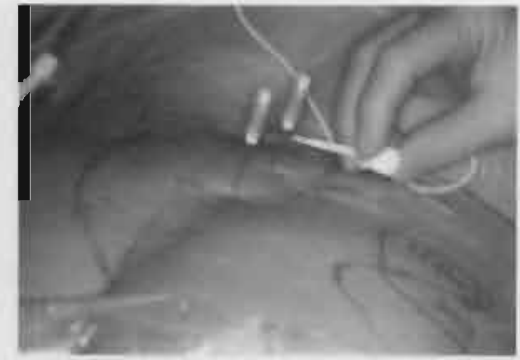

Levalive of formening

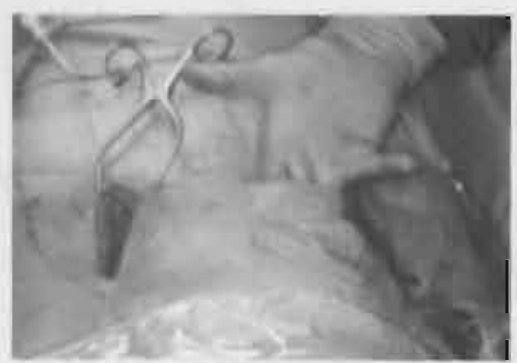

Subvulanouse povkel

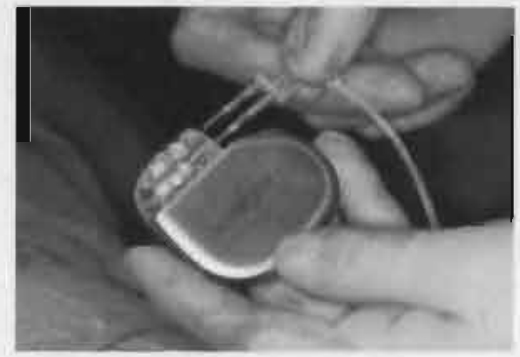

Fivation of extension arble be stimualctior 



\section{CHAPTER 11 SUMMARY AND CONCLUSIONS}

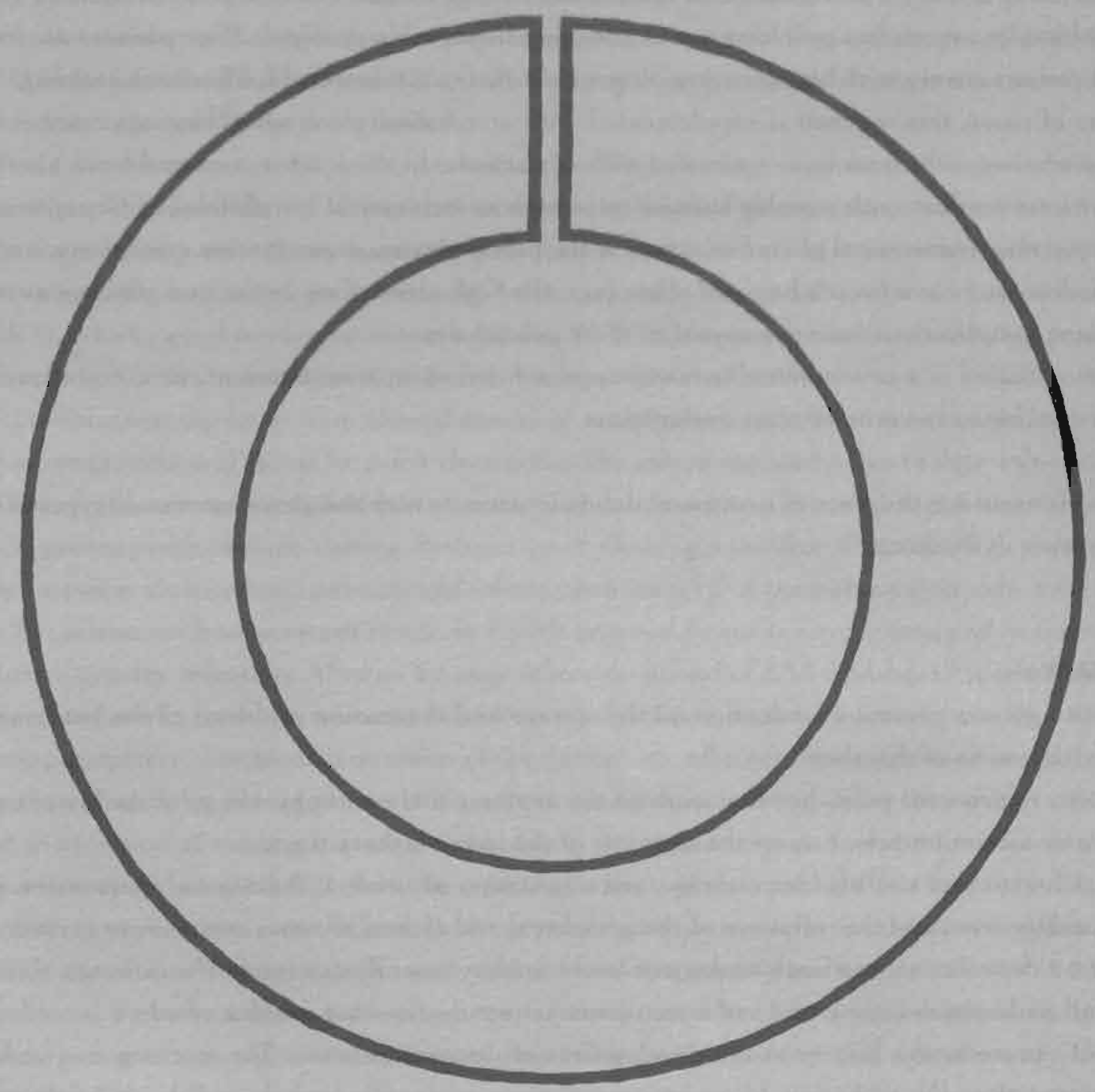




\section{SUMMARY AND CONCLUSIONS}

Chronic lower urinary tract dysfunction such as motor urge incontinence, urgency frequency syndrome and bladder evacuation problems is a challenging therapeutic problem. Most patients are initially treated conservatively with bladder retraining. pelvic floor exercises and biofeedback training. In the majority of cases, this regimen is supplemented with anticholinergic drugs. These approaches fail to yield satisfactory outcomes in an estimated $40 \%$ of patients. In these refractory problems, alternative invasive interventions with variable success rates such as incravesical installations of Capsaicin, bladder transection, transvesical phenol injection of the pelvic plexus, augmentation cystoplasty, and even urinary diversion have been advocated. However, the high rates of recurrent incontinence as well as signilicant complications limit the appeal of these procedures.

Neuromodulation is a new minimal invasive approach based on stimulation of the sacral nerves that aims at treating lower urinary tract dysfunction.

This thesis evaluates the place of neuromodulation in patients with the above mentioned types of lower' urinary tract dysfunction.

\section{SUMMARY}

CHAPTER I gives a general introduction on the storage and evacuation problems of the lower urinary tract and the aims of this thesis.

CHAPTER 2 reviews the published literature on the anatomy and neurophysiology of the lower urinary tract. Affer a brief introduction on the anatomy of the lower urinary tract.

the dual function of the bladder (storage and evacuation of urine), the normal innervation of the lower urinary tract and the influence of the peripheral and central nervous systems are presented.

CHAPTER : describes the pathophysiology of lower urinary tract dysfunction. The different classifications and parhophysiologic entities of lower urinary tract dyslunction are described

CHAPTER a presents the history of the development of neurostimulation. The working mechanism of neuromodulation, the technique of percutaneous nerve evaluation and the technique of permanent implantation are described. 
CHAPTER 5 gives the first clinical results of a feasibility study on neuromodulation of sacral nerves for incontinence and voiding dysfunction. 19 out of 23 patients with an implanted neuroprosthesis for neuromodulation showed a more than $50 \%$ improvement and 14 out of 23 a more than $90 \%$ improvement of their main symptoms after a median follow up of 12 months. In the urge incontinent patients, the number of leakage episodes decreased from 7.4 to $1.5 /$ day and the functional capacity of the bladder increased from 135 to $227 \mathrm{ml}$. Two of the three patients with retention voided without residual urine. Complications were limited.

CHAPTER 6 introduces a new implantation technique. The two-stage implant technique increased the results of neuromodulation. In 10 patients in whom the original percutaneous nerve evaluarion had failed to improve the micturition diary parameters such as the amount of urine voided, the frequency of micturition, the number of pads used, the volume of urine lost and the urge to urinate with more than $50 \% .8$ had a good to very good result (60 \% - $90 \%$ improvement) during the testing period and were implanted with a permanent implant 5 to 14 days after the first stage.

CHAPTER 7 presents the long-term clinical results of sacral neuromodulation for chronic voiding dysfunction using unilatera! sacral foramen electrodes. The aim of the study was to determine the longterm clinical efficacy and complications of neuromodulation with a unilateral sacral foramen electro. de in 36 patients with chronic voiding dystunction. Following a positive effect of a 3 to 4 day pereutaneous nerve evaluation test, patients underwent open surgery. A permanent electrode was implanted in 24 patients with urge incontinence, in 6 with urgency frequency syndrome, and in 6 with nonobstructive urinary retention. After an average follow-up period of 37.8 months, 19 patients $(52.8 \%)$ continued to benefit from the neuromodulation with significant improvement of symptoms and urodynamic parameters. The median duration of the therapeutic effect for the total study population was longer than 60 months. No significant difference in the median duration of the therapeutic effect with regard to sex, type of voiding disorder, or implant pulse generator was found. However, in patients with previous psychological disorders the median duration of therapeutic effect was only 12 months $(p<0.008)$. Complications were limited. In the group of patients in whom the therapeutic effect remained, 37 re-operations had to be performed. Although re-operations were needed to overcome technical problems, patients achieve lasting symptomatic improvement. Special attention is needed with regard to patients with a previous history of psychological dysfunction and sexual abuse. The data indicate that $82 \%$ of these patients showed poor results as compared with $28 \%$ of the patients without a history of psychological disorders ( $P=0.002)$. 
CHAPTER 8 presents the results of a prospective randomized clinical trial of sacral root neuromodulation in the treatment of refractory urinary urge incontinence. Forty-four patients with refractory urge incontinence were randomized to undergo neuromodulation with an implantable impulse generator (21) or to continue with their previous conservative management (23).

At 6 months, the control group was eligible for a crossover to implant. The mean number of leakage episodes, leakage severity and pad usage in the implant group was significantly lowered by $88 \%$ (p< $0.0005) .24 \%(\mathrm{p}<0.047)$ and $90 \%(\mathrm{p}<0.0005)$, respectively, compared to the corresponding control group mean values. Improvements in leakage episodes and pad usage of $>90 \%$ were needed in 75 and $85 \%$ of the implant group. respectively, but in none of the control group. One-third of implanted patients, bus none of the control patients, achieved. $.50 \%$ improvement in leakage severity. Over half of the implanted patients $(56 \%)$ were completely dry compared with only 1 control patient $(4 \%)$. Implant patients, but no control patients, exhibited significant improvement with respect to two quality-of-life measures. Neuromodulation resulted in increases of $220 \%(\mathrm{p}<0.0005)$ and $39 \%(\mathrm{p}<0.013)$. respectively, in urodynamically assessed bladder volume at first contraction and maximum fill. At 36 months, the actuarial rate of treatment failure was $32.4 \%(95 \% \mathrm{Cl}, 17.0-56.0 \%)$. Adverse events most frequently involved were pain at implant site, although the incidence of serious complications was low. We conclude that neuromodulation is markedly more effective than conservative management in alleviating symptoms of refractory urge incontinence. Quality of life and urodynamic function also improve. The effects of neuromodulation are long lasting, and the associated morbidity is low.

CHAPTER 9 presents the evaluation of the ability of two novel coiled test stimulation lead designs to reduce or eliminate undesired migration and concomitant loss or attenuation of responsiveness to sacral nerve stimulation associated with standard percutaneous nerve evaluation leads is presented. Coiled lead designs to offer a potentially promising alternative to standard leads for percutaneous nerve evaluation, allowing a larger number of patients to be correctly identified as candidates for sacral root neuromodulation. Particularly the coiled lead with the coil rype tip merits further investigation in human subjects.

CHAPTER 10 outlines buttock placement of the implantable pulse generator, a new technique for sacral nerve stimulation is outlined. This new technique of implantation is pertormed under general anaesthesia. After administration of prophylactic intravenous antibiotics, with the parient in a prone decubitus position, the lead is placed in the selected foramen through a sacral midline incision. The stimulator is placed in a subcutaneous pocket in the lateral-superior quadrant of the buttock approxi- 
mately $5-10 \mathrm{~cm}$ caudal to the iliac crest. 39 patients were implanted, 22 with urge incontinence, 6 with urgency-frequency syndrome, 9 with urinary retention, 1 with pelvio pain syndrome and 1 with faecal incontinence. The average follow-up time was 5,3 months ( $1-10$ months). There was a reduction in operation time of 1 - 1.5 hours. Burtock placement of the implantable pulse generator in sacral nerve stimulation entails less pain at the implant site, shorter operation time, two instead of three incisions and a shorter subcutaneous tunnel. We conclude that buttock placement is superior to standand positioning of the implantable pulse generator. It is advantageous for both the patient and the surgeon.

Conclusions The technique of neuromodulation as described in this thesis has proved to be a reliable treatment for patients with severe voiding dysfunction. Complications are rare and results long lasting. With the new percutaneous flexible test lead more patients with lower urinary tract dysfunction can be selected for neuromodulation. The two-stage implant technique can be of benefit for those patients in whom the percutaneous test result does not justify definitive implantation of the implantable pulse generator. Buttock placement of the implantable pulse generator has proved to be superior over standard abdominal placement and is nowadays the technique of choice.

We expect that neuromodulation will become a routine treatment procedure in the daily practice of the urologist, although it requires careful training. We hope that with further research in the field of electrostimulation this treatment will become available for a larger group of patients not only with urinary voiding dysfunction but also for patients with defaecation problems. 

CHAPTER 12 SAMENVATTING EN CONCLUSIES

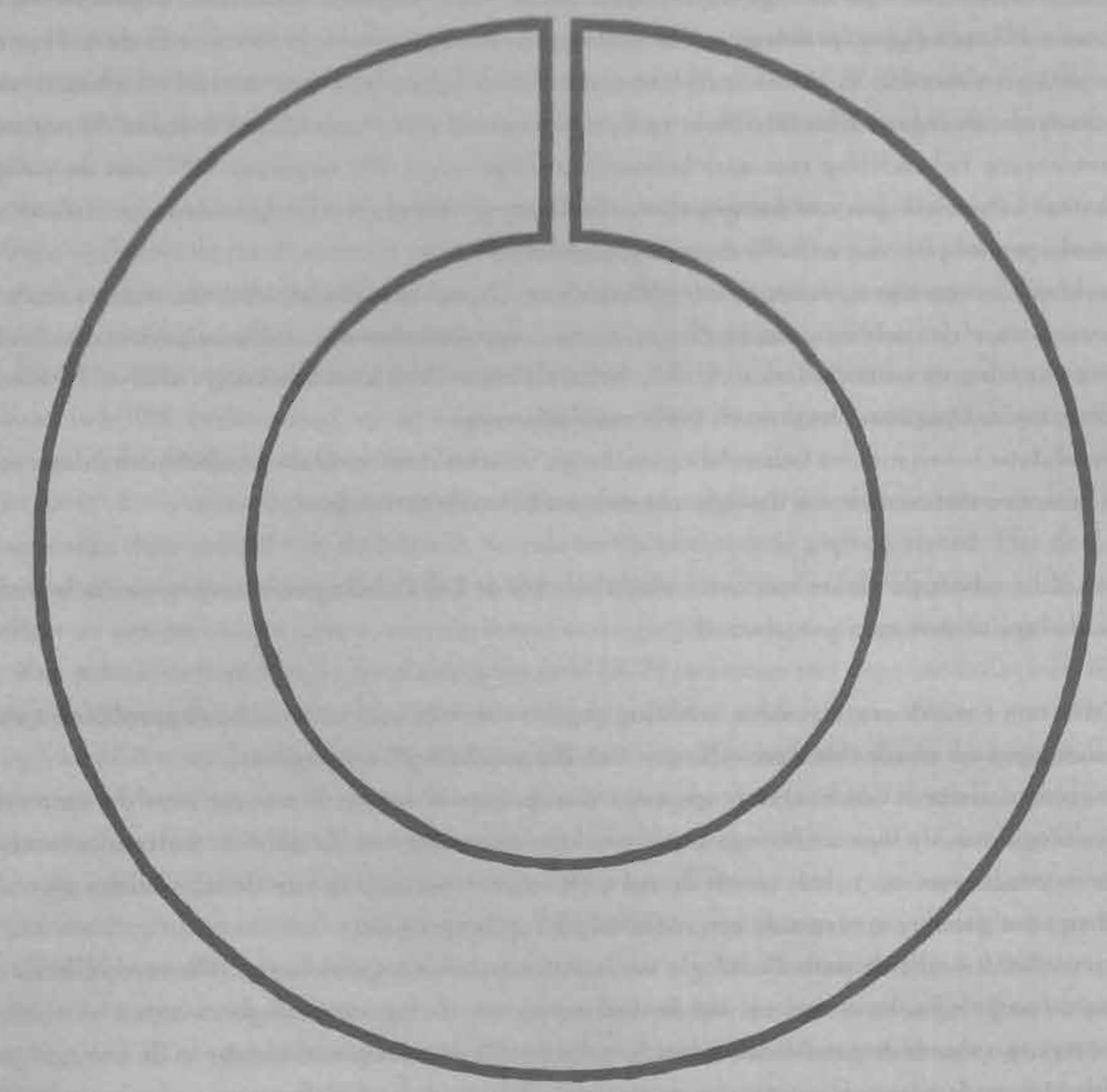




\section{SAMENVATTING EN CONCLUSIES}

Chronische disfuncties van de lage urinewegen, zoals motor-urge incontinentie, urgency-frequency. syndroom en blaasledigingsproblemen zịjn uitagende therapeutische problemen in de urologie. De meeste patiënten worden in eerste instantie conservatief behandeld door middel van blaastraining; bekkenbodemoefeningen en biofeedback. In de meerderheid van de gevallen wordt aan dit regime een medicamenteuze behandeling met anticholinergica toegevoegd. Bij ongeveer $40 \%$ van de patiènten leveren deze behandelingen niet het gewenste resultaat op. Aansluitend volgen dan alternatieve, meer ingrijpende procedures, die wisselend succes opleveren.

Vootbeelden hiervan zijn intravesicale instillaties met Capsaicine, blaastransectie, transvesicale phenol-injecties van de pelvine plexus, augmentatie- ileocystoplastiek, zelfs urinedeviaties volgens Bricker en continente urinedeviaties. Al deze behandelingen leiden tot een hoog risico op recidief van de incontinentie. Daarnaast leveren zij veel complicaties op.

Neuromodulatie is een nieuwe behandelingstechniek waarbij door middel van electrostimularie van de sacrale zenuwen disfuncties van de lage urinewegen behandeld worden.

In deze studie wordi de plats van neuromodulatie bij de behandeling van bovengenoemde disfuncties van de lage urinewegen geïvalueerd.

In HOOFDSTUK I wordt een algemene inleiding gegeven over de evacuatie en opslagproblemen van de lage urinewegen en worden de doelstellingen van dit proefschrift uiteengezet.

In HOOFDSTUK 2 wordt een overzicht gegeven van de gepubliceerde literatuur over de anatomie en neurofysiologie van de lage urinewegen. Na een kort overzicht van de dubbele functie, te weten het opslaan en evacueren van urine, wordt de normale zenuwvoorziening van de lage urinewegen en de invloed van het perifere en centrale zenuwstelsel hierop besproken.

In HOOFLSTUK 3 wordt de pathofysiologie van mictiestoornissen geèvalueerd. De verschillende classificaties en pathologische entiteiten van de disfuncties van de lage urinewegen worden beschreven. In HOOFDSTUK 4 wordt de geschiedenis van de ontwikkeling van neurostimulatie in de urologie gepresenteerd. Het werkingsmechanisme van de neuromodulatie, de techniek van percutane zenuwstimulatie en de methode van de implantatie van de sacrale zenuwstimulator worden beschreven. 
In HOOFDSTUK 5 worden de eerste klinische resultaten van een haalbaarheidsstudie naar het effect van neuromodulatie via sacrale zenuwstimulatie bij patienten met disfunctie van de lage urinewegen gepresenteerd. 19 van de 23 patiënten bij wie een neuromodulator geimplanteerd werd, hadden meer dan $50 \%$ en 14 van de 23 meer dan $90 \%$ verbetering van hun symptomatologie na een mediane followup van 12 maanden. In de urge-incontinentie-groep daalde het aantal lekkages van 7.4 naar 1.5 per dag en nam de functionele capaciteit van de blaas toe van 135 naar 227 cc. 2 van de 3 patiénten met urineretentie ledigden hun blaas zonder noemenswaardig residu. Er trad slechts een beperkr aantal complicaties op.

In HOOFDSTUK6 wordt een nieuwe techniek van implantatie geintroduceerd. De implantatietechniek in 2 fasen verbetert de resultaten van neuromodulatie significant. Bij 8 van de 10 patiênten waarbị de percutane zenuwstimulatie gefaald had om een verbetering van de micticparameters, zoals mictichoe* veelheid, mictiefrequentie, her aantal verbanden, de hoeveetheid urineverties en de mate van drang van meer dan $50 \%$ te geven, bleek gedurende de eerste fase van de operatie een goed tot zeer goed resultaat $(60-90 \%$ verbetering) op te treden. Bij hen werd vervolgens overgegaan tor definitieve implantatie 5 tot 14 dagen na de eerste fase.

In HOOFDSTUK 7 worden de lange-termijnresultaten van sacrale neuromodulatie voor chronische mictiestoornissen door middel van unilaterale, sacrale foramenstimulatie gepresenteerd. Het doel san de studie was om de lange termijn effectiviteit te bepalen en de complicaties bij 36 patiẻnten. Bij cen positief effect na een percutane zenuw stimulatie test ondergingen deze patiënten een definitieve implantatie. Een permanente elektrode werd geïmplanteerd bij 24 patiënten met urge-incontinentie, bij 6 met urgency-frequency syndroom en bij 6 met een niet-obstructieve urineretentie. Na een gemiddelde follow-up van 37,8 maanden hadden 19 patiënten $(52,8 \%)$ continu voordeel van de neuromodulatie met significante verbetering van de symptomen en urodynamische parameters. De mediale duui van het therapeutische effect voor de totale studiepopulatie was langer dan 60 maanden. Geen significant verschil in de mediale duur van het therapeutische effect betreffende sekse, type van mictieprobleem of geïmplanteerde puls-generator werd gevonden. Bij patiënten met vroegere psychologische problemen echter bleek de mediale duur van het therapeutisch effect slechts 12 maanden $(p=0,008)$ te zijn. De complicaties waren mild. In de groep van patiënten bij wie hẹt therapeutisch effect goed bleef, werden echter wel 37 re-operaties uitgevoerd. Wij concluderen dat patiënten een langdurige symptomatische verbetering kunnen verkrijgen door middel van neuromodulatie, alhoewel technische problemen door middel van reoperaties opgelost moesten worden. Speciale atandacht is vereist bij patiënten met 
een vroegere geschiedenis van psychologische problematiek of seksueel misbruik. $82 \%$ van deze patiënten vertoonden een slecht resultaat in vergelijking met $28 \%$ van de patiënten zonder deze voorgeschiedenis ( $p<0,002)$.

In HOOFDSTUK 8 worden de resultaten van een prospectieve, gerandomiseerde, klinische studie naar het effect van sacrale zenuwneuromodulatie bij de behandeling van hardnekkige onbehandelbare urine urge-incontinentie gepresenteerd. 44 Patiënten met onbehandelbare urge-incontinentie werden gerandomiseerd om neuromodulatie met een implanteerbare puls-generator (21) te ondergaan of gingen door met een oorspronkelijke conservatieve behandeling (23). Na 6 maanden werd de controlegroep geïmplanteerd. Het gemiddelde aantal lekkage-episodes, de ernst van de lekkage en het aantal verbanden dat werd gebruikt in de implantgroep werd significant lager, resp. bij $88 \%(\mathrm{p}<0,0005)$. $24 \%(\mathrm{p}<0.0047)$ en $90 \%$ ( $\mathrm{p}<0,005)$, dan de gemiddelde waarden ten opzichte van de controlegroep. Vermindering van het aantal lekkage-episodes en verbandgebruik van meer dan $90 \%$ werden bereikt bij 75 en $85 \%$ van de geïmplanteerde groep en bij geen van de patiënten in de controlegroep. Een derde van de geïmplanteerde patiënten en geen van de controlepatiënten bereikten meer dan $50 \%$ verbetering in de ernst van de lekkage. Meer dan de helft van de geïmplanteerde patiènten $(56 \%)$ werd volledig droog in vergelijking tot 1 patiënt in de controlegroep $(4 \%)$. De geimplanteerde patiënten en geen van de controlepatiënten ervoeren een significante verbetering bij 2 kwaliteit-van-leven-maten. Neuromodulatie resulteerde in een verbetering van $220 \%(p<0,0005)$ en $39 \%(p<0.013)$ respectievelijk van het urodynamisch aangetoonde blaasvolume bij de eerste blaassamentrekking en maximaal blaasvolume. Na 36 maanden was het feitelijke percentage van behandelingsfalen $32.4 \%(95 \% \mathrm{Cl}$, 17,0-56,0). De meest voorkomende bijwerking was pijn ter plaatse van de geïmplanteerde stimulator; doch ernstige complicaties deden zich nauwelijks voor. Wij concluderen dat neuromodulatie duidelijk effectiever is dan conservatieve behandeling bij moeilijk tot onbehandelbare urge-incontinentiepatiënten. De kwaliteit van leven en de urodynamische parameters verbeterden door neuromodulatie. Het effect van neuromodulatie is langdurig en de morbiditeit is laag.

In HOOFDSTUK 9 worden de ontwikkeling en de test van 2 nieuwe gespiraliseerde, flexibele testelektrodes geëvalueerd. In het verleden bleek dat met de standaard testelektrode er vaak migratie optrad. waardoor de respons op de sacrale stimulatie verloren ging. De gespiraliseerde elektrodes hebben een betere fixatie dan de standaard testelektrode. De gespiraliseerde elektrode met spiraaltip leverde de beste resultaten in een dierexperimentele studie op.

In HOOFDSTUK 10 wordt een nieuwe techniek van implantatie van de puls-generator ter plaatse van de 
musculus gluteus geintroduceerd en geèvalueerd. Deze techniek wordt onder algehele anesthesie uitgevoerd. Na toediening van profylactische intraveneuze antibiotica met de patiënt in buikligging wordt de elektrode in het geselecteerde foramen gefixeerd via cen mediane sacrale incisie. De stimulator wordt in een subcutane pocket in het laterale bovenkwadrant boven de Musculus Gluteus Maximus op 5 tot $10 \mathrm{~cm}$. caudaal van de Crista Iliaca Superior geplaatst. 39 patiènten werden geĭmplanteerd watrvan 22 met urge incontinentie, 6 met urgency frequency syndroom, 9 met urineretentie, 1 met bekkenbodempijn en I met fecale incontinentie. De gemiddelde follow-up was 5.3 maanden (1. - 10 maanden). Er was een vermindering van de operatietijd van I - 1.5 uur. Wij concludeerden dat gluteale plaatsing van de neurostimulator een betere techniek is dan de oorspronkelijke standaardoperatie (abdominale positie). Gluteale plaatsing van de stimulator veroorzaakt minder pijn ter plaatse van de implantatieplek, leidt tot kortere operatietijd als gevolg van een kortere submuceuze tunnel die gemaakt moet worden en het feit dat er slechts 2 in plaats van 3 incisies moeten worden gemaakt. De techniek heefi zowel voor de patient als voor de chirurg grote voordelen.

Conclusies De techniek van neuromodulatie zoals beschreven in dit proefschrift heeft bewezen een betrouwbare behandelingsmogelijkheid te zijn voor patiënten met ernstige mictiestoornissen. De complicaties zijn beperkt. De resultaten op lange termijn zijn goed. Met de nieuwe flexibele testelektrode kunnen meer patiënten geselecteerd worden voor neuromodulatie. Bij patiënten waarbij de percutane test geen betrouwbaar resultaat oplevert, kan de 2- Fasen-operatietechniek alsnog een oplossing zijn om toch nog over te gaan tor definitieve implantatie van de neuromodulator. De Gluteale implantatietechniek blijkt betere resultaten te hebben dan de standaard abdominale implantatietechniek en is tegenwoordig de operatietechniek van eerste keuze. Wii verwachten dat neuromodulatie in de naaste toekomst een routinebehandeling zal worden in de dagelijkse urologische praktijk. Wij hopen dat door verdere research op het gebied van elektrostimulatie deze behandelingsmogelijkheid in de toekomst bij grotere groepen patiënten toegepast kan worden, en dat niet alleen voor patiënten met mictiestoornissen doch ook bij patiënten met defecatieproblematiek. 


\section{CURRICULUM VITAE}

Name: Ernest, Henk, Johan Weil Date of Birth: 02 August 1947 Place of Birth: Eindhoven

Marital status: Married to Stephanie, Patricia, Maria Tiggelovend

Father of: 2 daughters, Amber and Phebe

1967 HBS-B Gemeentelijk Lyceum, Kampen (O), The Netherlands

1977 General Practitioner Faculty of Nedicine, Amsterdam University, Amsterdam, The Netherlands

1977 Aedical Offeer Detachment Military Health Service. Amersfoort, The Netherlands

1980 Awtalan General Suryery Prof. dr. L. Koekenberg, orthopedic surgeon, Hilversum. The Netherlands. Dr. C.M. Grasveld, surgeon, Hilversum. The Netherlands. Dr. H.J.H. Bolhuis, surgeon. Utrecht, The Netherlands

1983 Urologit Prof, dr. B.L.R.A. Coolsaet, University Hospital Utrecht, The Netherlands Dr. D. Tjabbes, urologist. Red Cross Hospital, The Hague. The Netherlands.

1983 unil now Senior Staff member urolegy Department of Urology, University Hospital Maastricht Former Head: Prof. dr. R.A. Janknegt. Present Head: Prof. dr. Ph.E.V. Van Kerrebroeck

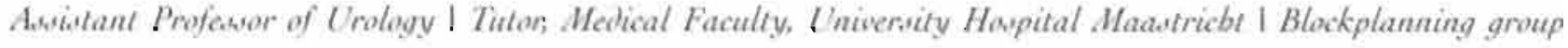
Member; Medical Faculty, Univervity Maatricht I. Hember of Planning Group for surgical training. Univerity. Hacalricbt I Hember of Natisnal and International Societier in Urology Treasurer DUST (Dutcb and Belgian

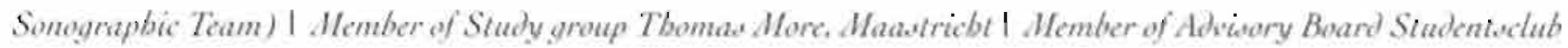
Banaliha, Maasiricht 


\section{CURRICULUM VITAE}

Naam: Ernest Henk Johan Weil Geboortedatum: 02 augustus 1947 Geboorteplaats: Eindhoven, Nederland Burgerijike Staat: Gehuwd met Stephanie. Patricia, Maria Tiggelovend Vader van: 2 dochters. Amber en Phebe

1967 HBS-B Gemeentelijk Lyceum te Kampen (O), Nederland

1977 Arlv Faculteil der Ciencakunde, Universiteit van Amsterdam, Amsterdam, Nederland

1977 Militair Arts, Detachement Militair Geneeskundige Dienst. Amersfoort. Nederland

1980 Avistent woropleiding Alycmene Heelkunde Prof. dr. L.J.L. Koekenberg, orthopaedisch chirurg, Hilversum. Nederland. Dr. C. M. Grasveld, chirurg, Hilversum, Nederland. Dr. H.J.H. Bolhuis, chir rurg, Utrecht, Nederland

1983 Urologg Prof.dr. B.L.R.A. Coolsaet, Academisch Ziekenhuis Utrecht, Nederland. Dr. D. Tjabbes, uroloog, Rode Kruis Ziekenhuis, Den Haag, Nederland

Sedert 1983 Staflid-uroloog afdeling Urologie Academisch Ziekenhuis Maastricht, Voormalig hoofd: Prof, dr. R.A. Janknegt. Hoofd: Prof. dr. Ph.E.V. Van Kerrebroeck

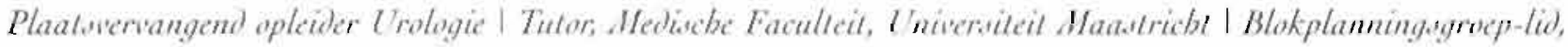

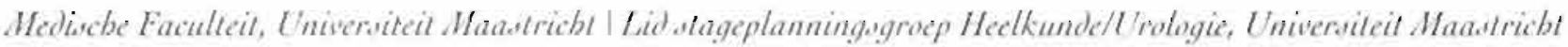
Lid Natianale en Internationale wetensebappelijke urotogiacbe verenigingen I Penningmeen DUST (Duteb and Betgian Sonograpbie Team) I Lid Studickring Tbomas. Hore I Member du Conseil Studentenvereniging Banalitas, Matastricht 


\section{AKNOWLEDGEMENTS}

The results which are described in this thesis could not have been accomplished without the contributions of many others. I would like to express my gratitude to all those who supported me in the work of this thesis. I am also very grateful for the help of everybody I did not mention by name.

Prof.dr. Ruud A. Janknegt, you initiated the research and the use of neuromodulation in our department and stimulated me both in clinical and experimental work.

Prof.dr. Philip Van Kerrebroeck, after you became head of the department of Urology, your dynamic approach and scientific knowledge gave me the extra energy to write and finish this thesis.

Dr. Gosse Oosterhof and Dr. Gommert van Koeveringe, you both supported me with your scientific vision, especially in the last phase of this thesis.

The other staff members of the department of Urology I thank for their criticisms which gave me an extra stimulus to finish my thesis.

Dr. José Luis Ruiz Cerdá, Urologist in Valencia, Spain, Dear José, I am grateful for our co-operation in the last few years. After your training in our department of Urology in the Academic Hospital Maastricht, we were able to communicate via telephone and E-mail and analyse all the material we had gathered. 1 am glad and proud that you introduced neuromodulation in your country.

Dr. Pedro Eerdmans and Drs. Wout Scheepens, I thank you for your enthousiastic co-operation in the different projects that have been carried out in the department of urology.

Dr. Ton van den Bogaard, head of the department of Animal Experiments, Joyce Suyk and Mae Bost, 1 thank you for your advice and assistence during our animal experiments.

The nurses and co-workers of the out-patient clinic and function-laboratory of the department of Urology as well as the nurses of the department A1, A2, BI and B2, I thank you all for your good care given to the patients.

The nurses and co-workers of the Central Operation Complex and of the Day Surgery Center and especially Bert Huang, I thank you for the professional assistence during the many operations we have done.

Medtronic Europe S.A. Medtronic Interstim and Medtronic Bakken Research, all co-workers of these companies especially do Merkun. Rob ten Hoedt. Maurizio Cevolani. Florence Jacobs. Ubi van 
den Hombergh, Diederik Keizer, Antoine Camps and Victor Duyzens, I am especially grateful for your long-time support.

The secretaries of the department of Urology, especially Anja Dullens, I thank you for your work and patience.

All the co-workers of the Audiovisual- and Printing Department of the University Hospital Maastricht, I thank you for you very professional work.

Rene Verwaaijen, I am especially grateful for the linguistic corrections.

Dr. Mahlon M. Wilkes of Hygeia Associates, I thank you for your very helpful contribution.

Jos and Irene Caelen and Ber Crouzen, you in an unbelievable way supported me with the lay-out and printing process of this thesis.

Mr. and Mrs. Henk and Ans Weil-Viveen: Mum and Dad how lucky I am to be your son. I am happy that both of you can be with me today.

Mr. and Mrs. Wim and Julie Tiggelovend-Gibbs; how lucky I was to meet you daughter.

Thank you for your wisdom.

Amber and Phebe, perhaps 1 was less available for you both but be sure you were in my thoughts.

Steffie, thanks for your unconditional love, support and criticism. 
Vele mensen waren betrokken bij het klinische en experimentele werk ten behoeve van dit proefschrift. Allen die op welke wijze dan ook hebben bijgedragen aan dit proefschrift ben ik zeer erkentelijk. Ook zij die hier niet persoonlijk genoemd worden, dank ik.

Prof.dr. Ruud A. Janknegt, jij initicerde het onderzoek naar het gebruik van neuromodulatie bij patienten en stimuleerde mij zowel in het klinische als het experimentele werk.

Prof.dr. Philip Van Kerrebroeck, sinds jii hoofd bent van de afdeling Urologie heb jij door jouw dynamische aanpak mij extra energie gegeven om het werk zoals beschreven in dit proefschrift mogelijk te maken.

Dr. Gosse Oosterhof en Dr. Gommert van Koeveringe, jullie hebben mij met jullie wetenschappelijke visie bijzonder gesteund in de laatste fase van mijn proefschrift.

De overige stafleden van de afdeling Urologie dank ik voor hun kritische houding die mij extra heeft gestimuleerd om dit proefschrift tot een goed einde te brengen.

Dr. José Luis Ruiz Cerdá, uroloog te Valencia, José ik dank je voor de bijzondere samenwerking die wij hebben opgebouwd. Na jouw stage op de afdeling Urologie in het azM, Maastricht, zịn we in staat geweest om via telefoon en e-mail regelmatig met elkaar te werken aan de wetenschappelijke analyse van het vele materiaal dat wij hadden verzameld. !k ben blij en trots dat jii de neuromodulatie in jouw land hebt geintroduceerd.

De. Pedro Eerdmans en Drs. Wout Scheepens, jullie dank ik voor de enthousiaste medewerking aan de verschillende projecten die op de afdeling Urologie zijn gerealiseerd.

Dr. Ton van den Bogaard, Hoold Dierexperimenteel Laboratorium, Joyce Suyk en Mae Bost,ook jullie dank ik voor advies en assistentie bij de uitvoering van de dierexperimenten.

De verpleging en de medewerkers van de polikliniek en functiekamer Urologie alsmede de verpleging van afdeling A1, A2, B1 en B2 jullie dank ik voor de goede zorg voor de patiënten.

De verpleging en de medewerkers van het centraal operatiekamercomplex en van het Dagcentrum en in het bijzonder Bert Huang, jullie dank ik voor de professionele ondersteuning tijdens de vele operaties die wij samen hebben uitgevoerd.

Medtronic Europe S.A., Medtronic Interstim en Medtronic Bakken Research, alle medewerkers van 
deze ondernemingen maar in het bijzonder Jo Merkun, Rob ten Hoedt, Maurizio Cevolani, Florence Jacobs, Ubi van den Hombergh, Diederik Keizer, Antoine Camps en Victor Duyzens ben ik bijzonder erkentelijk voor de jarenlange ondersteuning.

Het secretariaat van de afdeling Urologie, in het bijzonder Anja Dullens dank ik voor het vele werk en het geduld dat zij hebben opgebracht om mij te ondersteunen bij dit proefschrift.

Audiovisuele Dienst en Drukkerij van het azM, alle medewerkers van deze afdelingen dank ik voor de zeer professionele bijdrage.

Rene Verwaaijen, ik dank je voor de taalkundige correcties.

Dr. Mahlon M. Wilkes van Hygeia Associates, ik dank jou voor de vruchtbare bijdrage.

Jos en Irene Caelen en Bèr Crouzen, jullie hebben mij op een buitengewone manier ondersteund bij de lay-out en het drukproces van dit proefschrift.

Dhr. en Mw. Henk en Ans Weil-Viveen, pap en mam wat ben ik gelukkig een zoon van jullie te zijn. Ik ben dankbaar dat jullie bij deze promotie aanwezig kunnen zijn.

Dhr. en Mw. Wim en Julie Tiggelovend-Gibbs, pa en ma wat een geluk heb ik gehad om jullie dochter te ontmoeten. Dank voor jullie wijsheid.

Amber en Phebe, ik was de laatste tijd misschien wat minder beschikbaar, maar heb niet minder aan jullie gedacht.

Steffie, bedankt voor jouw onvoorwaardelijke liefde, steun en kritiek. 
The publication of this thesis was realised by financial support of:

Main sponsory

Medireva, Medtronic Interstim, WAMU, Yamanouchi

Spanores

Abbott. Astra Tech. Astra Zeneca, Aventis Pharma, Bard, Bayer, Byk, Coloplast, Christiaens, Ferring. Glaxo Welleome, MSD, Plizer, Pharmacie \& Upjohn. Pie Medical Benelux, Rembrandt Medical. Sanofi Synthelabo, Schering NL, Stöpler, Uroplasty. 


\section{COLOFON}

Illustratie omslag en binnenwerk Jos Caelen, 's Gravenvoeren

Taalkundige adviezen René Verwaaijen, Balance, Maastrich::

Ontwerp Bèr Crouzen, Eckelrade

Drukwerkverzorging Scorpio bv, Eckelrade

Papier Gardapat $90 \mathrm{gr} / \mathrm{m} 2$ (Cartiere del Garda, Riva dG)

Lettertypen Cochin (Debergny \& Peignot) en Frutiger

Bindwerk Arno Lipsch, Maastricht

ISBN 90-71630-22-6

(c) Ernest Weil, Maastricht, 2000. 


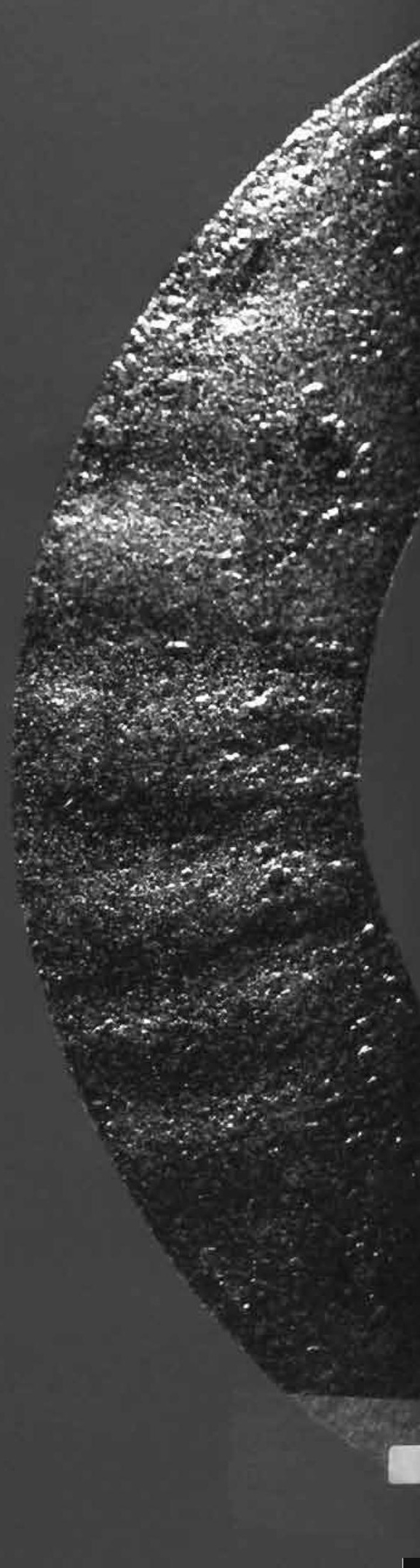

